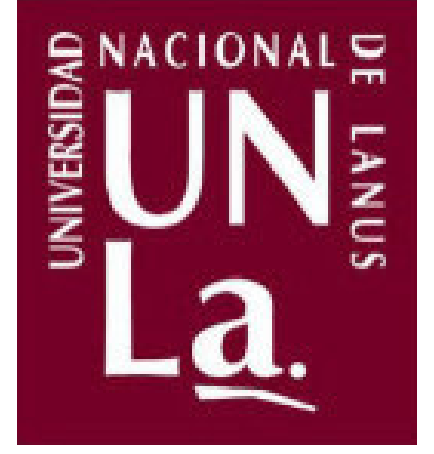

\title{
UNIVERSIDAD NACIONAL DE LANÚS
}

Departamento de Salud Comunitaria

\author{
MAESTRIA EN EPIDEMIOLOGIA, \\ GESTION Y POLITICAS DE SALUD \\ COHORTE $20^{\mathrm{a}}-2017-2019$
}

TESIS PARA LA OBTENCIÓN DEL TÍTULO DE MAGÍSTER

TÍTULO

Procesos de atención y cuidado desde la perspectiva de los trabajadores: una meta-etnografía en hospitales de Latinoamérica

MAESTRANDA

Lic. Brenda Moglia

DIRECTORA

Dra. Anahí Sy

FECHA DE ENTREGA

Septiembre, 2020

Lanús, Argentina 


\title{
UNIVERSIDAD NACIONAL DE LANÚS
}

Departamento de Salud Comunitaria

\author{
MAESTRIA EN EPIDEMIOLOGIA, \\ GESTION Y POLITICAS DE SALUD \\ COHORTE $20^{\mathrm{a}}-2017-2019$
}

TESIS PARA LA OBTENCIÓN DEL TÍTULO DE MAGÍSTER

$$
\text { TÍTULO }
$$

Procesos de atención y cuidado desde la perspectiva de los trabajadores: una meta-etnografía en hospitales de Latinoamérica

MAESTRANDA

Lic. Brenda Moglia

DIRECTORA

Dra. Anahí Sy

INTEGRANTES DEL JURADO

Dra. Inmaculada Hurtado

Dra. Jaqueline Ferreira

Dr. Hugo Spinelli

FECHA DE APROBACIÓN

06/07/21

CALIFICACIÓN

9 (nueve)

Distinguida 


\section{AGRADECIMIENTOS}

Quiero agradecer, especialmente, a mi directora por su acompañamiento crítico durante todo el proceso de aprendizaje. Le agradezco a mi familia por su apoyo incondicional en todas las aventuras que emprendí. A mi compañero por prestarme su oído en momentos de crisis y alentarme a seguir adelante. A mis compañeres y docentes de la $20^{\mathrm{a}}$ cohorte de la maestría por las experiencias de trabajo. Al Consejo Nacional de Investigaciones Científicas y Técnicas y a la Universidad Nacional de Lanús por su apoyo económico. 


\section{RESUMEN}

Los procesos de atención y cuidado de la salud-enfermedad que tienen lugar en los hospitales se configuran en torno a diferentes dimensiones y tensiones entre los actores implicados. En las sociedades occidentales se ha naturalizado a estas instituciones como espacios que suponen una estructura vertical, dominada por la racionalidad biomédica. Sin embargo, en las prácticas de atención y cuidado que llevan a cabo los trabajadores de la salud, se involucran otros vínculos, saberes y emociones que configuran aspectos que se encuentran por fuera de lo normado desde la institución. Esta tesis se orienta a desentrañar estas complejidades en el proceso de trabajo en hospitales. El objetivo es describir y analizar los procesos de atención y cuidado a partir de las experiencias de los trabajadores de los hospitales ubicados en la región geográfica de América Latina. La propuesta metodológica se orienta a desarrollar una metaetnografía que consiste en sintetizar investigaciones cualitativas con el propósito de producir una nueva interpretación del problema estudiado. De este modo, se conformó un corpus de 36 artículos científicos a partir de las búsquedas en las bases de BVS, PubMed, SciELO y Scopus. En los resultados se indaga en los sentidos y significados que aquellos le atribuyen a los escenarios de trabajo, así como también se describen las prácticas desarrolladas en dichos contextos, los saberes y racionalidades puestos en juego, los vínculos construidos y las emociones emergentes. Por último, se reflexiona a partir de diferentes categorías teóricas y empíricas, principalmente del campo antropológico y de la salud colectiva, y se propone un modelo de atención y cuidado situado en hospitales latinoamericanos.

PALABRAS CLAVE: Hospitales; América Latina; Revisión; Proceso de atención y cuidado; Trabajadores de la salud. 


\begin{abstract}
The health care processes that take place in hospitals are shaped around different dimensions and tensions between the actors involved. In western societies these institutions have been naturalized as spaces that represent a vertical structure, dominated by biomedical rationality. However, the health care practices that workers carry out involve other bonds, knowledge, and emotions that shape aspects that are outside the norm from the institution. This thesis is aimed at unraveling these complexities in the process of working in hospitals. The objective is to describe and analyze health care processes based on the experiences of hospital workers located in the geographical region of Latin America. The methodological proposal is aimed at developing a meta-ethnography that consists of synthesizing qualitative research with the purpose of producing a new interpretation of the problem studied. In this way, a corpus of 36 scientific articles was formed from the searches in the bases of BVS, PubMed, SciELO and Scopus. The results look into the senses and meanings that those attribute to the work scenarios, as well as describe the practices developed in those contexts, the knowledge and rationalities put into play, the constructed links and the emerging emotions. Finally, reflexions has been made from different theoretical and empirical categories, mainly from the anthropological field and collective health, and proposes a model of health care located in Latin American hospitals.
\end{abstract}

KEY WORDS: Hospitals; Latin America; Review; Health care process; Health workers. 


\section{LISTADO DE FIGURAS}

Figura 1. Diagrama del proceso de selección de las referencias bibliográficas que conforman el corpus de investigación. 39

Figura 2. Categorías de análisis elaboradas a partir de aquellas identificadas en la bibliografía analizada.....

Figura 3. Esquema de síntesis. 


\section{LISTADO DE TABLAS}

Tabla 1. Resultados de las búsquedas exploratorias. Realizada en febrero y abril, 2019 .....36

Tabla 2. Búsqueda de artículos científicos en bases electrónicas BVS, PubMed, SciELO y

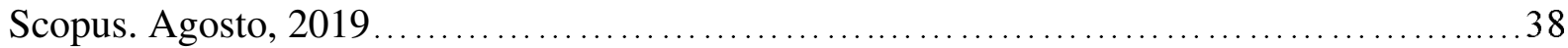




\section{LISTADO DE ABREVIATURAS Y SIGLAS}

BVS - Biblioteca Virtual en Salud

PSEA - Proceso de salud-enfermedad-atención

SciELO - Scientific Electronic Library Online (Biblioteca Científica Electrónica en Línea)

MMH - Modelo médico hegemónico

TraSa - Trabajadores de la salud 


\section{CONTENIDO}

\section{INTRODUCCIÓN.......................................................................................11}

2. DELIMITACIÓN DEL PROBLEMA.......................................13

2. 1. Pregunta de investigación.....................................................................13

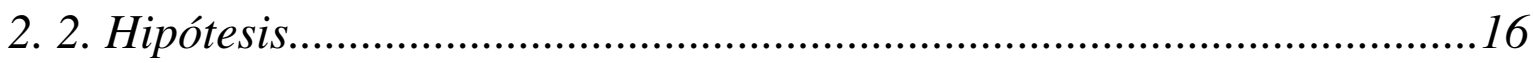

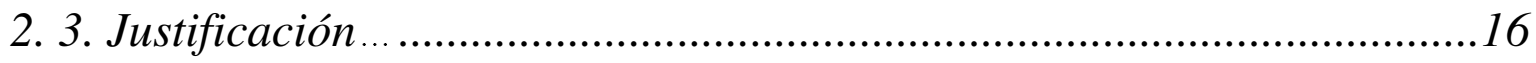

2. 3. 1. Social..................................................................................................................16

2. 3. 2. Académica.........................................................................................................17

2. 3. 3. Personal.................................................................................................................17

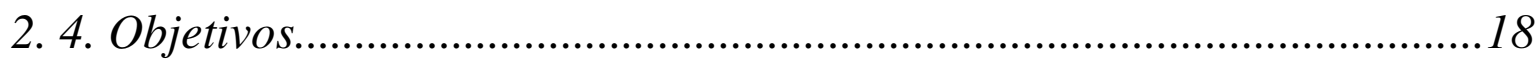

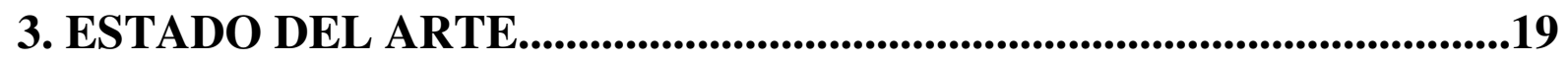

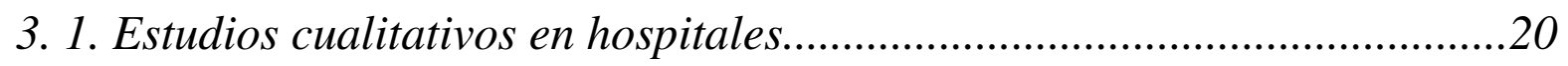

3. 1. 1. Sobre las culturas hospitalarias.............................................................................20

3. 1. 2. Sobre la organización social........................................................................21

3. 1. 3. Sobre el trabajo de campo....................................................................................22

3. 2. Estudios cualitativos en hospitales de América Latina..............................23

3. 1. 1. Abordajes desde la perspectiva de los usuarios.................................................23

3. 1. 2. Abordajes desde la perspectiva del trabajador.................................................24

4. MARCO CONCEPTUAL DE REFERENCIA......................................27

4.1. Abordajes metodológicos cualitativos......................................................27

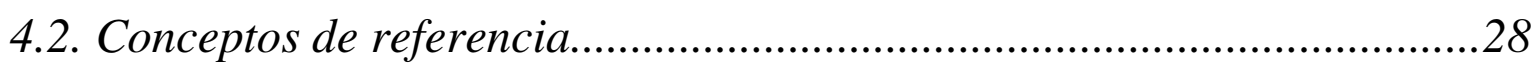

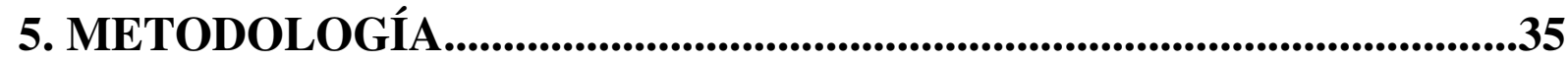

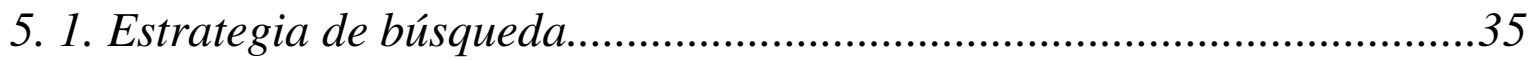

5. 1. 1. Criterios de inclusión y exclusión...........................................................................37

5. 1. 2. Resultados de las búsquedas..........................................................................37

5. 2. Estrategia de análisis: meta-etnografía...................................................40

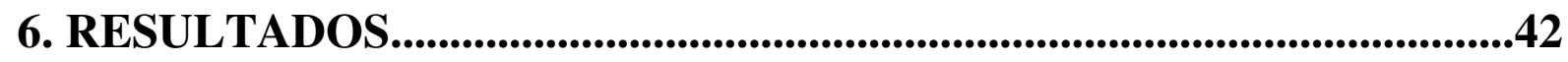

6. 1. Sintesis comparativa...............................................................................

6. 1. 1. Escenarios de trabajo..........................................................4

6. 1. 2. Procesos de atención y cuidado..............................................48

6. 1. 2. 1. Prácticas de atención y cuidado ..................................49 
6. 1. 2. 2. Humanización en la atención y cuidado

6. 1. 2. 3. Redes........................................................... 55

6. 1. 3. Racionalidad biomédica....................................................................................57

6. 1. 4. Emociones emergentes............................................................................61

6. 2. Síntesis interpretativa..............................................................65

6. 2. 1. “...A veces trabajas solo, trabajas al límite..."............................................66

6. 2. 2. Entre ruidos, acciones medicamentosas y diálogos.......................................70

6. 2. 3. La biomedicina no alcanza.............................................................................................74

6. 2. 4. De estar "satisfecho" a estar "frustrado" y sentirse "discriminado".........79

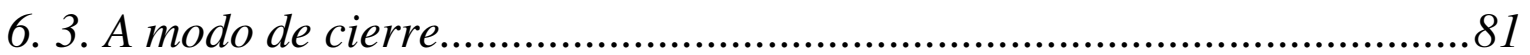

7. REFLEXIONES FINALES..................................................................86

REFERENCIAS BIBLIOGRAFICAS..............................................90

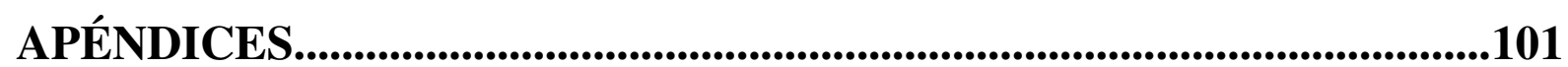


Moglia B. Procesos de atención y cuidado desde la perspectiva de los trabajadores: una metaetnografía en hospitales de Latinoamérica. [Tesis de maestría]. Maestría en Epidemiología, Gestión y Políticas de Salud. Universidad Nacional de Lanús. 2020.

\section{INTRODUCCION}

Esta tesis es producto de haber transitado por la Maestría en Epidemiología, Gestión y Políticas de Salud, al tiempo que constituye un abordaje interpretativo en el marco de un proyecto de investigación titulado "Salud Pública en y desde el hospital. Una aproximación Etno-epidemiológica a los Servicios de Salud" centrado en la comprensión de los servicios de atención a la salud desde una mirada etnográfica. En el caso particular de esta tesis, se presenta el análisis de las experiencias de los trabajadores de la salud ( $\mathrm{TraSa}^{1}$ en adelante) en hospitales respecto a los procesos de atención y cuidado a través de la recuperación de artículos científicos bajo la propuesta metodológica de la meta-etnografía.

La tesis se estructura en seis apartados que representan la culminación de un recorrido que involucró a distintos actores del ámbito académico por lo que podría pensarse a ésta como el resultado de un proceso de producción académica colectiva. El primer apartado consiste en la Delimitación del problema, en donde se especifican los distintos recortes temáticos y justificaciones que nos permitieron delinear tanto nuestro interrogante como una posible hipótesis de trabajo. Además, presentamos los objetivos (general y específicos) que se buscan desarrollar.

En el segundo apartado, Estado del arte, se reconstruyen los antecedentes que identificamos como un aporte a nuestro campo de estudio, asimismo se recuperan investigaciones internacionales y regionales, con un especial énfasis en aquellas centradas en la atención y el cuidado a la salud-enfermedad en hospitales. A continuación, se desarrolla el tercer apartado, dando lugar al Marco conceptual de referencia, que incluye las distintas categorías y conceptos que nos permitieron la delimitación del problema de investigación y el análisis de los resultados.

Posteriormente, se presenta la Metodología, donde se explican las dos estrategias que se realizan en la tesis: aquella que se enfoca en los procesos de búsqueda de artículos científicos y de conformación del corpus y, la estrategia de análisis, en la cual indagamos sobre la propuesta de la meta-etnografía.

En el quinto apartado se exponen los Resultados. Estos hallazgos se organizan en dos síntesis, una comparativa en la cual se indaga, de forma transversal al corpus, las distintas dimensiones recuperadas a partir de las experiencias de los TraSa de hospitales respecto a los

\footnotetext{
${ }^{1}$ Se utilizará la expresión TraSa a fin de incluir toda la diversidad sexo-genérica representada por los/las/les trabajadores de la salud, ya sea en término plural o singular.
} 
Moglia B. Procesos de atención y cuidado desde la perspectiva de los trabajadores: una metaetnografía en hospitales de Latinoamérica. [Tesis de maestría]. Maestría en Epidemiología, Gestión y Políticas de Salud. Universidad Nacional de Lanús. 2020.

procesos de atención y cuidado. Por otro lado, se realiza la síntesis interpretativa, en donde nos aproximamos a nuevas explicaciones con respecto a la pregunta de investigación.

Por último, en la última parte de la tesis se presentan las Reflexiones finales en torno a ambas síntesis, recapitulando los principales hallazgos y conclusiones. Asimismo, se proponen futuros interrogantes a abordar. 
Moglia B. Procesos de atención y cuidado desde la perspectiva de los trabajadores: una metaetnografía en hospitales de Latinoamérica. [Tesis de maestría]. Maestría en Epidemiología, Gestión y Políticas de Salud. Universidad Nacional de Lanús. 2020.

\section{DELIMITACION DEL PROBLEMA}

\section{1. Pregunta de investigación}

A finales del siglo XVIII, el hospital comienza a ser un instrumento terapéutico donde se busca "curar al enfermo" (Foucault, 1990). Este proceso tiene lugar a partir de una reorganización de dichas instituciones, que dejan de tener una funcionalidad relativa a la asistencia y exclusión de los pobres, y se establecen como un espacio para el ejercicio de la técnica médica. En paralelo con el cambio de funcionalidad, el personal religioso pierde poder con respecto a la organización del hospital y los médicos toman dicha responsabilidad. Lo que lleva, posteriormente, a incorporar un sistema de registros y de adquisición de conocimientos involucrados en la práctica, lo cual significó el fortalecimiento del saber médico y su reproducción en el ámbito del hospital. De esta forma, este último se constituye en la institución moderna que hoy conocemos, siendo uno de los espacios de referencia para la atención y cuidado de la salud y la enfermedad y también, de formación médica (Foucault, 1990).

En este sentido, podríamos suponer que, si existe un saber médico legitimado que se reproduce en los hospitales, los procesos de atención y cuidado que se realizan se enmarcarían en aquel y por lo tanto, tendrían cierta forma estandarizada de desarrollo. Sin embargo, autores como van der Geest y Finkler (2004) señalan que, a pesar de un modelo biomédico global, los antropólogos están comenzando a describir e interpretar la variedad de culturas hospitalarias en diferentes países y, por otro lado, que la biomedicina y el hospital como su principal institución, es un dominio donde los valores centrales y las creencias de una cultura comienzan a ser miradas. Estos autores sostienen que los hospitales reflejan y refuerzan los procesos sociales y culturales dominantes de una sociedad dada (van der Geest \& Finkler, 2004).

Desde una perspectiva antropológica, Byron Good (1994) plantea que el hospital, no sólo es el sitio de la construcción y el tratamiento del cuerpo medicalizado, sino que es el sitio del "drama moral"2, donde lo soteriológico se yuxtapone con lo técnico racional e irrumpe la dimensión moral del padecimiento. Estos mecanismos llevan a que se rompa el sentido común

\footnotetext{
${ }^{2}$ Este concepto remite al trabajo de Victor Turner (1974), quien plantea el concepto de "drama social" para explicar cómo funcionan los símbolos rituales en los grupos sociales. Para el autor el símbolo es la unidad más pequeña del ritual que conserva las propiedades de éste. Los símbolos rituales tienen dos polos de sentido: uno de orden moral (normas, valores) y otro de orden sensorial (deseos, sentimientos), que al yuxtaponerse se vincula con la función social de los símbolos. Los dramas sociales son planteados como formas procesuales, cuyos símbolos orientan la acción social (Sy, 2013).
} 
Moglia B. Procesos de atención y cuidado desde la perspectiva de los trabajadores: una metaetnografía en hospitales de Latinoamérica. [Tesis de maestría]. Maestría en Epidemiología, Gestión y Políticas de Salud. Universidad Nacional de Lanús. 2020.

hospitalario y, entonces, se tienda a canalizarlo a través de procedimientos médicos de rutina. Esto permite, por un lado, que no se desarrolle una reflexión moral y, por otro lado, restaurar el orden desde una racionalidad instrumental (Good, 1994). Por su parte, Comelles (2000) describe como se da un juego entre saberes populares y saberes científicos ante ciertas situaciones de incertidumbre y/o desconocimiento que ocurren en un hospital ubicado en España. El autor afirma que tanto la magia como el milagro constituyen prácticas subalternas, en mayor medida, descriptas para la red social del paciente, pero que también, forman parte de la lógica institucional y de la cultura del hospital. Esto constituye un producto de la interacción entre el personal, los enfermos y los acompañantes, entre culturas hegemónicas y culturas subalternas. Asimismo, el autor observa que son los médicos quienes canalizan y retroalimentan el pensamiento mágico y religioso, a pesar de su coraza técnica (Comelles, 2000). En este sentido, a pesar de que el modelo biomédico es muy fuerte en los protocolos asistenciales, donde el paciente se lo somete a una serie de intervenciones técnicas que implica una demarcación entre un adentro y un afuera de la institución -dado por lo técnico racional en el adentro y por lo mágico-religioso por el afuera-, el uso social de la creencia en el milagro en contexto hospitalario permite comprender aquello que la ciencia no puede dilucidar. Aunque permite desresponsabilizar a los profesionales y a la institución, amplia la explicación hacia el juego simbólico y ritual por parte de la red social del paciente, como soporte y contribución a la terapéutica (Comelles, 2000). Tanto Good (1994) como Comelles (2000) cuestionan o problematizan las prácticas biomédicas como precisas y objetivas, dando cuenta de que puesta en el juego social, no solo se diversifica sino que también están atravesadas por cuestiones soteriológicas/milagrosas.

En paralelo a estos desarrollos teóricos-conceptuales, autores latinoamericanos, referentes del campo de la salud colectiva, plantean que las organizaciones de salud, tal como los hospitales, son instituciones definidas por su complejidad (Testa, 1997). Sin embargo, este aspecto no es del todo problematizado lo cual lleva a un funcionamiento de la organización bajo falsos supuestos, donde se piensa a los trabajadores como sujetos cartesianos, y a la institución como una estructura piramidal (Spinelli, 2010). Spinelli (2010) discute dicha visión y propone caracterizar al campo de la salud como el producto de la combinación de la concentración de capital económico, las dificultades de financiamiento, la corrupción, la presencia de estructuras administrativas arcaicas, las bajas capacidades de gestión, la falta de regulación en el proceso formativo de los profesionales, el alto número de trabajadores, su elevada autonomía y el valor social de los temas que involucran sus prácticas. De esta manera, 
Moglia B. Procesos de atención y cuidado desde la perspectiva de los trabajadores: una metaetnografía en hospitales de Latinoamérica. [Tesis de maestría]. Maestría en Epidemiología, Gestión y Políticas de Salud. Universidad Nacional de Lanús. 2020.

entendemos al hospital definido por su complejidad desde el campo de la salud, con todas sus implicancias. Dentro de estas últimas, incluimos el papel del diálogo y el conocimiento como insumo para el trabajo en salud, debido a que opera con lógicas comunicativas que contradicen el diseño de una organización como la hospitalaria, pensada como una estructura vertical, dominada por la racionalidad (Spinelli et al., 2013). Dichos aspectos, dados por el tipo de relación que el TraSa establece con su trabajo, sus compañeros, sus superiores inmediatos, con los usuarios o con la organización en general, son considerados como fundamentales en el análisis sobre la forma en que se produce salud en los hospitales (Campos, 2009). En este sentido, se destaca la importancia de la dimensión comunicacional (verbal y no verbal) y de la dimensión vincular en los procesos de atención y cuidado (Merhy, 2006; Campos, 2006; Spinelli, 2010).

Asimismo, Campos (2006) señala la necesidad de superar las lógicas normatizadoras que supone la racionalidad biomédica, ya que sostiene que, en la atención a la saludenfermedad, hay un cruce de subjetividades directamente implicadas y entonces, propone incluir una dimensión subjetiva en la producción de cuidado (Campos, 2006; Franco \& Merhy, 2011). En el mismo sentido, recuperamos el estudio que realiza Bonet (1999) sobre el proceso de formación durante las residencias en un hospital de la provincia de Buenos Aires, ya que plantea que en estos espacios tiene lugar un proceso de delimitación entre lo "profesional y lo "humano" o del saber y del sentir, los cuales se constituyen como dos conjuntos de representaciones separadas que se manifiestan en forma permanente en las prácticas cotidianas del servicio. El autor denomina "tensión estructurante de la práctica biomédica" a la relación que se da entre el saber biomédico/dimensión científica-racional y el sentir/dimensión humano-pasional, es decir, "entre las exigencias del modelo biomédico con su énfasis en el saber y en las prácticas guiadas por algoritmos y protocolos por un lado y la experiencia individual, la dimensión de lo vivido, del sentir por el otro..." (1999, p.133). De esta forma, se identifica la subjetividad implicada en las prácticas médicas y la tensión que puede generar o no para los TraSa.

Dar cuenta de estas complejidades en el proceso de trabajo en hospitales nos orienta hacia el problema de investigación. En ese sentido, nuestro interrogante busca comprender de qué manera se expresa dicha complejidad a partir de las experiencias de los TraSa de los hospitales con respecto a los procesos de atención y cuidado, identificando aspectos comunes y/o divergentes entre países de Latinoamérica. 
Moglia B. Procesos de atención y cuidado desde la perspectiva de los trabajadores: una metaetnografía en hospitales de Latinoamérica. [Tesis de maestría]. Maestría en Epidemiología, Gestión y Políticas de Salud. Universidad Nacional de Lanús. 2020.

\section{2. Hipótesis}

Los procesos de atención y cuidado de la salud en el ámbito del hospital involucran no solo un saber técnico especializado, sino también una red de relaciones establecidas en el ámbito institucional, que van a delimitar y modelizar los vínculos y las características que adquiera la atención. Además, tales procesos se encuentran atravesados por la posición social que ocupa cada uno de los TraSa, su capital simbólico y material, así como intereses que demarcarán relaciones de desigualdad, diferencia y diversidad entre ellos, y de ellos con los usuarios.

Centrados en la perspectiva de los trabajadores, planteamos que dichos procesos de atención y cuidado superan la racionalidad biomédica, y pone en juego, en simultaneo las normas institucionales y las subjetividades en el espacio de trabajo. Esto configura la singularidad de cada trabajador y cierta homogeneidad entre TraSa.

Asimismo, consideramos que, a pesar de la diversidad de procesos que han atravesado las políticas sanitarias de cada país latinoamericano, hallaremos ciertas características comunes o convergentes en los procesos de atención y cuidado llevados a cabo en los hospitales.

\section{3. Justificaciones}

\section{3. 1. Social}

Los TraSa de los hospitales constituyen actores centrales para pensar en la calidad de los procesos de atención y cuidado que atraviesan los usuarios. Generalmente cuando se piensa en "mejorar" los servicios de atención en los hospitales se trabaja sobre aspectos técnicos vinculados a la organización y a la gestión, donde la dimensión sociocultural y simbólica de los servicios no son tenidos en cuenta (Ferrero, 2003). Ciertamente, las particularidades del trabajo en los hospitales (o en cualquier servicio público de salud), tal como la alta autonomía de los TraSa, la dificultad en definir el objeto al cual se aborda (la salud/enfermedad) y el hecho que el trabajo debe desarrollarse durante las 24 horas de los 365 días del año, afrontando sucesos tan importantes como la vida y la muerte, nos sugiere una complejidad que requiere un abordaje centrado en la perspectiva de los TraSa en el ámbito del hospital. En ese sentido, lo que se halla escrito sobre dichos actores consideramos que permitirá explorar y delimitar las dimensiones y tensiones que facilitan y/o obstaculizan la 
Moglia B. Procesos de atención y cuidado desde la perspectiva de los trabajadores: una metaetnografía en hospitales de Latinoamérica. [Tesis de maestría]. Maestría en Epidemiología, Gestión y Políticas de Salud. Universidad Nacional de Lanús. 2020.

atención y cuidado en los hospitales. Al mismo tiempo, este trabajo sería complementario de aquellas investigaciones centradas en la perspectiva de los usuarios.

De este modo, develar las complejidades que estructuran los procesos de atención y cuidado en el ámbito del hospital, implicaría explicar cómo se trabaja en dichos servicios de salud en América Latina y, en función de esto, ampliar el debate en torno a mejorar la calidad en la atención.

\section{3. 2. Académica}

Durante la cursada de la maestría, comencé a participar en el proyecto de investigación Salud Pública en y desde el hospital. Una aproximación Etno-epidemiológica a los Servicios de Salud. Este último se enmarca en la línea de investigación Teoría y Objetos en Epidemiología del Instituto de Salud Colectiva (ISCo - UNLa) y, en particular, en el desarrollo teórico-metodológico de la Etno-epidemiología, el cual constituye una aproximación a los procesos de salud-enfermedad-atención de las poblaciones desde una mirada que abarque la propia perspectiva de los actores en cuestión.

En este contexto, empiezo a realizar observaciones en el servicio de guardia en un hospital del conurbano bonaerense, lo que me permitió un primer acercamiento a los procesos de atención y cuidado. En paralelo, llevamos a cabo un proceso de búsquedas exploratorias donde pude observar que la producción en torno al campo disciplinar de la antropología de la salud era abundante y que se había ampliado en las últimas dos décadas (Epele, 2017). Sin embargo, no se han encontrados investigaciones que sinteticen los hallazgos, busquen respuestas más generales o de mayor alcance que permitan describir los procesos de atención y cuidado que ocurren en el espacio del hospital, desde la perspectiva de los TraSa.

Estos señalamientos orientaron el presente proyecto a una revisión bibliográfica de tipo meta-etnográfica a fin de comprender los procesos de atención y cuidado en los hospitales de Latinoamérica tomando como punto de referencia las experiencias de los TraSa.

\section{3. 3. Personal}

A lo largo de la carrera de grado me vinculé a distintos proyectos de investigación y extensión con el interés de abordar el campo de la salud y la enfermedad. Estos temas me motivaron a acercarme al Instituto de Salud Colectiva, con la necesidad de conocer otros enfoques teóricos-metodológicos posibles y formas de trabajo más articuladas entre otras 
Moglia B. Procesos de atención y cuidado desde la perspectiva de los trabajadores: una metaetnografía en hospitales de Latinoamérica. [Tesis de maestría]. Maestría en Epidemiología, Gestión y Políticas de Salud. Universidad Nacional de Lanús. 2020.

disciplinas. En ese contexto, comienzo la maestría, la cual considero que fue más allá de un proceso de formación en relación con distintos campos disciplinares como la epidemiologia, la planificación, las políticas y las ciencias sociales, permitiendo un espacio de diálogos y discusiones entre mis compañeros, compañeras y docentes. Esto me permitió conocer otras experiencias y saberes en torno a cotidianeidades laborales desconocidas por mí, como la de los hospitales. Estas vivencias relatadas se superpusieron con las observaciones realizadas en el contexto de un hospital y, en conjunto, ayudaron a la delimitación del problema de investigación.

Los hospitales comenzaron ser objeto de mi interés; sus actores, sus saberes y sus prácticas me despertaron una serie de inquietudes sobre la organización y desarrollo del trabajo en dichos espacios. Entonces, la definición del problema quedó enmarcada por los intereses señalados, apuntando hacia los aportes de los abordajes metodológicos cualitativos para pensar servicios de atención y cuidado más humanizados y abiertos hacia la comunidad.

\section{4. Objetivos}

El objetivo general consiste en describir y analizar los procesos de atención y cuidado a partir de las experiencias de los trabajadores de los hospitales, a través del análisis comparativo de artículos científicos con abordajes metodológicos cualitativos situados en Latinoamérica

Mientras que los objetivos específicos quedaron conformados de la siguiente manera:

Identificar y describir los sentidos y significados asociados a la organización del trabajo, las rutinas y los espacios en que tienen lugar los procesos de atención y cuidado, desde la perspectiva de los TraSa.

> Identificar y describir las prácticas, saberes, relaciones y emociones involucrados en la atención y cuidado, desde la perspectiva de los TraSa.

> Delimitar y caracterizar los principales rasgos de los procesos de atención y cuidado desarrollados en hospitales latinoamericanos. 
Moglia B. Procesos de atención y cuidado desde la perspectiva de los trabajadores: una metaetnografía en hospitales de Latinoamérica. [Tesis de maestría]. Maestría en Epidemiología, Gestión y Políticas de Salud. Universidad Nacional de Lanús. 2020.

\section{ESTADO DEL ARTE}

Desde la antropología, los procesos de atención y cuidado que ocurren en el espacio del hospital se constituyen como objeto de estudio de manera tardía en relación al desarrollo histórico de la misma. Autores como van der Geest y Finkler (2004), señalan que los hospitales no han sido objeto de interés para la disciplina debido a que estos se consideraban organizaciones similares entre sí en virtud de ciertos atributos compartidos tales como la burocracia, la división de las salas, la nomenclatura médica, los códigos de vestimenta del personal o los accesorios tecnológicos. Estas características dieron lugar a una apariencia de familiaridad para cualquier sector de la sociedad occidental. Además, se consideraba que los principios de la biomedicina gobernaban de manera uniforme y universal, con limitada referencia a lo local de determinado conjunto social (van der Geest \& Finkler, 2004). Otra de las explicaciones se vincula a las dificultades de acceso a dichas instituciones, las cuales, en mayor medida, tenían que ver con la actitud defensiva de las autoridades que impedían el desarrollo de alguna investigación (van der Geest \& Finkler, 2004; Tosal Herrero, Brigidi \& Hurtado, 2013).

A partir de 1950 comienzan a desarrollarse estudios sociológicos centrados en los hospitales (Parsons, 1951; Caudill, 1958; Goffman, 1961; Freidson, 1970; Foucault 1975; Carapinheiro, 1993), mientras que los abordajes etnográficos son más tardíos, pudiendo citar a Foster y Anderson (1978) en su trabajo Medical Anthropology, donde dedican un capítulo al análisis del hospital. Otro estudio etnográfico precursor es realizado por Coser (1962) sobre un hospital estadounidense, donde plantea a la sala del hospital como un espacio exótico, susceptible de ser analizada como una isla separada del continente. No obstante, estudios actuales sostienen que los hospitales no pueden ser pensados por fuera de la sociedad de la cual forman parte, sino que deben ser interpretados en el marco de la cultura local en la que se producen (van der Geest y Finkler, 2004). En este sentido, explican que la vida en el hospital no debe considerarse en contraste con la vida fuera del hospital, el mundo "real", sino que forma parte de la sociedad que lo integra. Estos autores van a decir que el hospital no es una isla, sino una parte importante del continente.

En adelante, organizamos el presente apartado en dos secciones que describen la producción científica desde diversas aproximaciones cualitativas, que reflexionan sobre distintas problemáticas que atraviesan los hospitales en general y, de América Latina en particular. 
Moglia B. Procesos de atención y cuidado desde la perspectiva de los trabajadores: una metaetnografía en hospitales de Latinoamérica. [Tesis de maestría]. Maestría en Epidemiología, Gestión y Políticas de Salud. Universidad Nacional de Lanús. 2020.

\subsection{Estudios cualitativos en hospitales}

En esta sección recuperamos aquellos abordajes cualitativos desarrollados en el ámbito de los hospitales, los cuales nos permitieron acceder a un panorama general sobre las temáticas y discusiones en torno a los servicios de atención y cuidado a la salud de las dos últimas décadas. En vista de ello, nos enfocamos en investigaciones sobre las culturas hospitalarias, la organización social de la práctica médica y el trabajo de campo en hospitales.

\section{1. 1. Sobre las culturas hospitalarias}

Tomamos como punto de partida aquellos trabajos que forman parte de un número especial de la revista Social Science \& Medicine, debido a que se basan en dos premisas: la primera, contraria a la idea que los hospitales son casi clones idénticos de un modelo biomédico global, señala que los antropólogos están comenzando a describir e interpretar la variedad de culturas hospitalarias en diferentes países y, segundo, que la biomedicina y el hospital como su principal institución, es un dominio donde los valores centrales y las creencias de una cultura comienzan a ser miradas. Van der Geest y Finkler (2004) plantean que los trabajos incluidos en el número muestran, como se adelantó en el planteamiento del problema, que los hospitales reflejan y refuerzan los procesos sociales y culturales dominantes de una sociedad dada.

Dentro del número referenciado, destacamos la producción de Anderson (2004) y Gibson (2004), quienes indagan sobre las desigualdades en la atención en África, orientando su explicación hacia una replicación de las relaciones de género y de clase que tienen lugar en las sociedades analizadas. Lo mismo se puede observar en los trabajos realizados por van Amstel y van der Geest (2004) en Papúa-Nueva Guinea y Zaman (2004) en Bangladesh, en los cuales describen y analizan el rol que cada sujeto circulante del hospital atraviesa para favorecer y reforzar la estructura jerárquica de la sociedad en general. Por otro lado, Tanasi (2004) lleva a cabo una etnografía en las salas de obstetricia de un hospital italiano e ilustra las formas en que se reproducen y refuerzan las percepciones culturales de las mujeres en dicha sociedad. En el mismo sentido, Inhorn (2004) y Vermeulen (2004) enfocan sus investigaciones en cuestiones éticas de las prácticas analizadas y, además, permiten dar cuenta de cómo estas últimas están atravesadas por los valores dominantes de cada sociedad. En el estudio de Inhorn (2004) el foco está en las prácticas de fertilización asistida, y como la infertilidad es vista como una condición estigmatizada, llevando a los usuarios a demandar un 
Moglia B. Procesos de atención y cuidado desde la perspectiva de los trabajadores: una metaetnografía en hospitales de Latinoamérica. [Tesis de maestría]. Maestría en Epidemiología, Gestión y Políticas de Salud. Universidad Nacional de Lanús. 2020.

alto nivel de privacidad. Mientras que Vermeulen (2004) indaga sobre las decisiones que se toman en una sala de neonatología de un hospital en Ámsterdam y cómo se acuerda o no la prolongación de la vida en recién nacidos entre los profesionales y los usuarios, proceso que refleja valores culturales holandeses de mediación y negociación.

De estos artículos, sobresalen el énfasis en mostrar las relaciones que se da entre el nivel micro circunscripto a un servicio de atención de un hospital y el nivel macro dado por la sociedad, reflejando las premisas planteadas al principio.

\section{1. 2. Sobre la organización social}

También hallamos una serie de artículos centrados en la organización y funcionamiento de equipos de salud en hospitales, los cuales plantean la dimensión comunicacional como un aspecto central en los procesos de atención y cuidado. Algunas de las investigaciones indagan dentro de determinado servicio -de emergencia- (Collin et al., 2012; Iedema \& Merrick, 2016; Nugus, 2019; Person, Spiva, \& Hart, 2013) y, otras, entre diferentes servicios (Iedema et al. 2012; Webster et al., 2015) dentro del mismo hospital. Este conjunto de artículos destacan la necesidad de un trabajo "colaborativo" entre los actores involucrados en los servicios de salud, siendo el tipo de comunicación, organizadora y coordinadora de las prácticas de atención.

También consideramos un conjunto de estudios que centran su análisis en las percepciones, emociones y experiencias de los trabajadores en los procesos de atención y cuidado ya que entendemos que dicha dimensiones orientan la organización social de las prácticas. Hunter, Spence y Scheinberg (2008) analizan las reflexiones y discusiones que los médicos realizan en torno a incidentes en un entorno pediátrico y como las prácticas médicas se encuentran atravesadas por dimensiones médicas y socioculturales. En el mismo sentido, hallamos producciones donde se analizan cómo las percepciones (Henderson, Stacey, \& Dohan, 2008) y los marcos interpretativos (Hilligoss, 2014) de los médicos influyen en la práctica profesional.

Asimismo, encontramos investigaciones desarrolladas en servicios de guardia médica, las cuales destacan cómo las condiciones de trabajo, tales como la sobredemanda, la urgencia, el cambio constante de prioridades, la presión, el desajuste entre la atención que desean brindar y lo que realmente logran, generan angustia y sufrimiento en los trabajadores (Henckes \& Nurok, 2015; Kelley et al., 2011; Parsons, Gaudine, \& Swab, 2018), reflexionando sobre la necesidad de analizar las diferentes emociones derivadas del trabajo en 
Moglia B. Procesos de atención y cuidado desde la perspectiva de los trabajadores: una metaetnografía en hospitales de Latinoamérica. [Tesis de maestría]. Maestría en Epidemiología, Gestión y Políticas de Salud. Universidad Nacional de Lanús. 2020.

urgencias para pensar en mejorar la atención y cuidado de los usuarios. En este caso particular, destacamos la referencia a las emociones que atraviesan las prácticas médicas como una dimensión pertinente para pensar la organización de los procesos de atención y cuidado, así también el aspecto comunicacional.

\section{1. 3. Sobre el trabajo de campo}

Por último, consideramos relevante una serie de publicaciones que centran su atención en aspectos metodológicos de las investigaciones centradas en hospitales, las cuales constituyen reflexiones acerca del rol del antropólogo en dicho espacio y como condiciona el material producido (Herrero et al., 2013; Muñoz Martínez, 2013; Wind, 2008), delimitando una serie de desafíos que, a veces, se naturalizan como parte del trabajo de campo.

En este sentido, hallamos los trabajos de Herrero et al. (2013) y Muñoz Martínez (2013), quienes reflexionan sobre las dificultades de acceso al hospital, donde se les demanda muchas veces un doble rol investigador/nativo debido a que, generalmente, se logra un acuerdo entre las autoridades del hospital, accediendo a usar una bata blanca para pasar desapercibido, lo que provoca tensiones entre los usuarios e investigadores. Asimismo, Wind (2008) realiza una reflexión metodológica sobre las limitaciones de la observación participante en entornos hospitalarios, cuestionando el rol del investigador como participante en dichos espacios y sugiere el término de observación interactiva negociada para explicar la labor etnográfica. Dicho concepto permite reflexionar y discutir sobre cómo acordamos hacer nuestro trabajo y, también, capta lo que sucede cuando uno está haciendo trabajo de campo sin asumir que puede transformarse en el otro (Wind, 2008). Según la autora, el concepto señalado habilita comprender las relaciones dialógicas críticas que creamos con las personas que estudiamos, cualquiera sea el lugar donde llevemos a cabo nuestra investigación.

Esta revisión nos permitió visualizar la amplitud temática de los estudios desarrollados y, también evidencia los posibles planos de análisis que van desde uno más general, el de las dimensiones socio-culturales y comunicacionales que atraviesan los procesos de atención y cuidado, hasta otros más particulares, donde se abordaron cuestiones subjetivas de los trabajadores. Estos últimos permiten observar un doble juego donde la subjetividad del trabajador va moldeando los procesos de atención y cuidado, a la vez que éstos son capaces de reproducir/transformar subjetividades. 
Moglia B. Procesos de atención y cuidado desde la perspectiva de los trabajadores: una metaetnografía en hospitales de Latinoamérica. [Tesis de maestría]. Maestría en Epidemiología, Gestión y Políticas de Salud. Universidad Nacional de Lanús. 2020.

\subsection{Estudios cualitativos en hospitales de América Latina}

En este apartado, indagamos en aquellos estudios realizados en hospitales de América Latina, los cuales son presentados por un lado, los que se centran en las perspectivas de los usuarios de los servicios de atención y por otro lado, los que refieren al punto de vista de los TraSa.

\section{2. 1. Abordajes desde la perspectiva de los usuarios}

Para Latinoamérica, el mayor número de producciones cualitativas situadas en hospitales se dan en Brasil y México, donde sus problemáticas indagan en la relación médicopaciente (Cortés, 1997; Ferreira, 2011); los valores del personal de salud desplegados en su quehacer cotidiano (Aredes, Firmo \& Giacomin, 2018; Aredes, Giacomin \& Firmo, 2018a, 2018b; Nava Diosdado et al., 2011) y las experiencias de usuarios en servicios de salud (Feltrin \& Velho, 2016; Oliveira, 2014; Ruiz Coronel, 2004; Sutton et al., 2013).

En Uruguay, encontramos el trabajo de Álvarez Pedrosian (2009), quien realiza una etnografía de un hospital público, donde apunta a dar cuenta de la creación de estrategias de supervivencia y convivencia de los enfermos internados en un contexto de implantación, crisis y caída del modelo neoliberal aplicado al campo de la salud específicamente. Por su parte, Rostagnol y Viera (2006) indagan y analizan como tienen lugar diferentes tipos de prácticas violentas en relación a la atención en salud reproductiva y sexual. Ambos estudios se centran en la perspectiva de los usuarios de los servicios de atención.

En Argentina, Crivos (1988) lleva a cabo una descripción de la dinámica institucional de una sala de un hospital, recabando información sobre el uso y distribución del espacio y de la organización del tiempo, las prácticas rutinarias y las interrelaciones entre miembros del personal de un hospital-escuela. Plantea la verticalidad como característica de las relaciones del personal de la sala y el fenómeno de "inversión de la relación de servicio", el cual postula la transformación del enfermo en paciente de la institución. Es decir, el hospital pasa de estar al servicio del enfermo a tratarlo como un paciente que se encuentra al servicio del hospital. Siendo un hospital-escuela lleva a pensar al paciente como objeto necesario para las actividades docentes y, la salud termina siendo accesoria, favoreciendo cierta calidad de aprendizaje pero no de salud. En el mismo sentido, la estructura administrativa del hospital produce una instrumentalización del paciente imponiéndole un ritmo de actividades que favorezca el interés principal de dicha estructura, es decir, la reducción de costos del servicio. 
Moglia B. Procesos de atención y cuidado desde la perspectiva de los trabajadores: una metaetnografía en hospitales de Latinoamérica. [Tesis de maestría]. Maestría en Epidemiología, Gestión y Políticas de Salud. Universidad Nacional de Lanús. 2020.

De esta forma, las prácticas de atención no se centran en el paciente sino en el "objeto"/enfermedad para lograr los objetivos extra-asistenciales.

Asimismo, recuperamos para Argentina las investigaciones desarrolladas por el grupo de trabajo dirigido por Auyero (2013), donde toman como categoría de análisis "la espera" para problematizarla como mecanismo de dominación del estado, a través de su normalización en distintos ámbitos donde se dan relaciones entre los distintos grupos de la sociedad y el Estado. Su trabajo demuestra que el conocimiento implícito encarnado en las personas de los sectores de menores ingresos, a quien Auyero llama "los pacientes del Estado", revela actos de reconocimiento del orden político (Auyero, 2013; Damín, 2014). Asimismo, Pecheny y Palumbo (2017) realizan una compilación titulada Esperar y hacer esperar: escenas y experiencias en salud, dinero y amor, donde uno de sus ejes se centra en la salud, analizando la espera en torno al acceso de servicios de salud (Ballesteros et al., 2017; Farji Neer et al., 2017; Ortega et al., 2017; Braz, 2017) y a distintos procesos emocionales vinculados a aquella (Fernández Vázquez \& Szwarc, 2017; Pereyra, 2017).

Asimismo, incluimos aquellas investigaciones enfocadas en las trayectorias terapéuticas y prácticas de atención y cuidado de poblaciones específicas, tal como la de quienes padecen migraña (Del Mónaco, 2015), personas afectadas por el VIH-sida (Barber, 2015; Margulies et al., 2006; Margulies, 2010), poblaciones migrantes con diagnostico de tuberculosis (Castilla, 2016; Cerrutti, 2007; Goldberg, 2013; Goldberg and Silveira, 2013; Jelin, 2007) y usuarios de drogas ilegales (Epele, 2007 y 2011).

\section{2. 2. Abordajes desde la perspectiva del trabajador}

Otro conjunto de estudios, llevados a cabo en Argentina, hicieron énfasis en la perspectiva del TraSa. Encontramos una línea de trabajo bastante desarrollada vinculada al proceso formativo del sector médico durante sus trayectorias profesionales durante las residencias en hospitales públicos (Pagnamento, 1993; Bonet, 1999, 2004; Silbergleit, 2009; Ferrer, 2015). Por otro lado, encontramos investigaciones que abordan la dimensión espaciotemporal de la atención a la salud-enfermedad. García, Recoder y Margulies (2017) analizan las rutinas médico-burocráticas de la admisión e internación de mujeres en un centro obstétrico de un hospital público; las disputas, transacciones y negociaciones entre profesionales, pacientes y familiares; la delimitación de espacios y las secuencias y jerarquías temporales en el pasaje del "afuera" hacia el "adentro" del hospital. Por su parte, Ferrero (2003) indaga en el procedimiento de asignación de turnos para dar cuenta de cómo operan 
Moglia B. Procesos de atención y cuidado desde la perspectiva de los trabajadores: una metaetnografía en hospitales de Latinoamérica. [Tesis de maestría]. Maestría en Epidemiología, Gestión y Políticas de Salud. Universidad Nacional de Lanús. 2020.

los planos de temporalidad dentro de un centro de atención primaria de la ciudad de Buenos Aires. La autora propone dicho proceso se despliega a través de formas de comportamientos ritualizadas, tal como el otorgamiento de turnos, las cuales van a orientar la interacción social de acuerdo con las normas institucionales.

Por último, hallamos una investigación llevada a cabo por Spinelli et al. (2013) cuyo objetivo fue analizar la situación de salud de los trabajadores de los hospitales públicos de la provincia de Buenos Aires, con el propósito de describir las relaciones entre empleo, trabajo y salud en un amplio espectro. Este trabajo se orientó a romper con la mirada de los hospitales como estructuras verticales, dominadas por la racionalidad, evidenciando el papel del diálogo y el conocimiento como insumo para el trabajo cotidiano. Asimismo, se resalta la necesidad de superar las lógicas normatizadoras del enfoque biomédico, ya que limitan la dimensión subjetiva en los procesos de trabajo en salud y, tal como establece Campos, en dichos procesos "hay un cruce de subjetividades en un contexto especial [...] En el trabajo en salud siempre hay una subjetividad de otro directamente implicada" (Campos 2006, p.124). Además, este antecedente recuperó una serie de datos, que a su vez, sirvieron para el desarrollo de tres investigaciones en relación a los procesos de trabajo en hospitales públicos, que concluyeron en tesis de maestría. Por un lado, Negrín (2016) describe y compara diferentes aspectos sobre el pluriempleo en los trabajadores de la salud, partiendo de la hipótesis que la sobrecarga de trabajo podría influir de manera negativa en los vínculos que los trabajadores establecen con su trabajo, con los compañeros, con la organización y con los usuarios. Por su parte, Morales Castellón (2016) caracteriza y compara los perfiles demográficos y de salud de los profesionales universitarios, así como también, los procesos de trabajo y la situación laboral, con la hipótesis de que existen diferencias entre los profesionales médicos y el resto de los profesionales de salud con tareas asistenciales. En cuanto la tercera tesis, se centra en el análisis del empleo, el trabajo y la salud de los trabajadores que realizan guardias con funciones asistenciales (García Martínez, 2016). Entre quienes realizan guardias, en comparación con aquellos que no realizan, encontraron una mayor proporción de trabajadores con pluriempleo, jornadas de trabajo semanal más extensas y problemas para comunicarse con los pacientes. Este autor señala que el servicio de guardia parece funcionar bajo una lógica orientada al funcionamiento continuo y, no tanto, por la calidad de atención hacia los usuarios o la salud de los trabajadores (García Martínez, 2016).

Este breve recorrido por diversas investigaciones centradas en hospitales nos permitió anclar nuestra revisión en aquellos estudios que refieren a metodologías cualitativas con un 
Moglia B. Procesos de atención y cuidado desde la perspectiva de los trabajadores: una metaetnografía en hospitales de Latinoamérica. [Tesis de maestría]. Maestría en Epidemiología, Gestión y Políticas de Salud. Universidad Nacional de Lanús. 2020.

enfoque local y reflexivo de los procesos de atención y cuidado. Sin embargo, observamos que la mayoría de los estudios revisados están centrados en los usuarios de los servicios de salud, siendo menor el número de trabajos sobre las perspectivas que los trabajadores tienen sobre su realidad laboral y sus prácticas situadas en los hospitales. 
Moglia B. Procesos de atención y cuidado desde la perspectiva de los trabajadores: una metaetnografía en hospitales de Latinoamérica. [Tesis de maestría]. Maestría en Epidemiología, Gestión y Políticas de Salud. Universidad Nacional de Lanús. 2020.

\section{MARCO CONCEPTUAL DE REFERENCIA}

\subsection{Abordajes metodológicos cualitativos}

Nuestro análisis considera los artículos científicos con abordaje metodológico cualitativo, entendiéndolo en el sentido propuesto por Souza Minayo (2013), quien plantea que son "....aquellos capaces de incorporar la cuestión del significado y de la intencionalidad como inherentes a los actores, a las relaciones, y a las estructuras sociales..." (p. 20). La metodología cualitativa está vinculada a un análisis que refiere "no a la cuantificación de los datos cualitativos, sino al proceso no matemático de interpretación..." (Straus y Corbin, 2002, p. 12), lo que nos permite aproximarnos a la complejidad de los procesos sociales. En otras palabras, dichos abordajes permiten captar la óptica de los actores que, en este caso, será a través de las interpretaciones que los investigadores hacen sobre las percepciones, representaciones y acciones de los sujetos en cuestión sobre cómo viven y experimentan su cotidianeidad en los hospitales.

Nos basamos en Tylor y Bodogan (1994) para dar cuenta de un conjunto de aspectos que caracterizan el modo de encarar el mundo empírico desde una metodología cualitativa: es inductiva, es decir, se parte de los datos para la construcción de conceptos y categorías a través de diseños flexibles de investigación. Dichos autores resaltan la importancia del contexto en el fenómeno a estudiar de forma de no reducir a los sujetos a variables de estudio sino orientar el pensamiento en términos holísticos y esto también incluye el impacto que el/la investigador/a tiene sobre las poblaciones que intenta estudiar. Asimismo, señalan que, como ya especificamos más arriba, centran el abordaje dentro del marco de referencia de las poblaciones en cuestión de forma tal de acercarse lo más posible a su mundo empírico (Tylor y Bodogan, 1994).

Al centrarnos en los procesos de atención y cuidado que se dan en los hospitales, sostenemos que los abordajes cualitativos nos permiten una aproximación a comprender “... cómo y por qué los actores en escena actúan, piensan y sienten en la forma en que lo hacen" (Wacquant, 2003, p.5) y, por otro, da cuenta de los procesos interaccionales y organizacionales en que los tratamientos y cuidados son llevados a cabo en las instituciones de salud; con la potencialidad que este tipo de estudios tiene en la construcción de servicios de salud más eficientes, efectivos y humanos (Murphy y Dingwall, 2007). Asimismo, los enfoques cualitativos invitan a la reflexión de los problemas de forma relacional bajo un 
Moglia B. Procesos de atención y cuidado desde la perspectiva de los trabajadores: una metaetnografía en hospitales de Latinoamérica. [Tesis de maestría]. Maestría en Epidemiología, Gestión y Políticas de Salud. Universidad Nacional de Lanús. 2020.

contexto particular, permitiendo un anclaje en lo local y en las prácticas cotidianas para captar el proceso de salud-enfermedad-atención (en adelante PSEA).

\subsection{Conceptos de referencia}

Iniciamos el presente apartado explicitando una serie de supuestos ya señalados por Menéndez (2002) en su texto Usos y desusos de conceptos en antropología social a fin de sentar nuestro posicionamiento en relación con el marco conceptual construido. En este sentido, entendemos que las categorías recuperadas se acuñan y aplican en un campo académico, también tienden a difundirse, a apropiarse y a re-significarse dentro de distintos ámbitos de aplicación. Por eso los conceptos deben pensarse en torno a problemas ya que son estos últimos a los cuales uno apunta a interpretar o explicar. Asimismo, consideramos que todo concepto es provisional, es decir, es una construcción que puede explicar más o menos la realidad y no debe tomarse como reflejo de esta última y, por último, advertimos que los conceptos seleccionados se modifican a través de su uso. Tomando dichas referencias, no pensamos los conceptos de referencia como si tuvieran cierta "pureza" sino que, dependen de cómo se usen, bajo que objetivos e intereses del investigador o investigadora, permitiendo la flexibilidad y creatividad al momento de problematizar (Menéndez, 2002).

En adelante, presentamos nuestro marco conceptual, el cual se organiza desde categorías de análisis generales en relación a nuestro objeto de estudio a categorías más particulares centradas en la hipótesis planteada. Asimismo, el recorrido conceptual propuesto se enmarca dentro de los campos de la salud colectiva y la antropología.

Comenzamos definiendo al PSEA como "un universal que opera estructuralmente (...) en toda la sociedad y en todos los conjuntos sociales estratificados que la integran" (Menéndez, 1994, p. 71). Dicho proceso involucra una gran cantidad de simbolizaciones y representaciones colectivas que tratan de dar cuenta de los padecimientos y la salud. En este sentido, en las sociedades latinoamericanas actuales existen diferentes formas de atención a la salud-enfermedad, las cuales utilizan diversas técnicas diagnósticas, diferentes indicadores para la detección del problema, así como variadas formas de tratamiento e inclusive diferentes criterios de curación (Menéndez, 2003).

Al concepto de PSEA le incorporamos la categoría de cuidado, la cual ha tomado diferentes sentidos y usos, destacando su polisemia (Michalewicz et al., 2014). En este caso tomamos como referencia conceptual los estudios sobre ética del cuidado (Fisher \& Tronto, 
Moglia B. Procesos de atención y cuidado desde la perspectiva de los trabajadores: una metaetnografía en hospitales de Latinoamérica. [Tesis de maestría]. Maestría en Epidemiología, Gestión y Políticas de Salud. Universidad Nacional de Lanús. 2020.

1990; Tronto, 1993; Mol, 2008; Kleinman \& van der Geest, 2009; Kleinman, 2013) у aquellos situados en el campo de la salud colectiva (Ayres, 2018; Merhy, 2016).

Los estudios sobre ética del cuidado han definido a éste de la siguiente manera "como un conjunto de actividades que incluye todo lo que hacemos para mantener, continuar y reparar nuestro 'mundo' para que podamos vivir en lo mejor posible"3 (Fisher \& Tronto, 1990, p. 40). La amplitud de dicha definición coincide con la propuesta de Tronto (1993) en entender que el cuidado involucra un compromiso, un interés y una responsabilidad para otro que lo necesita y supone un tipo de acción. La autora señala que no se debe presumir que el cuidado se lleva a cabo, solamente entre dos personas o individualmente, y, además, debe ser definido en términos culturales (Tronto, 1993). El cuidado constituye un continuo, que se puede dar como una actividad o un proceso a partir de los intereses de los sujetos en los procesos de la vida cotidiana y en este sentido, la variedad de cuidado es amplia. Del mismo modo, Mol (2008) plantea que el cuidado constituye un proceso continuo y abierto sin límites definidos donde intervienen, de manera conjunta, varias personas a través de acciones. Propone que el proceso de cuidado involucra a un equipo (de profesionales, máquinas, medicamentos, cuerpos, usuarios y otras personas relevantes), el cual dispone de una serie de tareas diarias para lograr una mejora en el padecimiento.

Arthur Kleinman y Sjaak van der Geest (2009) desarrollan el concepto de cuidado a partir de dos componentes: el emocional y el técnico/práctico. El primero involucra una acción con dedicación, compromiso o preocupación con un significado emocional asociado a ésta. El componente técnico/práctico refiere a actividades para un otro que no puede realizarlas solo, por ejemplo el cuidado de los hijos e hijas (alimentarlos, vestirlos) (Kleinman \& van der Geest, 2009). Los autores señalan que uno de estos componentes puede dominar o anular al otro dependiendo del contexto en el cual se den y, en el caso, del cuidado médico el componente técnico/práctico ha asumido un rol casi completamente dominante. Esto se puede atribuir, en parte, a la estructura burocrática que adquieren los servicios de salud y a las limitaciones económicas que lleva a disuadir a los profesionales del arte de cuidar y no favorecen que el hospital sea un espacio de cuidado (Kleinman \& van der Geest, 2009). Kleinman (2013) sostiene que las prácticas de cuidado no solo tienen que ver con medicar, sino también con actividades cotidianas como bañarse, ir al baño, alimentarse, apoyarse o estar allí. Esto es lo puesto en juego, emocional y moralmente. En este sentido, dicho autor

\footnotetext{
${ }^{3}$ Traducción libre de la autora: a species activity that includes everything that we do to maintain, continue, and repair our 'world' so that we can live in it as well as possible (Fisher \& Tronto, 1990, p. 40).
} 
Moglia B. Procesos de atención y cuidado desde la perspectiva de los trabajadores: una metaetnografía en hospitales de Latinoamérica. [Tesis de maestría]. Maestría en Epidemiología, Gestión y Políticas de Salud. Universidad Nacional de Lanús. 2020.

postula al cuidado como una experiencia moral que, desde la antropología puede ser vista como un intercambio de regalos entre personas que se importan entre sí, así como también:

\begin{abstract}
Hay un intercambio de historias y significados, pero también de la experiencia cruda de responsabilidad y sensibilidad emocional como en donar y recibir entre otros íntimos. Con el tiempo, el cuidado cambia la subjetividad tanto del cuidador como del quien es cuidado. En última instancia, el cuidado es hacer el bien por los demás; y hacer el bien en el mundo, tan serio e ingenuo como pueda sonar, es lo que la medicina se trata realmente ${ }^{4}$ (p.5)
\end{abstract}

Desde el campo de la salud colectiva, Ayres (2018) desarrolla la noción de cuidado vinculada a la humanización de la atención. El autor plantea al cuidado como un encuentro terapéutico humanizado donde la intervención apunta ir más allá de lo técnico y busca permeabilizar/flexibilizar la denominada normatividad morfofuncional (Ayres, 2018). En sus palabras el cuidado refiere a “... esa conformación humanizada del acto asistencial..." (Ayres et al., 2018 p. 124). Este encuentro tienen una dimensión dialógica donde el profesional intenta salirse de su discurso tecnocientífico y escucha al usuario bajo un autentico interés y deseo en dicha acción, es decir, el cuidado se asocia a un poder escuchar y un hacerse escuchar (Ayres, 2018). Esto deriva en que el cuidado es un modo de acogimiento del otro y, además, una responsabilidad en la relación con el otro (Ayres, 2018).

Por último, Merhy (2016) plantea al cuidado como un encuentro entre un trabajador de la salud o equipo y un usuario o grupo de usuarios de su servicio, es decir, entre actores sociales, de los cuales unos expresan o portan una necesidad de salud (demanda) y otros se encuentran como portadores de un cierto saber-hacer tecnológico, productor de cuidado en salud. Este encuentro se dirige a "la recuperación de su "modo de andar la vida" (p.152). En este caso, hacemos referencia a una parte de la propuesta conceptual del autor centrada en el cuidado como acontecimiento que involucra múltiples maletines tecnológicos, los cuales se representan como "cajas de herramientas". Merhy $(2002,2016)$ refiere a tres maletines: el de las tecnologías leves, vinculas a las relaciones que se dan entre los sujetos; el de las tecnologías leves-duras, correspondientes a los saberes científicos y, el de las tecnologías duras, que constituyen los remedios, los aparatos manuales y equipos físicos. Cada uno de estos maletines expresa un producto singular y, dependiendo de cómo se relacionen entre sí,

\footnotetext{
${ }^{4}$ Traducción libre de la autora: There is an exchange of stories and meanings but also of the raw experience of responsibility and emotional sensibility as in gift giving and receiving among intimate others. Over time caregiving changes the subjectivity of both caregiver and carereceiver. Ultimately, caregiving is about doing good for others; and doing good in the world, as earnest and naïve as it may sound, is what medicine is really about (Kleinman, 2013, p.5).
} 
Moglia B. Procesos de atención y cuidado desde la perspectiva de los trabajadores: una metaetnografía en hospitales de Latinoamérica. [Tesis de maestría]. Maestría en Epidemiología, Gestión y Políticas de Salud. Universidad Nacional de Lanús. 2020.

definirá el sentido social del acto en salud, es decir, si se da en términos de construcción de acogimientos, vínculos y responsabilidades o no (Merhy, 2016).

Por su parte, Menéndez (2015) refiere a la categoría de atención y prevención de los padecimientos, la cual se vincula a modelos, saberes y formas que buscan prevenir, tratar, controlar, aliviar y/o curar un padecimiento determinado $y$, que pueden darse de forma complementaria entre sí. . El autor incluye, entonces, a la biomedicina, a los saberes populares y tradicionales (parteas empíricas, yerberos, curanderos, entre otros), a las medicinas alternativas o paralelas (sanadores, bioenergéticos), otras tradiciones medicinas académicas (medicina ayurvédica, acupuntura) y saberes provenientes del grupo doméstico o de las organizaciones de grupo de autoayuda.

En este caso, nos interesamos por la biomedicina ya que constituye uno de los de modelos dominantes de atención a la salud y de expansión en las sociedades occidentales (Menéndez, 2003). Menéndez $(1978 ; 1983 ; 1990)$ vincula la biomedicina a un modelo médico hegemónico (en adelante $\mathrm{MMH}$ ), el cual se describe a partir de una serie de características: biologismo, a-sociabilidad, a-historicidad, aculturalismo, individualismo, eficacia pragmática, orientación curativa, relación médico/paciente asimétrica y subordinada, exclusión del saber del paciente, profesionalización formalizada, identificación ideológica con la racionalidad científica, la salud/enfermedad como mercancía, tendencia a la medicalización de los problemas, tendencia a la escisión entre teoría y práctica. El MMH ocupa como espacio de referencia las organizaciones asistenciales, de cura prevención y tratamiento de enfermedades como los hospitales. En dichos espacios, los procesos de trabajo se ven atravesados por normas y reglas, entendidas como imposiciones de la institución que estructuran su funcionamiento y su regulación (Ferrero, 2003).

Las prácticas de los trabajadores del hospital están atravesadas por dichas disposiciones que contribuyen a un conjunto de intervenciones relativamente homogéneas, que se producen y reproducen en los encuentros entre los trabajadores mencionados y la población (Ferrero, 2003). Entonces, el hospital provee la matriz en que ocurren los procesos de atención y cuidado, es decir, dispone de una serie de normas y reglas reguladoras de la interacción social a fin de asegurar marcos comunes de significado (Ferrero, 2003). Esta estructuración del saber médico (Ferrero, 2003) se superpone con la expresión de la racionalidad biomédica (Camargo, 2005; García, 2013), la cual no reconoce las dimensiones sociales, culturales, económicas y políticas en las cuales se entremezcla su trabajo cotidiano. Camargo (2005) ha definido dicha racionalidad como “... un sistema lógico y teóricamente 
Moglia B. Procesos de atención y cuidado desde la perspectiva de los trabajadores: una metaetnografía en hospitales de Latinoamérica. [Tesis de maestría]. Maestría en Epidemiología, Gestión y Políticas de Salud. Universidad Nacional de Lanús. 2020.

estructurado..." (p. 178), bajo tres lineamientos: (1) el carácter generalizador ya que produce discursos y modelos de aplicación universal sin hacer un abordaje de casos particulares; (2) el carácter mecanicista ya que plantea dispositivos fundados en los principios de la causalidad lineal tales como el funcionamiento de una máquina y (3) el carácter analítico ya que, siguiendo las líneas anteriores, presupone un aislamiento de las partes y que su suma habilita al funcionamiento del todo (Camargo, 2005).

Ahora bien, teniendo este contexto de trabajo es necesario agregar que los sujetos que intervienen los espacios de los hospitales a través de acciones no se da como

\footnotetext{
....un acto congelado en el espacio-tiempo (...), sino como un proceso que es dinámico, que se modifica y es atravesado por muchos intereses, tantos cuantos sean los sujetos que interactúen en la actividad que le da vida... (Franco y Merhy, 2009, p. 186).
}

En este sentido, proponemos un abordaje analítico del hospital a fin de centrarnos, no tanto su estructura determinada y constituida, sino en sus trabajadores y sus prácticas de atención y cuidado, bajo el supuesto de que al interior de las organizaciones de salud operan diferentes planos que emergen sobre la estructurada dada, constituida y preexistente. De esta forma, se configura una dinámica de escenarios que se superponen y descomponen cotidianamente en los procesos de atención y cuidado. Asimismo, en estos últimos involucran encuentros entre actores/sujetos que habilitan relaciones de diferentes intensidades para la producción de salud y, en este sentido, operan de manera superpuestas a sistema normativo, organizado y estructurado (Franco \& Merhy, 2009). Ir más allá de la estructura organizativa de los hospitales implica entender a dicha organización en varios planos, dando lugar a la emergencia de subjetividades en relación (Franco \& Merhy, 2009). Franco y Merhy (2011) explican, entonces, que existe un modo singular de producción del cuidado, bajo el supuesto que los TraSa actúan de forma diferente, no sigue un patrón y el usuario del servicio de salud, también, plantea una atención/cuidado diferencial. Es decir, señalan que se presenta una estandarización de las actividades de los trabajadores, pero que influye de forma restringida en las formas de atención ya que "...cuando se encuentran en situación de trabajo, en relación con el usuario, son ellos mismos los que, en acto, definen cómo se realiza ese cuidado" (p. 10) [resaltado nuestro]. Trabajo vivo en acto constituye el "sustrato sobre el cual la producción de los actos de salud va ocurriendo" (Franco \& Merhy, 2009, p. 186). Se da en el momento de la interacción entre los sujetos, lo cual no puede suponerse un modelo rígido y estereotipado de producción de salud (Merhy, 2006). En este sentido, introducimos el concepto de identidades para pensar dichas interacciones ya que, tal como desarrolla Hall (2003), a través de estas 
Moglia B. Procesos de atención y cuidado desde la perspectiva de los trabajadores: una metaetnografía en hospitales de Latinoamérica. [Tesis de maestría]. Maestría en Epidemiología, Gestión y Políticas de Salud. Universidad Nacional de Lanús. 2020.

últimas “(...) emergen [las identidades] en el juego de modalidades específicas de poder y, por ello, son más un producto de la marcación de la diferencia y la exclusión que signo de una unidad idéntica y naturalmente constituida (...)” (p. 18). En este sentido, el autor sostiene que se van a dar dos procesos: el de sujeción, el cual refiere a los discursos y las prácticas que constituyen las posiciones sociales de sujeto y el de subjetivación, es decir, los procesos de producción de subjetividades que llevan aceptar, modificar o rechazar dichos posicionamientos (Hall, 2003).

A fin de complementar las categorías anteriores nos referimos a la definición de subjetividad construida por Sherry Ortner, antropóloga estadounidense, quien realiza de un recorrido a través de distintos abordajes teóricos acerca del sujeto y subjetividad se posiciona dentro de la antropología crítica. Dicha autora plantea la importancia de explorar la configuración cultural de las subjetividades en un mundo social atravesado por relaciones de poder desiguales. En este sentido planteamos que en el espacio del hospital, en las dinámicas de los procesos de atención y cuidado se configuran subjetividades, que aluden tanto al “...conjunto de modos de percepción, afecto, pensamiento, deseo, temor, etc., que animan a los sujetos actuantes" (Ortner, 2005, p. 25) y que se vinculan “... a las formaciones culturales y sociales que modelan, organizan y generan determinadas "estructuras de sentimiento" (Ortner, 2005, p. 25). Entonces, el concepto de subjetividad se plantea en dos planos: uno individual, que refiere a un sujeto cognoscente, que reflexiona sobre sí mismo y sus deseos y, otro sentido colectivo como parte de un conjunto de actores socialmente interrelacionados, que es el plano cultural (Ortner, 2005). La autora entiende las subjetividades como complejas porque, además de ser constituidas culturalmente, permiten explicar la relación del yo con el mundo.

Por último, presentamos un concepto que atraviesa, no sólo, nuestro marco conceptual sino también nuestro problema de investigación, el de cultura. En el campo de la antropología, coexisten múltiples definiciones, críticas y re-definiciones, sobre las cuales no vamos a profundizar aquí ya que no es el objetivo. En cambio, retomamos el concepto semiótico de cultura propuesto por Geertz (1973), su crítica y re-definición para lograr una explicación de lo que entendemos por cultura. Retomando a Max Weber, Geertz (1973) entiende “...que el hombre es un animal inserto en tramas de significación que él mismo ha tejido" y considera que "... la cultura es esa urdimbre y que el análisis de la cultura ha de ser por lo tanto, no una ciencia experimental en busca de leyes, sino una ciencia interpretativa en busca de significaciones" (p. 20). 
Moglia B. Procesos de atención y cuidado desde la perspectiva de los trabajadores: una metaetnografía en hospitales de Latinoamérica. [Tesis de maestría]. Maestría en Epidemiología, Gestión y Políticas de Salud. Universidad Nacional de Lanús. 2020.

Ortner (2005) sostiene que la definición de cultura de Geertz tiene dos dimensiones: una vinculada a la visión del mundo o ethos de un grupo particular de personas y otra dimensión que hace hincapié en la construcción de sentido que se dan a través de procesos simbólicos inmersos en el flujo de la vida social. La primera mirada ha sido criticada por su asociación a cierto esencialismo, que supone que un grupo social tiene ciertas propiedades o una esencia propia, quedando sin abarcar las diferencias y desigualdades sociales. La cultura pensada como una visión del mundo que es compartida, de manera homogénea, por los miembros de un determinado grupo social y no un recurso heurístico para hablar de la diferencia (Canclini, 2004; Ortner, 2005). Teniendo en cuenta dicho peligro, la autora parte de la segunda dimensión, la cual refiere al conjunto de formas simbólicas públicas que expresan y configuran sentidos y significados, los cuales pueden encauzar muchas y diferentes direcciones (Ortner, 2005). En este sentido, define la cultura como la comprensión del "mundo imaginativo" dentro del cual estos actores operan, las formas de poder y agencia que son capaces de construir, los tipos de deseos que son capaces de crear. Cultura se refiere más bien “...a los modos específicos en que los actores se enfrentan, se alían o negocian” (Grimson \& Semán, 2003, p. 8). En esta definición, encontramos una dimensión política en el encuentro entre agentes con formas culturales distintas que pueden insertar sus acciones en una lógica compartida y en ese sentido, pueden pertenecer al menos parcialmente a mundo imaginativos similares (Grimson \& Semán, 2005). Por lo que pensar cultura de esta forma permite vislumbrar si hay algo compartido entre actores aparentemente tan diferentes. Ortner (2005) politiza el concepto de cultura, y lo articula con una dimensión subjetiva, por la cual un sujeto internaliza, en parte una serie de circunstancias en las que se encuentra y reflexiona sobre éstas y finalmente reacciona contra dicha dimensión, introduciendo grietas, fisuras.

En sintonía con esta perspectiva, vinculamos la propuesta de van der Geest y Finkler (2004) al señalar que los hospitales no pueden ser pensados por fuera de la sociedad de la cual forman parte, sino que deben ser interpretados en el marco de la cultura local en la que se producen. Esto quiere decir que los hospitales reflejan y refuerzan procesos sociales y culturales dominantes de una sociedad dada (van der Geest \& Finkler, 2004). Desde este marco, definimos cultura hospitalaria como el modo en que los actores crean sentidos y significados compartidos y corporizados en la práctica cotidiana dentro del hospital, que expresan y a la vez configuran la subjetividad implicada los procesos de atención y cuidado, lo relacional, vincular y las emociones asociadas a las rutinas de trabajo en el hospital podrá identificarse. 
Moglia B. Procesos de atención y cuidado desde la perspectiva de los trabajadores: una metaetnografía en hospitales de Latinoamérica. [Tesis de maestría]. Maestría en Epidemiología, Gestión y Políticas de Salud. Universidad Nacional de Lanús. 2020.

\section{METODOLOGIA}

\section{1. Estrategia de búsqueda}

La estrategia de búsqueda se definió a partir de las bases de datos a utilizar y los términos de búsquedas. Las bases elegidas fueron de tipo electrónica: Scientific Electronic Library Online (SciELO), PubMed, Scopus y Biblioteca Virtual en Salud (BVS). La elección estuvo dirigida de forma de incluir servicios de indización que permitan una diversidad de enfoques de estudios, pero que, a la vez, no dejen de tener una consistencia y homogeneidad que permita su abordaje, para lo cual seleccionamos aquellos formatos que respondían a la estructura de un artículo científico. Luego, reflexionamos sobre la utilización o no de los descriptores (Descriptores en Ciencias de la Salud o Medical Subject Headings) y establecimos que dichas categorizaciones restringían la búsqueda. De esta manera, se seleccionaron términos libres para las búsquedas, los cuales en una fase exploratoria fueron: "etnografía", "hospital", "servicios de salud", "cualitativo", "investigación de servicios de salud", "etnografía hospitalaria", "institución médica", "cuidado de la salud" y, en algunas combinación se realizó un recorte geográfico a través de los términos "América" y "Sudamérica" (Tabla 1). Los términos seleccionados fueron combinados de diferentes formas, en inglés, en plural (si correspondía), bajo el operador lógico "and", a través del campo de búsqueda de "Title/Abstract" (según corresponda en cada base) y sin filtros. 
Moglia B. Procesos de atención y cuidado desde la perspectiva de los trabajadores: una metaetnografía en hospitales de Latinoamérica. [Tesis de maestría]. Maestría en Epidemiología, Gestión y Políticas de Salud. Universidad Nacional de Lanús. 2020.

Tabla 1. Resultados de las búsquedas exploratorias. Realizada en febrero y abril, 2019.

\begin{tabular}{|c|c|c|c|c|c|}
\hline Términos libres & BVS & SciELO & PubMed & Scopus & TOTAL \\
\hline $\begin{array}{l}\text { ethnography } \\
\text { hospital }\end{array}$ & 999 & 44 & 327 & 996 & 2366 \\
\hline $\begin{array}{l}\text { "hospital } \\
\text { ethnography" }\end{array}$ & 22 & 5 & 18 & 43 & 88 \\
\hline $\begin{array}{l}\text { "health services" } \\
\text { ethnography }\end{array}$ & 1023 & 22 & 0 & 928 & 1973 \\
\hline $\begin{array}{l}\text { qualitative } \\
\text { hospital } \\
\text { sudamerica }\end{array}$ & 22 & 1 & 0 & 37 & 60 \\
\hline $\begin{array}{l}\text { "health services } \\
\text { research" } \\
\text { ethnography }\end{array}$ & 150 & 0 & 17 & 0 & 167 \\
\hline $\begin{array}{l}\text { "qualitative } \\
\text { research" } \\
\text { "health services" }\end{array}$ & 11219 & 137 & 956 & 2 & 12314 \\
\hline $\begin{array}{l}\text { "medical } \\
\text { institution" } \\
\text { ethnography }\end{array}$ & 59 & 3 & 0 & 7 & 69 \\
\hline $\begin{array}{l}\text { "health services" } \\
\text { ethnography }\end{array}$ & 1027 & 22 & 119 & 952 & 2120 \\
\hline $\begin{array}{l}\text { "health care" } \\
\text { ethnography } \\
\text { América }\end{array}$ & 191 & $47 *$ & 119 & 50 & 407 \\
\hline TOTAL & 14712 & 281 & 1556 & 3015 & 19564 \\
\hline
\end{tabular}

Fuente: elaboración propia a partir de las búsquedas exploratorias.

Estas búsquedas exploratorias nos permitieron observar la cantidad relativa de producción académica en la región, en relación a investigaciones cualitativas en hospitales. A partir de esta trayectoria, orientamos nuestro recorte hacia los procesos de atención y cuidado que se dan en los hospitales en América Latina, desde una perspectiva cualitativa centrada en la perspectiva de los TraSa. 
Moglia B. Procesos de atención y cuidado desde la perspectiva de los trabajadores: una metaetnografía en hospitales de Latinoamérica. [Tesis de maestría]. Maestría en Epidemiología, Gestión y Políticas de Salud. Universidad Nacional de Lanús. 2020.

\section{1. 1. Criterios de inclusión y exclusión}

Los criterios de inclusión de las producciones seleccionadas fueron que: a) sean artículos científicos, a fin de que el corpus de análisis tenga cierta homogeneidad para la comparación; b) utilicen abordaje metodológico cualitativo centrado en la perspectiva de los TraSa, sin realizar, a priori, ningún recorte referido a quién específicamente incluir en dicha categoría y permitiendo que sea construida a partir del corpus y; c) su trabajo de campo se desarrolle en hospitales geográficamente ubicados en América Latina. Estos dos últimos criterios constituyen los recortes temáticos que configuran el problema de investigación.

Se descartaron los artículos que: a) no desarrollaron trabajo de campo (revisiones, editoriales, abordajes teóricos); b) no se pudieron recuperar a texto completo y c) abordaron procesos de atención y cuidado en hospitales monovalentes de salud mental, ya que consideramos que dichas instituciones tienen otras singularidades que conllevan que otro tipo de abordaje.

La aplicación de dichos criterios se realizó en dos momentos: en el primero, se llevó a cabo el recorte geográfico y en el segundo, se verificaron los restantes criterios. En caso de no ser suficiente, se leyeron de manera completa para decidir la inclusión o no.

\section{1. 2. Resultados de las búsquedas}

A través de los recorridos realizados, decidimos utilizar algunos términos de las búsquedas exploratorias e incluir aquellos que permitan la inclusión de artículos que indaguen sobre el punto de vista de los trabajadores. De esta forma, se articularon cinco conjuntos de términos libres para cada base (Tabla 2). 
Moglia B. Procesos de atención y cuidado desde la perspectiva de los trabajadores: una metaetnografía en hospitales de Latinoamérica. [Tesis de maestría]. Maestría en Epidemiología, Gestión y Políticas de Salud. Universidad Nacional de Lanús. 2020.

Tabla 2. Búsqueda de artículos científicos en bases electrónicas BVS, PubMed, SciELO y Scopus. Agosto, 2019.

\begin{tabular}{|c|c|c|c|}
\hline $\begin{array}{c}\text { Bases de } \\
\text { datos }\end{array}$ & Términos de búsqueda/Términos libres & $\begin{array}{l}\text { Campos de } \\
\text { búsqueda }\end{array}$ & $\begin{array}{c}\text { Cantidad de } \\
\text { artículos } \\
\text { científicos }\end{array}$ \\
\hline
\end{tabular}

BVS "healthcare delivery"; Ethnography; Hospital "Health workers"; Experience; Hospital Título, Cualitative; Hospital; Sudamérica resumen y "hospital care"; qualitative; "health workers" "hospital care"; "health workers" asunto

PubMed "health care wokers"; Ethnography

Hospital; Latinoamerica; Workers "Health workers"; Experience; Hospital Título y 695 Hospital; "health workers"; qualitative resumen

SciELO "care practices"; "health professionals"; Hospital "healthworkers"; Experiencie; Hospital

Resumen 298 Latin America; Hospital "hospital care"; qualitative Hospital; "health workers"; qualitative

Scopus Cualitative; Hospital; Sudamérica "healthcare"; Ethnography; Hospital; América "care practices"; Workers; Hospital Hospital; "health workers"; qualitative Título, 792 "hospital care"; Ethnography resumen y palabras clave

Fuente: elaboración propia a partir de las búsquedas realizada.

Luego, se llevó a cabo la construcción del corpus de artículos científicos para el posterior análisis a través de la eliminación de los duplicados y la aplicación de los criterios de exclusión (Figura 1), quedando un total 36 artículos. 
Moglia B. Procesos de atención y cuidado desde la perspectiva de los trabajadores: una metaetnografía en hospitales de Latinoamérica. [Tesis de maestría]. Maestría en Epidemiología, Gestión y Políticas de Salud. Universidad Nacional de Lanús. 2020.

Figura 1. Diagrama del proceso de selección de las referencias bibliográficas que conforman el corpus de investigación.

Número de artículos recuperados de las bases de datos SciELO, PubMed, Scopus, BVS

$$
(\mathrm{n}=2302)
$$
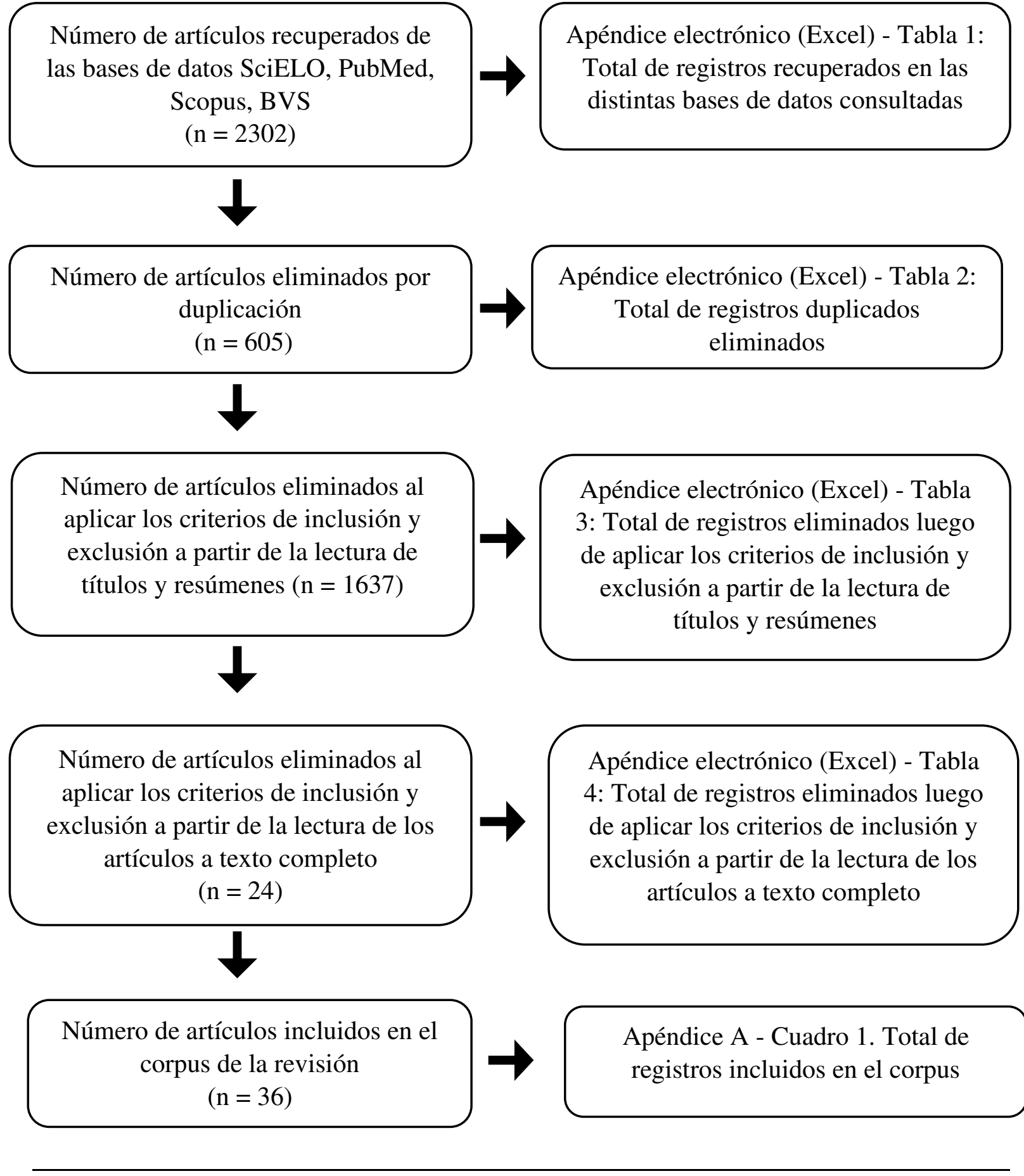

Fuente: Elaboración propia a partir de registros obtenidos en SciELO, Scopus, BVS y PubMed. 
Moglia B. Procesos de atención y cuidado desde la perspectiva de los trabajadores: una metaetnografía en hospitales de Latinoamérica. [Tesis de maestría]. Maestría en Epidemiología, Gestión y Políticas de Salud. Universidad Nacional de Lanús. 2020.

\subsection{Estrategia de análisis: meta-etnografía}

La meta-etnografía constituye un tipo de síntesis cualitativa ya que apunta a la integración de hallazgos procedentes de estudios empíricos. También ha sido denominada como meta-síntesis cualitativa (Sandelowski, Docherty \& Emden, 1997; Cassuli Matheus, 2009). En este caso, nos basamos en la propuesta de Noblit \& Hare (1988), quienes plantean a la meta-etnografía como un abordaje que va más allá del análisis de los datos de los estudios seleccionados, buscando una síntesis integrativa de estos últimos basándose en el paradigma interpretativo, aspecto que la distingue del meta-análisis. En términos generales, la metaetnografía consiste en la comparación sistemática de investigaciones cualitativas y su traducción para la construcción de interpretaciones a partir de un análisis de carácter inductivo.

Noblit \& Hare (1988) plantean un recorrido en siete fases que no adoptan un sentido lineal, sino más bien superpuesto al momento de llevar a cabo el análisis. Dichas etapas son:

(1) Identificación de un interés intelectual a partir de un conjunto de estudios que habilitan a la construcción de determinado problema de investigación.

(2) Delimitación de lo que es relevante para el interés inicial, en relación con los objetivos e hipótesis planteados.

(3) Lectura de los estudios. Esta fase incluye la lectura crítica de los estudios seleccionados para identificar los conceptos principales y la extracción de las metáforas interpretativas.

(4) Determinación de cómo se relacionan los estudios que van a ser sintetizados. Esta etapa incluye la comparación de temas, conceptos o frases entre los artículos del corpus a fin de poder demarcar similitudes (a), diferencias (b) o líneas de argumentos (c) entre los textos. De acuerdo de qué tipo de relaciones se trate, los autores plantean tres estrategias de análisis: : (a) la "traducción recíproca", en la que se examinan las similitudes temáticas a través del conjunto de conceptos, categorías y términos que referencian los textos y examinar la utilización en los distintos casos; (b) la "síntesis de refutación", la cual está orientada a la identificación de los desacuerdos entre los textos seleccionados y (c) "síntesis de línea de argumento", cuyo objetivo es desarrollar una interpretación integral del todo (organización, cultura, etc.) basada en las líneas argumentales.

(5) Reunir los artículos. Este es un nivel de síntesis que implica comparar sistemáticamente el significado de metáforas, conceptos o temas y sus relaciones establecidas anteriormente. 
Moglia B. Procesos de atención y cuidado desde la perspectiva de los trabajadores: una metaetnografía en hospitales de Latinoamérica. [Tesis de maestría]. Maestría en Epidemiología, Gestión y Políticas de Salud. Universidad Nacional de Lanús. 2020.

(6) Sintetizar los artículos. Se refiere a realizar un análisis más allá de lo que implican los hallazgos de los estudios individuales, construyendo nuevas interpretaciones del objeto a estudiar.

(7) Expresión de la síntesis. En esta fase final la síntesis es expresada a través de diferentes formas que expresen y comuniquen de manera efectiva los hallazgos.

Para terminar, resaltamos una cuestión a tener presente, vinculada con el recorte realizado en torno a la elección de textos en formato de artículo científico. Esto implicó dejar de lado otro tipo de literatura como libros o capítulos de libro u otras presentaciones de la investigación como puede ser en congresos o jornadas, en especial tratándose de trabajos etnográficos, que no se encuentren registradas en las bases de datos indizadas. Esto se debe a que las revisiones bibliográficas en general y la meta-etnografía en particular, requieren de cierta homogeneidad en el corpus construido. Es decir, “... un tipo de estructura, abordaje y textualidad que admitan ser interrogados por ciertos ejes comunes" (Martinovich, 2019, p. 1) Asimismo, no podemos dejar de advertir que la forma predominante de producción y circulación del conocimiento científico en general -y las ciencias sociales no son la excepción- es el formato de artículo, con todas las limitaciones y desafío que imprime a la presentación de un trabajo etnográfico. En este sentido, consideramos nuestro recorte no tanto como un límite sino más bien como un desafío.

Por último, consideramos que, si bien se parte de determinada pregunta, se trata de un diseño flexible y éstas pueden ser modificadas desde la especificidad de los textos. Esto equivale a introducir o incorporar categorías, conceptos y actores que, a priori, no se habían tenido en cuenta por ejemplo. Todo ello es parte de la dinámica procesual que se propone desde la metodología de la meta-etnografía. 
Moglia B. Procesos de atención y cuidado desde la perspectiva de los trabajadores: una metaetnografía en hospitales de Latinoamérica. [Tesis de maestría]. Maestría en Epidemiología, Gestión y Políticas de Salud. Universidad Nacional de Lanús. 2020.

\section{RESULTADOS}

El corpus de artículos analizado incluye investigaciones desarrolladas en Brasil (31), Colombia (2), Ecuador (1), México (1) y Argentina (1), todas realizadas en servicios ${ }^{5}$ de hospitales $^{6}$, los cuales fueron de distintos tipos: en su mayoría de enseñanza, escuela o universitario y en menor medida, eran hospital general, de emergencia y urgencia, pediátrico, filantrópico ${ }^{7}$ o maternidad. Asimismo, todos los artículos se centraron en la perspectiva de los TraSa, en algunos casos tomando como referencia al sector de enfermería o de médicos y en otros, abordando el conjunto de $\mathrm{TraSa}^{8}$ de un determinado servicio del hospital.

La presentación de los resultados del análisis se realiza siguiendo la propuesta metodológica de Noblit y Hare (1988). Esto es a través de un proceso analítico en dos etapas: inicialmente realizamos una síntesis comparativa, a través de la cual confrontamos los conceptos, ideas y metáforas interpretativas entre los artículos del corpus. Luego, elaboramos una síntesis interpretativa, orientada a ir más a allá de las particularidades de cada investigación con el propósito de construir una nueva interpretación acerca de los procesos de atención y cuidado en los hospitales y en ese sentido, entendemos pertinente incluir el conjunto de servicios de atención y de TraSa delimitado a partir del corpus.

\section{1. Sintesis comparativa}

Los trabajos abordan una multiplicidad de espacios y sujetos de estudio, sin embargo, hicimos hincapié en aquellos conceptos, ideas y metáforas interpretativas que los TraSa resaltan para referirse a distintos aspectos y/o dimensiones sobre los procesos de atención y cuidado en el contexto del hospital. A continuación presentamos los resultados del proceso de análisis, para el cual, inicialmente se realizó la lectura de cada uno de los textos y se extrajeron conceptos, categorías y metáforas. Estas fueron agrupadas según representaran cierta equivalencia conceptual en categorías de análisis, en las cuales converge, nuestro marco conceptual de referencia y las propuestas de los/as autores de los artículos del corpus. Luego, se llevó a cabo un proceso de comparación para identificar perspectivas semejantes o

\footnotetext{
${ }^{5}$ Los espacios donde se llevaron a cabo las investigaciones realizadas fueron los servicios de emergencia o guardia, terapia intensiva, oncología, paliativos, pediatría, obstetricia, neonatología, servicios sociales y archivo. ${ }^{6}$ La mayoría de los hospitales donde se realiza el trabajo de campo integran el sector público.

${ }^{7}$ Se trata de una institución privada, sin fines de lucro, contratada por gerentes públicos para prestar servicios al Sistema Único de Salud (SUS), en Brasil.

${ }^{8}$ En este caso incluyen (dependiendo del servicio que se trate), además del sector médico y enfermería, psicólogos/as, trabajadores/as sociales, fisioterapeutas, fonoaudiólogas, nutricionistas, dentistas, terapistas ocupacionales.
} 
Moglia B. Procesos de atención y cuidado desde la perspectiva de los trabajadores: una metaetnografía en hospitales de Latinoamérica. [Tesis de maestría]. Maestría en Epidemiología, Gestión y Políticas de Salud. Universidad Nacional de Lanús. 2020.

diferentes entre los sujetos, para el desarrollo de una interpretación integral del corpus (Figura 2):

Figura 2. Categorías de análisis elaboradas a partir de aquellas identificadas en la bibliografía analizada.

\section{PROCESOS DE ATECIÓN Y CUIDADO}

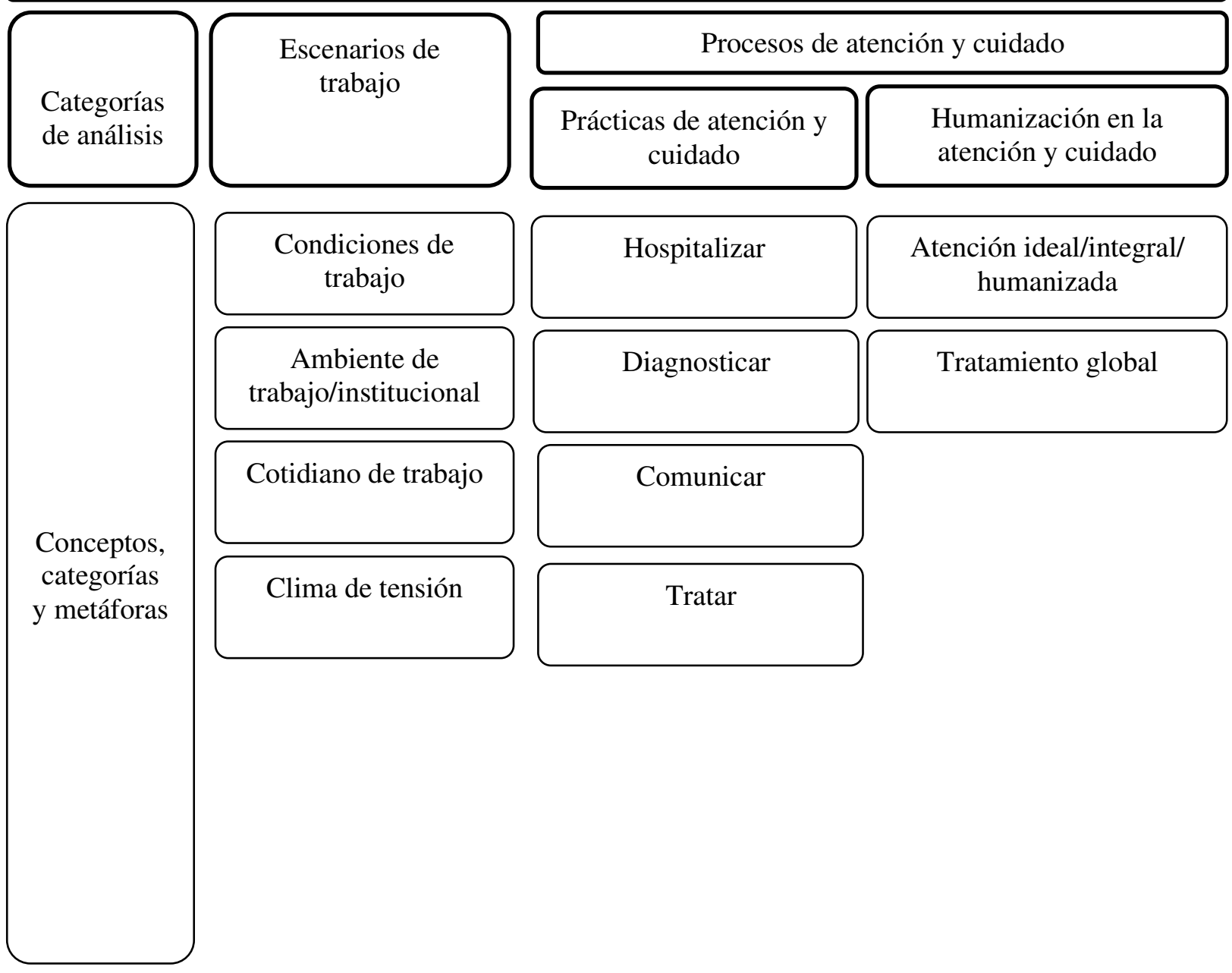


Moglia B. Procesos de atención y cuidado desde la perspectiva de los trabajadores: una metaetnografía en hospitales de Latinoamérica. [Tesis de maestría]. Maestría en Epidemiología, Gestión y Políticas de Salud. Universidad Nacional de Lanús. 2020.

Figura 2. Continuación

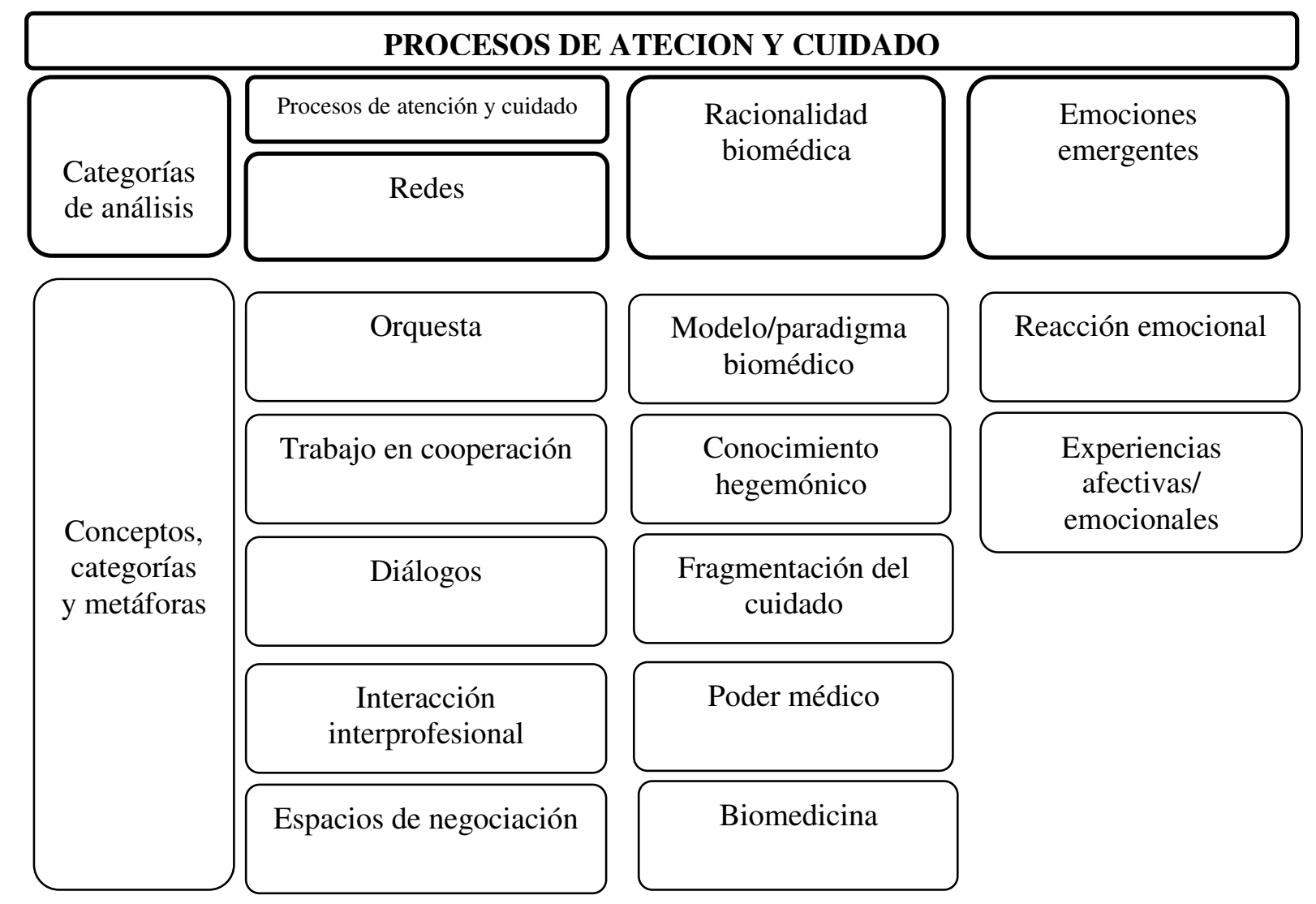

Fuente: elaboración propia.

A continuación, presentamos cada una de las categorías de análisis y su definición, para luego desarrollar los resultados del análisis del corpus, lo cual permite dar cuenta de su alcance teórico y empírico.

\section{1. 1. Escenarios de trabajo}

Los escenarios de trabajo refieren a diferentes configuraciones laborales donde se desenvuelven e interactúan los TraSa, y, sobre los cuales se desarrollan prácticas, relaciones de poder y de comunicación, siendo los contextos para la construcción de subjetividades en el trabajo (Soto Roy, 2015). En estos escenarios se “...posicionan a los actores sociales en un espacio particular de recursos para obtener reconocimiento dentro del sistema social, desde el cual dar sentido a su experiencia de trabajo" (Soto Roy, 2015, p. 202). Soto Roy (2015) refiere a tres dimensiones para explicar en conjunto los escenarios de trabajo: la organización del trabajo, la cual tiene que ver con el tipo de tarea o el contenido de la actividad llevada a cabo; la situación de empleo, que refiere a la relación laboral que se establece con los TraSa y 
Moglia B. Procesos de atención y cuidado desde la perspectiva de los trabajadores: una metaetnografía en hospitales de Latinoamérica. [Tesis de maestría]. Maestría en Epidemiología, Gestión y Políticas de Salud. Universidad Nacional de Lanús. 2020.

la gestión de personas, que involucra los discursos y dispositivos que se utilizan para asegurar el compromiso y alineamiento con la organización (Soto Roy, 2015). El concepto de escenarios de trabajo es planteado como punto de partida para la sistematización de procesos sociales y subjetivos vinculados al trabajo y asimismo, consiste en un marco de análisis de las condiciones concretas en las cuales se desempeñan las actividades del trabajo (Soto Roy, 2015).

En los textos se reconocieron diferentes modos de nombrar lo que nosotros categorizamos como escenarios de trabajo: "condiciones de trabajo", "ambiente de trabajo", "cotidiano del trabajo", "clima de tensión" y "ambiente institucional", las cuales refieren a sentidos semejantes que pueden ser nucleados en esta categoría.

Los TraSa atribuyen como "condiciones de trabajo" a una serie de características, tal como la insuficiencia de profesionales, de materiales y de equipos; los bajos salarios; a las formas de contratación flexibles; a las prolongadas jornadas y el exceso de tareas, las cuales son consideradas como aspectos recurrentes en su trabajo (Arenas-Monreal et al. 2004; Fernandes, Nery, \& Filho 2018; Formozo \& Oliveira 2010; Littike \& Sodré 2015; LunaGarcía et al. 2015; Rosado, Russo \& Maia 2015). Este "ambiente institucional” es señalado por los TraSa y expresan su impacto tanto en ellos y en los usuarios como en sus prácticas en el hospital.

Una problemática señalada entre los TraSa es la tercerización laboral, la cual tuvo lugar en hospitales situados en Colombia y Brasil. En el primero, se da en términos más acentuados y constituye una forma de contratación, que otorga "contratos a corto plazo, sin vinculación a la seguridad social, lo que genera alta rotación debido a los pocos beneficios, incentivos y la demora en los pagos" (Molina-Marín et al., 2013, p. 138). Mientras que en Brasil la tercerización implica la contratación externa de personal por parte del gobierno federal, con el fin de aliviar la demanda y aliviar la escasez de TraSa (Littike \& Sodré, 2015). Sin embargo, los gestores refieren que la tercerización lleva a una gran carga a nivel financiero para el propio hospital, sin resolver el problema para el cual se realiza. Además, en algunos casos dicho modo de contratación puede generar conflictos entre los TraSa debido a las diferencias implicadas entre otras formas de vinculación con la institución, tal como la carga de trabajo, la remuneración, las licencias, entre otros (Littike \& Sodré, 2015).

También, los TraSa indican que la falta de camas, la presencia de estructuras físicas inadecuadas y el hacinamiento configuran debilidades o fragilidades en el espacio de trabajo para una atención y un cuidado integral (Amaral, Moraes \& Ostermann, 2010; Molina-Marín 
Moglia B. Procesos de atención y cuidado desde la perspectiva de los trabajadores: una metaetnografía en hospitales de Latinoamérica. [Tesis de maestría]. Maestría en Epidemiología, Gestión y Políticas de Salud. Universidad Nacional de Lanús. 2020.

et al., 2013; Rocha, Souza \& Texeira, 2015; Rosado et al., 2015; Luz et al., 2016; Alves Souza et al., 2018). Esto se evidenció principalmente en los servicios de obstetricia, donde las médicas y enfermeras señalaron que no es posible generar un ambiente de privacidad y acompañamiento para las pacientes (Busanello et al., 2011):

Lo ideal es tener un acompañante. Pero hay varios problemas que enfrentar. Primero, tiene que ser completamente individual e independiente. La ordenanza del Ministerio de Salud muestra que el paciente debe tener privacidad y comodidad. Aquí, no tenemos, por lo tanto, no se permiten compañeros ${ }^{9}$ (Busanello et al., 2011, p. 220).

Así como los TraSa dan cuenta de espacios inadecuados e insuficientes para los pacientes, también reconocen la ausencia de espacios de autocuidado ante las situaciones de empleo y las vivencias del trabajo en hospitales (Arenas-Monreal et al., 2004; Cardoso et al., 2013). Dichos espacios son entendidos como grupos de reflexión donde los TraSa puedan expresar dificultades, ansiedades o sentimientos, de forma de cuidarlos (Cardoso et al., 2013) o también como espacios donde puedan acceder a una revisión médica (Arenas-Monreal et al., 2004). Los TraSa explican que debido a la dinámica cotidiana o a la falta de políticas no están garantizados esos tipos de espacios (Arenas-Monreal et al., 2004), ni tampoco el tiempo de descanso, el cual debe de acordarse entre los compañeros y compañeras:

...yo, por ejemplo, se supone que por cada día tendría derecho de dos horas y hay
veces que sí me tomo las dos horas, otras veces no, ni una hora pero es variado
porque no está reglamentado en qué momento, a quién y si no estás, quién va a
estar y si cuando no estás pasa algo qué significa. Así es no hay [reglamentación],
se supone que eso se tiene que hacer sobre la marcha, en el servicio, con los
compañeros, con el jefe de servicio, pero nunca se le ha tomado importancia y una
de las cosas que dices: una hora de descanso y idónde descanso?; no hay una sala
de descanso propia para los médicos adscritos, nada más para los internos y los
residentes. Una sala que tú digas voy y me recuesto, un sillón, no, nunca se ha
construido, bueno cuando modificaron urgencias la primera vez sí había una sala,
un cuarto destinado, pero al final en la operación se convirtió en un cuarto de
guardar cosas. Sí [una] bodega para guardar material (Arenas-Monreal et al.,
2004, p. 330).

De esta forma, aparecen acuerdos, arreglos o consensos implícitos en la organización del trabajo en los hospitales, tratando de hacer frente al degaste psíquico y/o físico de los TraSa a través de lo no normado o lo informal.

Todas estas características se dan en hospitales donde la demanda suele ser alta tanto en relación a la cantidad de usuarios como de tareas a desarrollar en el cotidiano del servicio.

\footnotetext{
${ }^{9}$ Traducción libre de la autora: O ideal é ter acompanhante. Só que tem vários problemas para nós vencermos. Em primeiro lugar, tem que ser leito completamente individual e independente. A portaria do Ministério da Saúde mostra que a paciente tem que ter privacidade e conforto. Aqui, nós não temos, por isso, os acompanhantes não são permitidos (Busanello et al., 2011, p. 220).
} 
Moglia B. Procesos de atención y cuidado desde la perspectiva de los trabajadores: una metaetnografía en hospitales de Latinoamérica. [Tesis de maestría]. Maestría en Epidemiología, Gestión y Políticas de Salud. Universidad Nacional de Lanús. 2020.

En este sentido, el tiempo constituye una limitación para ofrecer una atención pertinente (Souza et al., 2018), donde el TraSa pueda acercarse y conocer al usuario. En el sector de enfermería de un hospital de Brasil, se observó que los TraSa rechazan el diálogo o lo tienen de manera rápida debido al ritmo de trabajo que deben cumplir (Formozo \& Oliveira, 2010). En relación a esto tiene lugar la naturalización del "no parar", es decir, de un trabajo sin pausas, el cual constituyen el fundamento de los TraSa en relación a la limitada construcción de vínculos (Rocha et al., 2015). Al mismo tiempo, los TraSa se encuentran en un estado constante de atención y vigilancia, principalmente en servicios como los de urgencias o terapias, donde los procesos de atención y cuidado pueden resultar de forma incierta, requiriendo intensificar el trabajo, la cual puede generar efectos en la salud de los TraSa (Rocha, Souza \& Teixeira, 2015).

En sintonía con lo anterior, los TraSa asocian este "ambiente o cotidiano de trabajo" a una serie de situaciones de degaste físico y psicológico ante un trabajo estresante, frustrante y conflictivo (do Amaral et al., 2013; Formozo \& Oliveira, 2010; Luz et al., 2016):

\footnotetext{
... a veces trabajas solo, trabajas al limite, sabes que no podes prestar atención a lo que debes dar a todos (...), que sos uno. Esto es algo que me molesta un poco... ${ }^{10}$ (Rocha, Souza \& Teixeira, 2015, p. 854).

El proceso de trabajo se ha reflejado en dolor muscular, columna vertebral y dolor de cabeza que no sentía antes ${ }^{11}$ (Rosado, Russo \& Maia, 2015, p. 3025).

Estar demasiado tiempo causa dolor en las extremidades inferiores, articulaciones, etc. ${ }^{12}$ (Rosado, Russo \& Maia, 2015, p. 3025).
}

En países como Colombia, donde el modelo de flexibilización laboral rige en los hospitales, los TraSa caracterizan dichas situaciones como violentas, y generadas como parte del sistema de salud (Luna-García et al., 2015). Esto se evidencia en las narrativas de los TraSa, principalmente con respecto a la situación de empleo:

El hecho de no pagar el salario, eso ya de entrada es violento, va en contra de una
política de equidad... iAh, y como no vino a trabajar porque no tenía para el bus
entonces mañana le clavo 3 fines de semana!, ;eso es violencia! (Luna-García et al.,
2015, p. 411).

Que los pagos no se den a tiempo... que pasen varios meses sin pago... que la gente se quede sin contrato y le toque seguir trabajando sin saber si le renuevan o no, y sin pago, eso es violencia (Luna-García et al., 2015, p. 411).

\footnotetext{
10 Traducción libre de la autora: ... às vezes você trabalha sozinho, trabalha no limite, você sabe que não pode dar atenção que você deveria dar a todas (...), que você é um só. Isso é uma coisa que me incomoda um pouco... (Rocha, Souza \& Teixeira, 2015, p. 854)

${ }^{11}$ Traducción libre de la autora: $O$ processo de trabalho tem se refletido em dores musculares, coluna e cefaleias que não sentia antes daqui (Rosado, Russo \& Maia, 2015, p. 3025).

12 Traducción libre de la autora: ficar muito tempo em pé provoca dor nos membros inferiores, articulações etc. (Rosado, Russo\&Maia, 2015, p. 3025).
} 
Moglia B. Procesos de atención y cuidado desde la perspectiva de los trabajadores: una metaetnografía en hospitales de Latinoamérica. [Tesis de maestría]. Maestría en Epidemiología, Gestión y Políticas de Salud. Universidad Nacional de Lanús. 2020.

Por otro lado, algunos de los TraSa señalaron aspectos "positivos" sobre el trabajo en los hospitales, vinculados con el bienestar y la satisfacción que les genera (Rosado et al., 2015):

...el trabajo proporciona calidad de vida para viajes, hogar, automóvil, etc., salud y bienestar $^{13}$ (Rosado, Russo \& Maia, 2015, p. 3028).

Actualmente, mi relación con el trabajo es favorable, ya que me da satisfacción personal sin afectar mi salud ${ }^{14}$ (Rosado, Russo \& Maia, 2015, p. 3028).

Siendo una enfermera obstétrica un logro profesional y personal, no me veo haciendo otra cosa, es lo que siempre he querido ${ }^{15}$ (Oliveira \& Penna, 2017, p. 5).

Amo mi trabajo, me gusta cuidar de otros, para mí el parto natural es emocionante y gratificante $^{16}$ (Oliveira \& Penna, 2017, p. 5).

Estos argumentos son explicados en el estudio desarrollado por Rosado et al. (2015) como dos dimensiones en el trabajo: una objetiva, vinculada a la "recompensa financiera" que permite adquirir bienes necesario para la vida y la otra, subjetiva, referida a la satisfacción que produce una actividad profesional, definiendo la identidad y el reconocimiento social de los profesionales del hospital.

Hasta aquí hemos señalado y descripto los escenarios de trabajo, ligados, por los TraSa a la relación que tienen con la institución del hospital, la cual, en mayor medida, está marcada por el reclamo en torno al tiempo y espacio de descanso, al tipo de contratación, a la falta de insumos e infraestructura de trabajo y al degaste físico y mental que dichos escenarios traen aparejados. Además, hicimos hincapié en aspectos que organizan el trabajo y que adquieren modos distintos según el servicio: el trabajo es continuo, vinculado a la noción del "no parar" y se da en modos distintos de intensidad laboral, según las circunstancias.

\section{1. 2. Procesos de atención y cuidado}

Esta categoría abarca tres dimensiones de análisis de los textos. En primer lugar, prácticas de atención y cuidado, que incluye las expresiones que utilizan los TraSa para dar cuenta de las actividades y tareas que llevan adelante cotidianamente. En segundo, humanización en la atención y el cuidado aquella que describe los significados acerca de la

\footnotetext{
${ }^{13}$ Traducción libre de la autora: ...o trabalho proporciona qualidade de vida viagem, casa, carro etc., saúde e bem-estar (Rosado, Russo \& Maia, 2015, p. 3028).

14 Traducción libre de la autora: Atualmente, minha relação com o trabalho é favorável, pois me dá satisfação pessoal não afetando minha saúde (Rosado, Russo \& Maia, 2015, p. 3028).

15 Traducción libre de la autora: Being an obstetric nurse a professional, personal achievement, I don't see myself doing anything else, it is what I've always wanted (Oliveira \& Penna, 2017, p. 5).

${ }^{16}$ Traducción libre de la autora: I love my job, I like to take care of other, to me natural childbirth is exciting and and rewarding (Oliveira \& Penna, 2017, p. 5).
} 
Moglia B. Procesos de atención y cuidado desde la perspectiva de los trabajadores: una metaetnografía en hospitales de Latinoamérica. [Tesis de maestría]. Maestría en Epidemiología, Gestión y Políticas de Salud. Universidad Nacional de Lanús. 2020.

ética y la humanización de la atención y el cuidado reconocida por los/las trabajadores como forma necesaria, alternativa e ideal, a implementarse en los hospitales. Y, por último, redes refiere a una forma de organización del trabajo, la cual se basa en los vínculos entre los TraSa y entre éstos y los usuarios en una producción intersubjetiva del cuidado (Franco, 2016). Estas redes son interesantes porque pueden entrar en conflicto con la normativa sobre el funcionamiento de los servicios de salud, lo que provoca, en ciertos momentos, ataduras y desencuentros entre los TraSa. La configuración en redes permite superar dichas situaciones, en tanto se desee, abriendo líneas de fuga o conexiones en muchas direcciones, es decir, a través de procesos de ruptura y re-configuración (Franco, 2016).

\section{1. 2. 1. Prácticas de atención y cuidado}

Entre las prácticas de atención y cuidado se puede identificar cuatro dimensiones del trabajo centrales: hospitalizar, diagnosticar, tratar y comunicar.

La primera, hospitalizar, constituye un proceso por el cual el paciente permanece determinado tiempo en el hospital, es la "estancia hospitalaria" debido a las dificultades de control sobre los síntomas, a la falta de un cuidador por fuera de la institución o equipos específicos para monitoreo (Molina-Marín et al., 2013). La hospitalización implica cambios en la rutina del paciente y de los familiares, lo cual es percibido como un momento o situación de estrés. En este contexto, el equipo de enfermería es el encargado de llevar a cabo acciones e intervenciones que mejoren dicha situación, ya sea a través de procedimientos técnicos, de la escucha o del diálogo (dos Santos et al., 2013; Formozo \& Oliveira, 2010). Se ha identificado la importancia del rol del equipo de enfermería (tanto auxiliar como profesional) para orientar e informar a las familias que acompañan a los pacientes (dos Santos et al., 2013):

Informar sobre horarios y conductas hospitalarias ${ }^{17}$ (dos Santos et al., 2013, p. 222).

Orientaciones sobre la rutina en el sector ${ }^{18}$ (dos Santos et al., 2013, p. 222).

Aclarando los estándares y las rutinas en el sector e informando sobre el papel del acompañante para el paciente ${ }^{19}$ (dos Santos et al., 2013, p. 222).

En estos casos de promoción de cuidado, se observa la relación de poder entre los

\footnotetext{
17 Traducción libre de la autora: Informing about hospital times and conducts (dos Santos et al., 2013, p. 222).

18 Traducción libre de la autora: Giving orientations about the routine in the sector (dos Santos et al., 2013, p. 222).

19 Traducción libre de la autora: Clarifying the standards and routines at the sector and informing about the companion's role for the patient (dos Santos et al., 2013, p. 222).
} 
Moglia B. Procesos de atención y cuidado desde la perspectiva de los trabajadores: una metaetnografía en hospitales de Latinoamérica. [Tesis de maestría]. Maestría en Epidemiología, Gestión y Políticas de Salud. Universidad Nacional de Lanús. 2020.

profesionales y los usuarios, donde estos últimos son "autorizados" por aquellos a la participación de determinados cuidados, siendo más bien prescriptivos (Araújo et al., 2018). A pesar de determinadas autonomías en el ejercicio de la práctica de enfermería, las decisiones en torno a la hospitalización son definidas por el médico o la médica, a veces con participación de otros profesionales.

Otras de las prácticas principales realizadas en los espacios de los hospitales consisten en "diagnosticar y "tratar". Se diagnostica a partir de una serie de síntomas, es decir, "certezas" o "respaldo" que se observan e identifican y habilitan en la entrevista con el/la paciente (Acosta et al., 2018). Una vez definido el diagnóstico se decide el tratamiento, es decir, la forma de atención de la enfermedad. En su mayoría, estas prácticas, tal como sucede en la hospitalización, corresponden a los médicos y las médicas:

\begin{abstract}
La hospitalización y el manejo del niño(a) con neumonía es definido por el pediatra, con la participación de enfermeras(os) profesionales, auxiliares de enfermería y terapeutas respiratorios, quienes realizan las órdenes médicas y proporcionan los cuidados que se requieren (...) El egreso, al igual que el ingreso, es definido por el/la pediatra, quien da a la familia información sobre el tratamiento que seguir; las auxiliares de enfermería son las encargadas del resto del egreso, apoyadas en las enfermeras profesionales (Molina-Marín et al., 2013, p. 142).
\end{abstract}

"Diagnosticar" y "tratar" implica la puesta en juego de conocimientos teóricoprácticos que se van modificando en relación a la experiencia en el servicio, estableciendo conductas asistenciales dependientes de la enfermedad y clasificando al usuario según los "criterios de gravedad" (Pan et al., 2018). Además de dichos saberes, existen protocolos de atención estipulados por algunos de los organismos correspondientes, como el Ministerio de Salud que carecen de regulación y no siempre son tenidos en cuenta al momento de la atención y cuidado. Otro aspecto señalado en relación con las prácticas de "diagnosticar" y "tratar", es que se transforman, lo cual exige una constante actualización. Pan et al. (2018) señalan a la relación entre el conocimiento y la autonomía profesional como esencial ante cuestionamientos de otros profesionales por las decisiones tomadas, siendo el saber el justificativo de las acciones realizadas. A pesar de esto, en muchos casos, las transformaciones en el saber-quehacer son resistidas por aquellas generaciones más antiguas en el servicio, disputándose sus espacios de actuación (Pan et al., 2018).

El tratamiento puede incluir "acciones medicamentosas" ante el dolor (Pan et al., 2018) e intervención a través de equipamientos, instrumentos o materiales que supone mejorar el estado de salud. Son descriptos como parte de la "innovación tecnológica" que cumplen tres funciones principales: seguridad, mantención y sobrevida de los pacientes y, además, 
Moglia B. Procesos de atención y cuidado desde la perspectiva de los trabajadores: una metaetnografía en hospitales de Latinoamérica. [Tesis de maestría]. Maestría en Epidemiología, Gestión y Políticas de Salud. Universidad Nacional de Lanús. 2020.

facilita el trabajo (Baggio \& Erdmann 2016). Algunas de las investigaciones se han basado en la propuesta teórica de Emerson Merhy (2006), denominando dichas herramientas-máquinas como tecnologías duras ya que son usadas en las acciones que intervienen sobre el usuario.

Por último, la práctica de "comunicar" es definida a partir de un contexto, un mensaje e interlocutores (Aredes et al., 2018). En el hospital, se da tanto entre usuarios y trabajadores como entre éstos últimos, y es reconocida como fundamental para lograr una atención y un cuidado adecuado. Sin embargo, la comunicación no se da sin conflictos, sino que está atravesada por "ruidos" (Cardoso et al., 2013; Costa \& Abrahão, 2018; Klossoswski et al., 2016; Littike \& Sodré, 2015), generados a partir de un modelo de comunicación vertical y burocrático (Klossoswski et al., 2016), tal como se da en los momentos de explicación de un diagnostico. Dichos "ruidos" constituyen una forma de comunicar que determina que el trabajo sea fragmentado y que los TraSa no se conozcan, los servicios no se comuniquen y que los profesionales no estén al tanto de la realidad del territorio en el que trabajan o el resultado de sus acciones (Klossoswskiet al., 2016). Esto se observa en las formas discursivas que el sector de enfermería utiliza en la promoción de cuidado, donde domina la visión recomendada por las políticas públicas de forma prescriptiva y sin darle lugar al usuario en cuestión, fomentando un cuidado tecnicista, tal como mencionamos más arriba (Araújo et al., 2018):

...estamos enseñando y monitoreando para que ellas [las pacientes] puedan hacer bajo supervisión, al principio una supervisión más atenta y luego un poco más de lejos para que ella también pueda tomar la iniciativa, tener un poco de libertad ${ }^{20}$ (Araújo et al., 2018, p. 5).

A pesar de dichas prácticas supervisadas, se puede observar que el sector de enfermería muestra acciones de aproximación o acercamiento, de vinculación hacia los pacientes (Araújo et al., 2018). Las enfermeras y los enfermeros reconocen dentro de sus prácticas el escuchar, compartir y expresar ciertas emociones por parte del usuario, como así también aquellas tareas más técnicas (Oliveira \& de Mattos Penna, 2017). Es decir, que las prácticas de atención y cuidado llevadas a cabo por el sector de enfermería no se encuentran restringidas en los procedimientos y en este sentido, establecen "diálogos" con los usuarios, siendo parte importante de su trabajo, en especial cuando se trata de personas que están hospitalizadas:

\footnotetext{
${ }^{20}$ Traducción libre de la autora: ... a gente vai ensinando e acompanhando para que ela [lãs pacientes] possa fazer sob supervisão, num primeiro momento uma supervisão mais atenciosa e depois mais um pouquinho distante pra que ela também tenha, possa tomar inciativa, tenha um pouco de liberdade (Araújo et al., 2018, p. $5)$.
} 
Moglia B. Procesos de atención y cuidado desde la perspectiva de los trabajadores: una metaetnografía en hospitales de Latinoamérica. [Tesis de maestría]. Maestría en Epidemiología, Gestión y Políticas de Salud. Universidad Nacional de Lanús. 2020.

Cuando el paciente (...) está bien, el profesional de enfermería habla. Cuando no está bien el profesional de enfermería no habla mucho, pero siempre le dice al paciente (...) que intente mejorar para ser dado de alta del hospital ${ }^{21}$ (Formozo \& Oliveira, 2010, p. 233).

Desde la perspectiva de los/as enfermeros/as, esta necesidad de establecer "relaciones de diálogo" se debe a la desconfianza generada por los médicos y las médicas en ciertos momentos de la relación. A pesar del intenso ritmo de trabajo, los servicios de enfermería tratan de tener un diálogo con los usuarios y con sus familias, orientando y mostrando lo necesario para un cuidado adecuado (Araújoet al., 2018; Formozo \& Oliveira, 2010).

Los médicos y las médicas utilizan otras formas de "comunicar", donde se muestra un dominio del conocimiento que apunta a su imparcialidad. Estos términos se pueden observar en aquellas situaciones no esperadas, teniendo que comunicar "malas noticias". Según los médicos y las médicas, justifican esta distancia en la comunicación como forma de protegerse ante el miedo de haber cometido algún error y ser penalizados legalmente y moralmente (Oliveira \& Penna, 2017; Souza et al., 2018). En el caso del servicio de obstetricia se evidencia la relación entre médicos-pacientes y su forma de comunicarse:

Tienes que tener mucho cuidado porque cualquier pequeña cosa que sucede en obstetricia es culpa del obstetra ${ }^{22}$ (Oliveira \& Penna, 2017, p. 8).

La obstetricia es la segunda especialidad con la mayoría de los juicios, esto lleva a una posición defensiva con los pacientes y obstaculiza las relaciones médicopaciente. No siempre puedes expresarte ${ }^{23}$ (Oliveira \& Penna, 2017, p. 7).

Asimismo, los "ruidos" se identificaron en la comunicación entre enfermeros y médicos, dando lugar a barreras entre disciplinas y obstaculizando la atención y el cuidado (Azevedo et al., 2017):

Con enfermería, observamos que tenemos relaciones muy duras. Aquí y en varios hospitales, la enfermera está tomando un papel muy imperativo y muy agresivo con el médico ${ }^{24}$ (Azevedo et al., 2017, p. 1997).

\footnotetext{
21 Traducción libre de la autora: Quando o paciente (...) está bem, o profissional de enfermagem conversa. Quando não está bem o profissional de enfermagem não conversa muito, mas sempre fala para o paciente (...) tentar melhorar para receber alta hospitalar (Formozo \& Oliveira, 2010, p. 233).

22 Traducción libre de la autora: You have to be very careful because any little thing that happens in obstetrics is the obstetrician's fault (Oliveira \& Penna, 2017, p. 8).

23 Traducción libre de la autora: Obstetrics is the second specialty with most lawsuits this is leading to a defensive position with patients and gets in the way of doctor-patient relations. You can not always express yourself (Oliveira \& Penna, 2017, p. 7).

24 Traducción libre de la autora: Com a enfermagem a gente observa que tem relações muito ríspidas. Aqui e em diversos hospitais a enfermeira está tomando um papel muito imperativo e muito agressivo com o médico (Azevedo et al., 2017, p. 1997).
} 
Moglia B. Procesos de atención y cuidado desde la perspectiva de los trabajadores: una metaetnografía en hospitales de Latinoamérica. [Tesis de maestría]. Maestría en Epidemiología, Gestión y Políticas de Salud. Universidad Nacional de Lanús. 2020.

Este tipo de relaciones generan un malestar entre dichos profesionales, el cual se atribuye no solo a la comunicación, sino también a las relaciones de poder que se han ido construyendo y disputando entre los dos grupos (Azevedo et al., 2017). Entonces, señalamos que los procesos de atención y cuidado implican relaciones de poder, principalmente entre los actores que fuimos mencionando: por un lado, los médicos siendo quienes deciden los aspectos centrales en los abordajes de los problemas de salud-enfermedad, generando distancia con el usuario y rispideces con el sector de enfermería. Por otro lado, éste último se desempeña como intermediario entre médico y usuario lo que favorece un acercamiento hacia ellos, aunque no se debe dejar de mencionar que también hay situaciones donde el usuario pasa a estar bajo la órbita de las disposiciones de enfermería, tal como se observó en las tareas de promoción de cuidado.

\section{1. 2. 2. Humanización en la atención y cuidado}

Aquí se incluye aquello que los TraSa consideran la atención y el cuidado "ideal" o "humanizado". En algunos casos, los TraSa refieren a la necesidad de un "tratamiento global", "atención integral" (Klossoswski et al., 2016) o "atención humanizada" (Busanello et al., 2011; Silva et al., 2011) remitiendo a la complejidad bio-psico-social del humano. La atención humanizada es entendida a partir de una serie de principios: el reconocimiento del usuario como sujeto de derechos, la garantía de la privacidad, la confidencialidad, el consentimiento informado y el respeto (Busanello et al., 2011). En otras palabras, consiste en:

...mucho más que un artificio, una técnica o simplemente una intervención, significa fortalecer las relaciones interpersonales, que permiten a los trabajadores reconocer la interdependencia y complementariedad de sus acciones ${ }^{25}$ (Busanello et al., 2011, p. 220).

La humanización de la atención y cuidado se situó, principalmente, en los servicios de obstetricia, paliativos y crónicos (Aguiar et al., 2013; Busanello et al., 2011; Cardoso et al., 2013; Silva et al., 2011, 2013), donde los TraSa discutieron sobre dicho enfoque alternativo y lo caracterizaron como:

\footnotetext{
... una asistencia ideal (...) con un entorno adecuado para un procedimiento $y$ personal técnicamente capacitado ${ }^{26}$ (Silva et al., 2011, p. 346).
}

\footnotetext{
25 Traducción libre de la autora: ...muito mais do que um artifício, uma técnica ou apenas uma intervenção, significa estreitar relações interpessoais, que possibilitem aos trabalhadores reconhecer a interdependência e a complementaridade de suas ações (Busanello et al., 2011, p. 220).

${ }^{26}$ Traducción libre de la autora: Considero assistência ideal (...) com ambiente adequado para tal procedimento e equipe capacitada tecnicamente (Silva et al., 2011, p. 346).
} 
Moglia B. Procesos de atención y cuidado desde la perspectiva de los trabajadores: una metaetnografía en hospitales de Latinoamérica. [Tesis de maestría]. Maestría en Epidemiología, Gestión y Políticas de Salud. Universidad Nacional de Lanús. 2020.

Ser respetado por la privacidad (...), proporcionando un ambiente confortable, en general, eso es todo ${ }^{27}$ (Silva et al., 2011, p. 346).

Para los TraSa la humanización en la atención requiere sensibilidad y capacitación, como así también merece su reconocimiento y valorización en el contexto del hospital (Cardoso et al., 2013).

En los servicios de obstetricia, los TraSa asociaron la humanización con una atención "ideal", donde se reflejen los señalamientos propuestos por políticas públicas de salud. Sin embargo, esto termina siendo difícil de abordar e implementar en los contextos de los hospitales (Aguiar et al., 2013; Busanello et al., 2011; Silva et al., 2011):

Para tener una asistencia ideal, antes que nada, tenemos que tener una estructura ideal, algo que no tenemos. Y, por supuesto, a veces, todo lo que defiende el Ministerio de Salud, dentro de nuestra realidad, no es viable. Como es el caso con la presencia de la familia. Tenemos que analizar qué es lo mejor por el momento ${ }^{28}$ (Busanello et al., 2011, p. 221).

Dicha estructura "ideal" refiere a garantizar las condiciones de privacidad, intimidad y acompañamiento necesarios (Silva et al., 2011, 2013) y, también, el abandono de prácticas perjudiciales o inadecuadas en la asistencia del parto vinculadas con el uso violento e indiscriminado de tecnologías que resultan en altas tasas de cesáreas y dolor iatrogénico (Aguiar et al., 2013; Silva et al., 2013). En este sentido, la humanización implica no solo una reestructuración sino también, un cambio en las actitudes de los TraSa (Silva et al., 2011).

En los servicios paliativos los TraSa buscan aliviar el dolor, sabiendo que no existe la posibilidad de cura del paciente a través del control de síntomas, pero sobre todo dando valor a las necesidades de alivio ante malestares psicológicos y espirituales (Cardoso et al., 2013). Asimismo, los TraSa señalan como importante la preservación de la autonomía del paciente a fin de fortalecer la relación con el equipo de salud (Cardoso et al., 2013):
...creo que tienen que tener autonomía, deben ser respetados. Por ejemplo, en el caso de este paciente (...) ¿quién soy yo para obligarla a someterse a esta cirugía? Lo que hice fue lo que estaba a mi alcance, conversé, el médico conversó con ella (...) le avise a la ambulancia que todo estaba listo para su partida. Lo que dependía del equipo de salud se hizo, ahora depende de ella. Creo que tenemos que respetar eso. Es un derecho ${ }^{29}$ (Cardoso et al., 2013a, p. 1137).

\footnotetext{
27 Traducción libre de la autora: Ser respeitada a privacidade (...), proporcionar um ambiente confortável,no geral é isso (Silva et al., 2011, p. 346).

${ }_{28}$ Traducción libre de la autora: Para ter uma assistência ideal, primeiramente, temos que ter uma estrutura ideal, coisa que não temos. E é claro que, às vezes, tudo que o Ministério da Saúde preconiza, dentro de nossa realidade, é inviável. Como é o caso da presença da família. Temos que analisar o que é melhor para o momento (Busanello et al., 2011, p. 221).

29 Traducción libre de la autora: ...eu acho que eles têm que ter autonomia, tem que ser respeitados. Por exemplo, no caso dessa paciente (...) quem sou eu para obrigar ela a fazer essa cirurgia? O que eu fiz foi aquilo que estava aо meu alcance, eu conversei, o médico conversou com ela (...) avisei a ambulância, ficou tudo
} 
Moglia B. Procesos de atención y cuidado desde la perspectiva de los trabajadores: una metaetnografía en hospitales de Latinoamérica. [Tesis de maestría]. Maestría en Epidemiología, Gestión y Políticas de Salud. Universidad Nacional de Lanús. 2020.

Por último, Lima y Trad (2011) señalan que el dolor crónico "impone la humanización del terapeuta", es decir, que ante ciertas enfermedades los TraSa reconocen la insuficiencia de los protocolos de atención y cuidado y la necesidad de flexibilizarlos en relación al cotidiano, a la integración y la propia existencia del enfermo. Esto lleva a la construcción de estrategias distintas, tal como la "circuloterapia", la cual se lleva a cabo por medio de la multiplicidad de servicios organizados en equipo multiprofesional y abordaje flexibles que permita una atención transversal (Lima \& Trad 2011). En este sentido, los autores se basaron en la propuesta de Emerson Merhy (2006) sobre los maletines tecnológicos utilizados en la producción de salud. Habiendo mencionado anteriormente aquellas tecnologías duras, nos restan dos: las vinculadas con los saberes que actúan en la atención y cuidado, como la clínica o la cirugía y que reciben el nombre de tecnologías leves-duras y, las denominadas tecnologías leves, las cuales son las intervenciones que se producen en acto y que se dan en el encuentro entre dos personas (Silva et al., 2011). Esta intervención se da en términos de vínculos de acogimiento, de relaciones de acompañamiento e implican una humanización en la atención y cuidado. Tal como se evidenciaron en los testimonios, las tecnologías blandas proponen un enfoque alternativo y ético que implica un cambio de la perspectiva en los TraSa sobre las formas de asistir a los/as otros/as.

\section{1. 2. 3. Redes}

Partiendo del concepto de redes, definido en el inicio del apartado, analizamos esta forma de organización identificada por los TraSa de los hospitales como "equipo multiprofesional", "equipo multidisciplinar", “equipo de trabajo" o "trabajo en cooperación".

Estos equipos pueden estar integrados por profesionales o técnicos de diferentes disciplinas, constituyendo equipos multiprofesionales o multidisciplinares. Más allá de la forma en que se agrupen, el trabajo en equipo implica desafíos necesarios para una organización adecuada. En primer lugar, los TraSa señalan que "hablar la misma lengua" (Silva \& Santos 2006) es fundamental para no generar confusiones en el usuario y su familia y no producir inseguridad o desconfianza en el equipo.

En segundo lugar, se observa que el trabajo en equipo puede caracterizarse por las "richas", entendidas como "rivalidades" entre los servicios, donde los TraSa desvalorizan las opiniones y el conocimiento entre sí, remarcando su autonomía profesional (Klossoswski et 
Moglia B. Procesos de atención y cuidado desde la perspectiva de los trabajadores: una metaetnografía en hospitales de Latinoamérica. [Tesis de maestría]. Maestría en Epidemiología, Gestión y Políticas de Salud. Universidad Nacional de Lanús. 2020.

al., 2016), y la falta de consenso en las acciones (Cardoso et al., 2013a). Esto supone, según los autores, la escasez de diálogo o lo que llaman "ruido negativo" (Cardoso et al., 2013b), lo cual siembra desconfianza y falta de integración en el equipo, perjudicando la atención y el cuidado. Tal como se puede observar en el siguiente fragmento:

El control de los sintomas (...) depende mucho del profesional que esté (...) allí vemos que falta esta asistencia, que a veces falta la observación. No ha visto a este paciente durante días, supongamos que hay días en que el médico no estaba y no sabe, siempre mantiene la misma receta y el paciente siempre tiene las mismas quejas, siempre lo mismo y no se hace nada. Y vas y hablas una vez, y vas y hablas de nuevo y no se hace nada ${ }^{30}$ (Cardoso et al., 2013b, p. 86).

En este sentido, identificamos que el trabajo en equipo entre médicos/as y enfermeros/as es caracterizado, históricamente, por sus tensiones y conflictos (Azevedo et al., 2017), al punto que el sector de enfermería describe que tienen la sensación de trabajo en equipo pero no se sienten valorados y valoradas o, incluso aún, se dan situaciones donde directamente no perciben un trabajo en equipo (Cardoso \& da Silva 2010; Palmer, 2014). Sin embargo, se identificaron momentos donde el sector de enfermería siente ser parte del equipo de trabajo:

Tenemos una buena relación con el equipo médico, lo que facilita nuestras actividades en el sector ${ }^{31}$ (Cardoso \& Silva, 2010, p. 453).

En sintonía con esto, los enfermeros y las enfermeras explican su "buena relación" con el sector médico a partir de una transformación en relación a los médicos y médicas más jóvenes:

Los médicos no escuchaban a las enfermeras (...) Antes, humillaban a enfermería. Los médicos más jóvenes son más abiertos. Los nuevos médicos se acercan a enfermeria y preguntan por el paciente (...) tenemos una mejor comunicación. Antes, los asistentes médicos solían colgarnos. (...) La mejora en la atención de enfermería favoreció la mejora de la relación con los médicos, mejoró el vínculo con el médico ${ }^{32}$ (Azevedo et al., 2017, p. 1997).

Las explicaciones en torno a las relaciones tensas son atribuidas, como ya se mencionó anteriormente, no solo a problemas de comunicación, sino también a la manera en que se

\footnotetext{
${ }^{30}$ Traducción libre de la autora: $O$ controle de sintomas (...) depende muito do profissional que está ali (...) A gente vê que falta essa assistência, que falta, às vezes, a observação. Faz dias que tu não vêese paciente, vamos supor, tem dias que o médico não estaba por ali e não sabe, mantém sempre a mesma prescrição e o paciente sempre com as mesmas queixas, sempre aquela mesma coisa e nada é feito. E tu vai e fala uma vez, e tu vai e fala outra vez e nada é feito (Cardoso et al., 2013b, p. 86).

${ }^{31}$ Traducción libre de la autora: Nós temos um bom relacionamento com a equipe médica,o que facilita as nossas atividades no setor (Cardoso \& Silva, 2010, p. 453).

32 Traducción libre de la autora: Os médicos não ouvem os enfermeiros (...) Antes eles humilhavam a enfermagem. Os médicos mais novos têm a cabeça mais aberta. Os médicos novos abordam a enfermagem e perguntam sobre o paciente (...) temos uma comunicação melhor. Antes, os médicos assistentes chegavam a desligar o telefone na nossa cara. (...) A melhoria da assistência de enfermagem favoreceu a melhoria da relação com os médicos, melhorou o vínculo com o médico (Azevedo et al., 2017, p. 1997).
} 
Moglia B. Procesos de atención y cuidado desde la perspectiva de los trabajadores: una metaetnografía en hospitales de Latinoamérica. [Tesis de maestría]. Maestría en Epidemiología, Gestión y Políticas de Salud. Universidad Nacional de Lanús. 2020.

construye el poder en cada profesión y como se muestra en relación a aspectos intersubjetivos en los procesos de atención y cuidado, donde la autonomía profesional y la responsabilidad representan puntos de tensión en los equipos multiprofesionales (Azevedo et al., 2017).

En tercer lugar, hallamos como desafío para el trabajo en equipo, las discusiones que se dan por dentro, las cuales son centrales para decidir qué acción terapéutica se llevara a cabo y cómo (Cardoso \& da Silva 2010). También, se señala la necesidad de generar espacios de discusión en relación a situaciones de sufrimiento que experimentan los TraSa llamadas "rondas" para poder intercambiar y encontrar alguna forma de reducir dichas condiciones (Luz et al., 2016; Silva \& Santos, 2006).

Este tipo de organización puede ser pensado, metafóricamente, como una "orquesta" donde cada sujeto mantiene su voz profesional y, al mismo tiempo, se enriquece con las voces de sus compañeros y compañeras, dando lugar a un proceso de atención y cuidado más rico (Silva \& Santos, 2006). Es decir, donde la polifonía genera un arreglo musical integrado.

Esta organización en redes o equipos, en algunos casos, incluye al usuario dando lugar a "espacios de negociación", donde lo relacional y los "diálogos" son centrales para el proceso de atención y cuidado no solo en el plano interprofesional, sino también, en el plano profesional-usuario. En el cual el usuario fue considerado por los profesionales como un agente con voz y, por lo tanto, con decisión de su trayectoria terapéutica (Lima \& Trad, 2011). En estos casos el "diálogo permanente" se constituye como un requisito para el desarrollo de un clima de respeto y soporte emocional, entre los usuarios y los profesionales y entre éstos (Silva \& Santos, 2006).

A pesar de que esta forma de organizar el trabajo es reconocidas por los TraSa como fundamental para una adecuada atención y cuidado constituyen un desafío en el contexto de los hospitales ya que requiere un esfuerzo para desarrollar habilidades relacionales que implican lidiar con padecimientos (Luz et al., 2016) y romper con las contradicciones que se generan en la organización del trabajo entre los distintos tipos de profesionales en hospitales (Rocha et al., 2015).

\section{1. 3. Racionalidad biomédica}

Esta categoría remite al "un sistema lógico y teóricamente estructurado, compuesto por cinco elementos teóricos fundamentales, a saber: a) una morfología o anatomía humana; b) una fisiología o dinámica vital humana; c) un sistema de diagnóstico; d) un sistema de intervenciones terapéuticas; e) una doctrina médica" (Camargo, 2005, p. 178), que orienta el 
Moglia B. Procesos de atención y cuidado desde la perspectiva de los trabajadores: una metaetnografía en hospitales de Latinoamérica. [Tesis de maestría]. Maestría en Epidemiología, Gestión y Políticas de Salud. Universidad Nacional de Lanús. 2020.

pensamiento y los fundamentos de la medicina y, organiza, en cierta medida, los procesos de atención y cuidado en los hospitales. El autor resume dichos componentes en tres proposiciones que fueron explicadas en el Marco Conceptual de Referencia.

Muchos TraSa reconocen que su formación profesional y sus prácticas en el hospital están atravesadas por un conjunto de conocimientos científicos denominados "modelo o paradigma biomédico"; "biomedicina" o "conocimiento hegemónico". A continuación identificamos y describimos tres aspectos que refieren a dicha racionalidad y que son observados en las experiencias de los TraSa.

En primer lugar, el biologicismo domina en los procesos de atención y cuidado, de forma tal que los TraSa identifican problemas orgánicos en un cuerpo físico (do Amaral et al., 2013). En este sentido, los usuarios son atendidos cuando hay signos biológicos/físicos evidencien enfermedad en alguna parte de su cuerpo, y al centrarse en solo un aspecto conlleva a una "fragmentación del cuidado". Es decir, que el "paradigma biomédico" posee una estructura cuyos contenidos son primordialmente biológicos y orientan una atención direccionada a un tipo de patología (Cardoso et al., 2013). Esta perspectiva no solo se observa en los momentos de explicar o diagnosticar una enfermedad, sino que se presenta en las situaciones donde los TraSa dan cuenta del fallecimiento del paciente a su familia. En este caso, las explicaciones tratan de ser "objetivas", apoyándose en las limitaciones del cuerpo físico vinculado a aspectos meramente biológicos. En la lógica biomédica se trata de “domesticar a la muerte”(Souza et al., 2018).:

...hicimos todos los intentos posibles para revertir las lesiones y complicaciones, pero desafortunadamente no respondió a ninguno de nuestros intentos y murió ${ }^{33}$ (Souza et al., 2018, p. 9).

...la lesión fue mucho más fuerte que el paciente, él peleó, peleó, peleamos, pero la enfermedad fue mucho más fuerte que él ${ }^{34}$ (Souza et al., 2018, p. 9).

Esta forma de respuesta hacia la muerte niega el proceso social y cultural que implica (Aredes, Firmo \& Giacomin, 2018; Rocha, Souza \& Teixeira, 2015), simplificando los sentidos y los significados asociados a ésta.

En segundo lugar, en el hospital domina una visión mecánica del sujeto sin subjetividad, sin intenciones, sin deseos, la cual imposibilita la atención integral y reproduce

\footnotetext{
${ }^{33}$ Traducción libre de la autora: ...nós fizemos todas as tentativas possíveis para reverter as lesões e as complicações, mas infelizmente ele não respondeu a nenhuma das nossas tentativas e foi a óbito (Souza et al., 2018, p. 9).

${ }^{34}$ Traducción libre de la autora: ... a lesão foi muito mais forte que o doente, ele lutou, lutou, nós lutamos, mas a doença foi muito mais forte do que ele (Souza et al., 2018, p. 9).
} 
Moglia B. Procesos de atención y cuidado desde la perspectiva de los trabajadores: una metaetnografía en hospitales de Latinoamérica. [Tesis de maestría]. Maestría en Epidemiología, Gestión y Políticas de Salud. Universidad Nacional de Lanús. 2020.

la construcción de modos de cuidado centrados en procedimientos (Klossoswski et al., 2016). En el mismo sentido, para la mayoría de los profesionales, los usuarios no deberían opinar sobre su proceso de atención y cuidado (da Silva et al., 2013) y, a través de las prácticas intervencionistas puede observarse el lugar que el usuario ocupa en el hospital: relegado y secundario a la enfermedad, donde las tecnologías duras dominan los procesos de atención, generando fragilidades en la relación con el usuario.

Asimismo, esta mirada construida acerca del sujeto potencia el "poder médico", llevando incluso a establecer lógicas clasificatorias según el grado de colaboración o de cumplimiento de sus pareceres (Silva et al., 2011). En general, domina una representación del paciente como "carente de habilidades de comprensión" y, en alguno casos, es considerado como "no colaborativo" al no cumplir con las indicaciones de la autoridad médica (Aguiar et $a l ., 2013$ ). Bajo este presupuesto, justifican las acciones violentas (amenazas, aumentos de voz, conductas ríspidas):

\begin{abstract}
... he dicho también: "No grites, sino no voy a venir a verte! ¡Si continúa, dejaré de hacer lo que estoy haciendo ahora!" (...) Porque quería intentar llamar la atención sobre su colaboración en el trabajo de parto. Nunca iba a hacer eso porque nunca lo hice, dejar al paciente solo en la habitación. Esta es una... Es una forma de 'coerción', una forma de tratar de 'disuadir' a [los pacientes] (....) Disuadir, no, ya sabes. Intenta que (...) [los pacientes] colabore más ${ }^{35}$ (Aguiar, d'Oliveira \& Schraiber, 2017, p. 2291).
\end{abstract}

Estas "conductas necesarias del trabajo" están legitimadas en el ejercicio de la autoridad profesional. Si bien en algunos casos son percibidas y nombradas como violencias, también los TraSa las banalizan, restándole importancia e indicando que en realidad no tienen la intención de llevarlas a cabo (Aguiar et al., 2013).

En tercer lugar, los TraSa cuestionan una serie de "certezas" impuestas por el conocimiento hegemónico como "la verdad", habilitando accionares por parte de los profesionales médicos. Este poder médico es explicado por el saber legitimado y también, por la posición jerárquica que ocupan. En los hospitales, se evidencia a través de conflictos con los profesionales no médicos, generando "ruidos" en las relaciones (Costa \& Abrahão, 2018). A pesar de la presencia de otros servicios de atención, como el psicosocial, el biomédico es priorizado, quedando aquel como secundario. Los profesionales psicosociales, es decir, psicólogos, psicólogas, trabajadores y trabajadoras sociales señalan que no tienen un rol

\footnotetext{
${ }^{35}$ Traducción libre de la autora: Ah, isso eu já falei também: "Não grita se não eu não venho te atender! Se continuar eu paro agora o que eu estou fazendo!" (...) Porque eu queria tentar chamar atenção pra ela colaborar no trabalho de parto. Eu jamais ia fazer isso porque eu nunca fiz isso, de largar a paciente sozinha na sala. Isso é uma... É uma forma de 'coação', uma forma de tentar 'dissuadir' a gestante... Dissuadir, não, né. Tentar fazer com que a gestante colabore mais (Aguiar, d'Oliveira \& Schraiber, 2017, p. 2291).
} 
Moglia B. Procesos de atención y cuidado desde la perspectiva de los trabajadores: una metaetnografía en hospitales de Latinoamérica. [Tesis de maestría]. Maestría en Epidemiología, Gestión y Políticas de Salud. Universidad Nacional de Lanús. 2020.

decisor en los procesos de atención y cuidado ya que no son vistos como parte integral del equipo (Brage \& Vindrola-Padros, 2017). Solamente son consultados cuando hay circunstancias "difíciles":

Ellos [el equipo médico] nos llaman por situaciones difíciles, familias disfuncionales, falta de aceptación del tratamiento, violencia doméstica ${ }^{36}$ (Brage \& Vindrola-Padros, 2017, p. 95).

Nos llaman en casos relacionados con la adherencia y aceptación del tratamiento, principalmente la aceptación desde la perspectiva de los padres ${ }^{37}$ (Brage \&Vindrola-Padros, 2017, p. 95).

Asimismo, la biomedicina como disciplina científica y técnica para explicar ciertos padecimientos, así como el biologicismo del saber médico como verdad única es reconocido por los propios TraSa como insuficiente, limitado en ciertos casos. (Acosta et al., 2018):

\begin{abstract}
Quizás mejoraría si tuviéramos más conocimiento, nos sentiríamos aún más apoyados para tomar medidas. Probablemente dé un poco de miedo, en el momento en que experimente, que esté viendo la situación en la que se va a encontrar. Miedo a represalias, miedo a que sus propios colegas digan: en qué se metió, qué dijo. $O$ el agresor mismo diciendo: ¿Qué quieres saber? ¿Por qué viniste a meterte conmigo? porque no eres nada ${ }^{38}$ (p. 6).
\end{abstract}

De esta forma, se puede observar la preocupación por posibles "represalias" por parte de otros compañeros o compañeras al acercarse hacia otras alternativas por fuera del modelo biomédico. En este sentido, plantean la necesidad de formación en determinados problemas sociales que se observan de forma recurrente en los servicios de atención con apoyo de los gestores con cargos jerárquicos de manera de legitimar su intervención. Los TraSa identificaron como problemas de difícil abordaje desde el paradigma biomédico a la violencia de género o la violencia física hacia ancianos (Acosta et al., 2018; Lima et al., 2010), destacando que, a pesar de los años de formación no han aprendido la forma de proceder ante estos (Acosta et al., 2018). Además, tampoco hay protocolos clínicos específicos para atender dichas problemáticas ni una estructura física adecuada para su atención en los hospitales, obstaculizando aún más otro tipo de abordaje por fuera de la biomedicina:

El servicio en muestra red es un servicio (...) poco dirigida a los ancianos... el
usuario es atendido globalmente, no tiene un tratamiento específico para ese

\footnotetext{
${ }^{36}$ Traducción libre de la autora: They [medical team] call us for the difficult situations, dysfunctional families, lack of acceptance of treatment, domestic violence (Brage \& Vindrola-Padros, 2017, p. 95).

${ }^{37}$ Traducción libre de la autora: ... they call us in cases related to the adherence and acceptance of treatment, mainly acceptance from the parent's perspective (Brage \& Vindrola-Padros, 2017, p. 95).

38 Traducción libre de la autora: Talvez melhorasse se tivéssemos mais conhecimento nos sentíssemos até mais amparados para tomar atitudes. Provavelmente dê um pouco de medo, no momento que tu está vivenciando, que tu estás vendo a situação que vais te meter. Medo de represália, medo de teus próprios colegas dizerem: o que tu foi te meter, o que tu foi falar. Ou o próprio agressor dizer: O que tu queres saber? Por que tu vieste te meter? porque tu não és nada (Acosta et al., 2018, p. 6).
} 
Moglia B. Procesos de atención y cuidado desde la perspectiva de los trabajadores: una metaetnografía en hospitales de Latinoamérica. [Tesis de maestría]. Maestría en Epidemiología, Gestión y Políticas de Salud. Universidad Nacional de Lanús. 2020.

segmento [etario]. Puede tocar un paciente (...) que sufrió un accidente, victima de la violencia; se atiende como si fuera una cosa rutinaria del servicio (...) no tiene un protocolo específico ... ${ }^{39}$ (Lima et al., 2010, p. 2682)

\section{1. 4. Emociones emergentes}

Esta categoría de análisis quedó conformada por una serie de expresiones verbales, no solo de estados internos, sino también de las relaciones de poder entre actores (Lutz \& AbuLughod, 1990). Si bien se muestran de manera secundaria en el corpus, constituye una dimensión que aparece asociada a las narraciones de los TraSa al describir su cotidianeidad en el hospital. Estas emociones no pueden ser pensadas por fuera de un contexto social y un sistema moral que articula la manera de ser y actuar de los sujetos. Por eso planteamos que la presente categoría nos permite observar como los sujetos a través de la expresión de emociones comunican y explican situaciones, relaciones y posiciones morales dentro del hospital. La emoción es entendida como una "herramienta a poner en circulación en el contexto de la interacción social. Un insumo para conocer el mundo del otro" (Sirimarco \& Spivak L'Hoste, 2019, p. 306). Además, entendemos que las emociones y sus significados están “...fundamentalmente estructurados por sistemas culturales particulares y medios ambientes sociales y materiales también particulares" (Lutz, 1988, p.5 citado en: Bourdin, 2016). Sirimarco y Spivak L'Hoste (2019) señalan, a partir de los aportes de los estudios antropológicos "clásicos" de las emociones, tres aspectos a tener en cuenta en el análisis de las emociones. En primer lugar, explican que las emociones no deben ser entendidas como un objeto de análisis individual e independiente del mundo social, sino que constituyen interpretaciones de un determinado grupo social involucradas en el cuerpo (Rosaldo, 1980, 1983, 1984 citado en: Sirimarco y Spivak L'Hoste, 2019). De esta forma, propone que las emociones son pensamientos encarnados, es decir, que no se oponen al pensamiento y que para comprender su sentido y significado tienen que ser analizadas en vinculación a prácticas y/o discursos (Rolsado, 1984 citado en Bolaños, 2016). En segundo lugar, sostienen que las emociones siempre se expresan por alguien y se dirigen hacía alguien determinado (Sirimarco y Spivak L'Hoste, 2019). Por su parte, Mauss (1979) explica un aspecto clave vinculado a esto último, ya que plantea que las emociones se expresan socialmente de forma reglada, con esto se quiere significar que no son fenómenos exclusivamente psicológicos o fisiológicos, sino que son sociales que varían de acuerdo al tiempo, las condiciones y los agentes de

\footnotetext{
39 Traducción libre de la autora: $O$ atendimento na nossa rede é um atendimento (...) pouco dirigida ao idoso... o usuário é atendido globalmente, não tem um tratamento específico para esse segmento. Pode pegar paciente (...) que sofreu um acidente, vitima de violência; ele é atendido como se fosse uma coisa de rotina do serviço (...) não tem um protocolo especifico... (Lima et al., 2010, p. 2682).
} 
Moglia B. Procesos de atención y cuidado desde la perspectiva de los trabajadores: una metaetnografía en hospitales de Latinoamérica. [Tesis de maestría]. Maestría en Epidemiología, Gestión y Políticas de Salud. Universidad Nacional de Lanús. 2020.

expresión. Por último, las autoras, refieren a que las emociones vehiculizan distintos modos de relacionarse, siendo aquellas emergentes de los vínculos y de las interacciones (Lutz y Abu-Lughod, 1990 citado en: Sirimarco y Spivak L'Hoste, 2019). Teniendo en cuenta dichos señalamientos con respecto a la categoría "emociones", evidenciamos enunciados o relatos de los TraSa que remiten a "experiencias afectivas o emocionales" o "reacciones emocionales", tratando de reconstruir en qué situaciones emergen y qué reacciones se producen en el espacio del hospital.

Las "experiencias o reacciones emocionales" se vinculan, principalmente, con situaciones de insatisfacción laboral y de sufrimiento (Cardoso \& da Silva, 2010; Lopes et al., 2007; Luz et al., 2016). En algunos casos, donde la atención se realiza de forma indirecta (por ejemplo, el servicio de laboratorio de los hospitales, realizado por el sector de enfermería), es vivida por los TraSa como una molestia, la cual se evidencia a través de expresiones de deseos de cambiar de unidad o servicio debido a la falta de adaptación o desvalorización por parte de otros TraSa (Lopes et al., 2007):

\begin{abstract}
Entonces, porqué te encargas del material de lavado (...) de la suciedad, de esas cosas contaminadas. Así que no eres tan bueno como el que hace medicamentos, que trabaja en la industria. Podemos notar esa diferencia. Ellos critican nuestro trabajo como si fuera una cosa pequeña (...) Sentimos eso. Cuando alguien pregunta, ¿qué hay de ti, dónde estás? ¡Oh! ¿Pero en el centro material? ¿No había otro lugar? Nos sentimos discriminados como si fuera un pequeño servicio ${ }^{40}$ (p. 680).
\end{abstract}

En relación a dichas situaciones de no reconocimiento, la discriminación emerge como problema entre los profesionales y resulta en un ambiente de trabajo incómodo (Cardoso et $a l ., 2013)$. La discriminación es señalada por los TraSa como una forma de violencia que se da en distintos niveles: entre los profesionales médicos y los profesionales no médicos; entre los que pertenecen a la planta estable del hospital y los que no; entre mujeres y varones (Luna-García et al., 2015). En este sentido, los TraSa de enfermería expresan "sentimientos de stress" generados en el marco de las relaciones con sus superiores (Palmer 2014), manifestando un "clima de hostilidad" en el cotidiano del servicio debido a conflictos en las relaciones entre actores de distintas jerarquía (Arenas-Monreal et al., 2004).

\footnotetext{
40 Traducción libre de la autora: Então, porque você cuida de lavar material (...) de cuida (...) de sujeira, daquelas coisas contaminadas. Então, você não é tão bom como aquele que faz medicações, que trabalha no setor. A gente percebe esta diferença. Recriminam como nosso trabalho como se fosse uma coisa pequena (...) A gente sente isso. Quando alguém pergunta: e você, onde você está? AH! Mas no centro de material? Não tinha outro lugar? A gente se sente recriminado como se fosse um serviço pequeno (Lopes et al., 2007, p.680).
} 
Moglia B. Procesos de atención y cuidado desde la perspectiva de los trabajadores: una metaetnografía en hospitales de Latinoamérica. [Tesis de maestría]. Maestría en Epidemiología, Gestión y Políticas de Salud. Universidad Nacional de Lanús. 2020.

Otras situaciones de insatisfacción laboral, como los accidentes con material biológico o las condiciones concretas de trabajo, fueron asociadas a miedos, ansiedades y molestias (Baasch \& Laner, 2011; Fernandes et al., 2018; Rocha et al., 2015; Rosado et al., 2015):

En mi trabajo, estoy expuesto a muchos riesgos laborales [biológicos, químicos, ergonómicos, etc.], así como a mi lado emocional debilitado por las injusticias, la negligencia, la falta de respeto hacia los pacientes, así como las relaciones entre profesionales no armoniosos $^{41}$ (Rosado, Russo \& Maia, 2015, p. 3027).

Las grandes limitaciones y las precarias condiciones de trabajo nos determinan ansiedad, tristeza, sensación de impotencia ${ }^{42}$ (Rosado, Russo \& Maia, 2015, p. 3027).

Y lo que me molesta a veces es que no puedes ayudar a un paciente debido a la falta de equipos o recursos o porque a veces realmente no tienen nada que hacer. Te sientes impotente al no poder ayudar, porque no depende solo de las personas ${ }^{43}$ (Baasch \& Laner, 2011, p.1103).

Las situaciones de sufrimiento y muerte experimentadas por los TraSa constituyen otro marco de desarrollo de emociones vinculadas a la angustia, la frustración y la impotencia. En mayor medida, estos eventos se pueden observar en servicios de atención paliativos o de terapias, en los cuales los usuarios tienen pocas posibilidades de sobrevivencia o carecen de éstas (Cardoso et al., 2013a; Luz et al., 2016):

...así que al principio era muy pesado, las primeras veces, cuando vine aquí y comencé a tratar con un paciente de oncología, fue muy angustiante, sufrimos mucho al principio (...). Y admitir que no tienes nada más que hacer. Se trata de impotencia $^{44}$ (Cardoso et al., 2013a, p. 1138).

...al principio fue muy difícil, fue muy difícil de aceptar, correcto, (...) no estamos preparados para ver a un paciente que vaya más allá de nuestro conocimiento. Parece que somos nosotros los que estamos fallando, que nos falta el conocimiento para poder asistir hasta el final de la vida (...) es muy frustrante para nosotros tener el conocimiento, tener los recursos y llegar al punto de ver que todo lo que estás haciendo, no puedes. Llega un punto que excede tu voluntad, es el límite ${ }^{45}$ (Cardoso et al., 2013a, p. 1138).

${ }^{41}$ Traducción libre de la autora: No meu trabalho estou exposta a muitos riscos ocupacionais [biológicos, químicos, ergonómicos etc.], como também fico com o lado emocional fragilizado pelas injustiças, negligências, desrespeito com os pacientes, bem como com as relações entre os profissionais desarmônicas (Rosado, Russo \& Maia, 2015, p. 3027).

42 Traducción libre de la autora: As grandes limitações e condições precárias de trabalho nos determina ansiedade, tristeza, sentimento de impotência (Rosado, Russo \& Maia, 2015, p. 3027).

${ }^{43}$ Traducción libre de la autora: E o que me aborrece às vezes é tu não poderes ajudar um doente por falta de equipamentos ou recursos ou porque às vezes não tem mesmo o que fazer. Tu te sentes impotente em não poder ajudar, porque não depende só da gente (Baasch \& Laner, 2011, p.1103).

${ }^{44}$ Traducción libre de la autora: ...então, no começo foi muito pesado, as primeiras vezes, quando eu vim para cá e comecei a tratar com paciente oncológico, foi muito angustiante, a gente sofre muito no início (...). E tu admitires que não tem mais nada o que fazer. É lidar com a impotência (Cardoso et al., 2013a, p. 1138).

${ }^{45}$ Traducción libre de la autora: ...no início foi muito difícil, era muito difícil aceitar, né,(...)nós não estamos preparados para enxergar um paciente que extrapola o nosso conhecimento. Parece que somos nós que estamos falhando, que falta conhecimento para conseguir atender até o fim da vida (...)é muito frustrante a gente ter o conhecimento, ter recursos, e chegar a um ponto de ver que tudo que tu estás fazendo, tu não consegues. Chega um ponto queltrapassa a tua vontade, é o limite (Cardoso et al., 2013a, p. 1138). 
Moglia B. Procesos de atención y cuidado desde la perspectiva de los trabajadores: una metaetnografía en hospitales de Latinoamérica. [Tesis de maestría]. Maestría en Epidemiología, Gestión y Políticas de Salud. Universidad Nacional de Lanús. 2020.

A partir de estas situaciones de dolor, sufrimiento y muerte, los TraSa construyen mecanismos o procedimientos defensivos, que son nombrados metafóricamente como "callosidad profesional", "armadura" o "desensibilización", que consiste en una indiferencia hacia las vivencias que generan un compromiso emocional, a través de la toma de distancia con los usuarios (do Amaral et al., 2013; Luz et al., 2016; Rocha, Souza \& Teixeira, 2015). Estos procesos recurrentes pueden generar un desgaste emocional, que consiste en un proceso gradual donde los TraSa pierden energía y donde el ambiente laboral pasa a estar regido por valores económicos, en detrimento de los humanos (Rocha, Souza \& Teixeira, 2015):

Hoy en día, para que valga la pena trabajar como médico, uno tiene que trabajar duro. Así que lo que sucede en el consultorio, por ejemplo, es que usted tiene que responder uno tras otro $^{46}$ (Rocha, Souza \& Teixeira, 2015, p. 849).

Por otro lado, los TraSa describen que los procesos de atención y cuidado están atravesados por "placeres" vinculados a la satisfacción laboral, la cual se da a partir del sentirse útil o de brindar ayuda hacia otro (Lopes et al., 2007; Rocha, Souza \& Teixeira, 2015; Rosado et al., 2015) y, en algunos casos, explicitan que el trabajo en salud va mas allá de la cuestión económica (Baasch \& Laner, 2011): Vale la pena mencionar ese reconocimiento, combinado con el valor simbólico
contenido en la sensación de ser útil para contribuir a revertir la enfermedad de los
usuarios $^{47}$ (Rosado, Russo \& Maia, 2015, p. 3025).

Es la satisfacción de lo que hago. Me gusta hacer UTI, me gusta. Es algo que ve un resultado, cuando tiene todo lo que tiene que hacer por el niño, es algo muy dinámico y realmente me gustó ${ }^{48}$ (Rocha, Souza \& Teixeira, 2015 p. 853).

Por supuesto, dinero (...) trabajamos por dinero, pero también tenemos que trabajar por placer. Entonces, para mí, son las dos $\operatorname{cosas}^{49}$ (Baasch \& Laner, 2011, p. 1102).

Asimismo, en una investigación realizada en un hospital en Ecuador sobre los entornos de trabajo de enfermería, se pudo identificar que las razones de sentirse satisfecho no solo recae en el propósito de ayudar a los pacientes, sino también en un "ambiente positivo" y en el ofrecimiento del hospital a una "educación continua" (Palmer, 2014).

\footnotetext{
46 Traducción libre de la autora: Hoje em dia, pra valer a pena você trabalhar como médico, você tem que trabalhar muito. Então, o que acontece no consultório, por exemplo, é que você tem que atender um atrás do outro (Rocha, Souza \& Teixeira, 2015, p. 849)

47 Traduccion libre de la autora: Vale salientar que o reconhecimento, aliado ao valor simbólico contido na sensação de ser útil ao contribuir para reverter o adoecimento dos usuários (Rosado, Russo \& Maia, 2015, p. 3028).

${ }^{48}$ Traducción libre de la autora: É a satisfação do que eu faço. Eu gosto de fazer UTI, eu gosto. É uma coisa que você vê um resultado, quando você tem tudo na mão pra fazer pela criança, é uma coisa muito dinâmica e eu gostei muito disso (Rocha, Souza \& Teixeira, 2015 p. 853).

49 Traducción libre de la autora: Claro que dinheiro (...) a gente trabalhar por dinheiro, mas também tem que trabalhar por prazer. Então, para mim, é as duas coisas (Baasch \& Laner, 2011, p. 1102).
} 
Moglia B. Procesos de atención y cuidado desde la perspectiva de los trabajadores: una metaetnografía en hospitales de Latinoamérica. [Tesis de maestría]. Maestría en Epidemiología, Gestión y Políticas de Salud. Universidad Nacional de Lanús. 2020.

Si bien se identificaron dichas situaciones, cabe destacar, que esto no es lo que prevalece en las narrativas de los TraSa. Por el contrario, las referencias hacia situaciones de malestar en el espacio del hospital son las que se destacan. Entonces, se observa que el sujeto, TraSa de un determinado servicio, tiene deseos e intenciones que se expresan en tensión entre lo que se puede hacer, lo que se desea y lo que se debe hacer. Esto último vinculado a emociones emergentes en el cotidiano y corporizadas en las quejas y los deseos de los TraSa que llevan a dichos sujetos a una producción singular de la salud.

\section{2. Sintesis interpretativa}

Este apartado interpretativo se desarrolla a partir de lo expuesto en la síntesis comparativa, tomando como referencia no solo los estudios cualitativos que sirvieron de antecedentes a nuestro tema de investigación y aquellos incluidos en el marco conceptual, sino también otra bibliografía que nos permiten interpretar los distintos aspectos recuperados sobre los procesos de atención y cuidado. En este sentido, esta síntesis interpretativa va a estar organizada en torno a cuatro argumentos centrales.

En primer lugar, tal como explicamos en la construcción del problema de investigación, el hospital constituye un espacio de atención a la salud-enfermedad y de formación médica, pero consideramos que, además, debe ser visto como un espacio de trabajo. Como tal, consideramos que deben tenerse en cuenta los sentidos y significados que los TraSa tienen sobre aquel y que a través de dichos códigos, socialmente establecidos, van a orientar los procesos de atención y cuidado como así también construir subjetividades (Ortner, 2005). Esto será interpretado a partir de las investigaciones de Merhy y Franco (2009, 2016) centradas en la micropolítica de la organización; así como también de estudios antropológicos sobre las dimensiones organizacional en hospitales (Crojethovic, 2010) y espacio-temporal de la atención hospitalaria (García, Recoder \& Margulies, 2017).

En segundo lugar, tal como se expresó en la hipótesis, los procesos de atención y cuidado para los TraSa van más allá del cumplimiento de normas, procedimientos y estándares, e implican procesos relacionales con los usuarios/as y con sus compañeros/as, lo cual es explicado a través de algunos conceptos propuestos desde el abordaje de la profesión médica, de Friedson (1978). Luego, a partir de las experiencias registradas sobre la conformación de redes, exploramos otras posibles dimensiones de los procesos de atención y cuidado, profundizando en la ética del cuidado (Tronto, 1993; Kleinman \& van der Geest, 2009) y la humanización de la atención (Ayres, 2018; Merhy, 2016). Por último, discutimos 
Moglia B. Procesos de atención y cuidado desde la perspectiva de los trabajadores: una metaetnografía en hospitales de Latinoamérica. [Tesis de maestría]. Maestría en Epidemiología, Gestión y Políticas de Salud. Universidad Nacional de Lanús. 2020.

en relación a la segunda parte de nuestra hipótesis, la cual propone que los procesos de atención y cuidado se encuentran atravesados por distintos tipos de relaciones entre los TraSa y entre éstos y los usuarios. En este caso, proponemos una interpretación a partir del concepto de identidades (Hall, 2003; Cascón-Pereira, 2013).

En tercer lugar, discutimos las limitaciones de la racionalidad biomédica (Camargo, 2005), que comienza a incomodar a algunos TraSa, al visibilizar nuevos o viejos problemas en relación a dicho paradigma. A partir del concepto de drama social (Turner, 1974) reflexionamos sobre la dinámica generada a partir de las tensiones que se observaron en las experiencias de los TraSa, respecto a los procesos de atención y cuidado. De esta forma, sostenemos que es en ese drama donde surge la incomodidad habilitando la reflexividad en torno a sus prácticas.

A modo de cierre, introducimos una discusión en torno a las emociones (Spivak \& L'hoste, 2019) que se presentan en torno a los procesos de atención y cuidado. Esta es una dimensión que no ha sido abordada como objeto de estudio en el corpus recuperado y por lo tanto, emerge del análisis desarrollado. Al observar transversalmente los artículos observamos que los TraSa expresan una diversidad de emociones vinculadas con el trabajo en el hospital, en general, y a los procesos de atención y cuidado, en particular. Dichas manifestaciones se convierten en una vía de acceso al malestar o bienestar en el trabajo, que pueden afectar a la salud-enfermedad de los TraSa.

Cabe señalar que cada una de las líneas argumentales que desarrollaremos a continuación, están pensadas hipotéticamente como aspectos que, de una u otra manera, atraviesan a los procesos de atención y cuidado en el ámbito de los hospitales en Latinoamérica. En este sentido, se trata de la modelización de un proceso con ciertos rasgos comunes, los cuales sería erróneo atribuir a una institución o localidad particular.

\section{2. 1. "...A veces trabajas solo, trabajas al límite..."}

Para comprender un proceso o hecho social es necesario, al menos en un primer momento de análisis, conceptualizar y describir el contexto en el que tiene lugar. En este caso, a partir de la categoría de "escenarios de trabajo" (Soto Roy, 2015) observamos que existe una relación entre estos últimos y los procesos de atención y cuidado, que buscamos comprender en este apartado. Tales escenarios no solo refieren al trabajo que está normado sino también a aquellas acciones que tienen lugar de manera implícita, ambas necesarias para que la institución del hospital funcione. En otras palabras, nos estamos refiriendo al trabajo 
Moglia B. Procesos de atención y cuidado desde la perspectiva de los trabajadores: una metaetnografía en hospitales de Latinoamérica. [Tesis de maestría]. Maestría en Epidemiología, Gestión y Políticas de Salud. Universidad Nacional de Lanús. 2020.

prescripto y al que se configura en las narrativas como trabajo cotidiano en el ámbito del hospital. Además, se le debe yuxtaponer aquellas "condiciones de trabajo" como la insuficiencia de profesionales, de materiales y de equipos, los bajos salarios, las contrataciones flexibles, las prolongadas jornadas y el exceso de tareas (Arenas-Monreal et al. 2004; Fernandes, Nery, \& Filho 2018; Formozo \& Oliveira 2010; Littike \& Sodré 2015; Luna-García et al. 2015; Rosado, Russo \& Maia 2015).

Ahora bien, dichos escenarios de trabajo llevan a construir determinados sentidos y significados en torno al hospital, que van a impregnar la organización de la atención y cuidado. Esta relación, entre los TraSa y el hospital, se observa en un análisis sobre la dimensión espacio-temporal de la atención en un centro obstétrico de un hospital público, en el cual García, Recoder y Margulies (2017) señalan que los TraSa identifican al servicio donde trabajan como "las trincheras". Esta asociación es explicada por los sujetos haciendo referencia a que su ejercicio profesional se da en un contexto de escasez de recursos, de deterioro del instrumental y de imprevisibilidad en el accionar de la institución, sintiendo el "abandono" de las autoridades. Asimismo, asocian "las trincheras" a las caracterizaciones y valoraciones que los TraSa le otorgan a la población usuaria, generalmente cargadas de estereotipos vinculados a la ignorancia, incompetencia y peligrosidad. Estas visiones se inscriben en los sentidos y significados de los TraSa y sirven de "coartada" para impregnarse en las prácticas de atención (García, Recoder \& Margulies, 2017). Esto guarda relación con lo hallado en el corpus, donde el "ambiente/cotidiano de trabajo" se caracterizó como estresante, frustrante y conflictivo, vinculado a un modo de trabajo cuya modalidad está regulado por grados de "intensidad", que varían en cada servicio pero que, en general, mientras se trabaja se tiende a "no parar". Asimismo, los escenarios de trabajo muestran la distancia entre trabajo prescripto y aquel que se configura en las narrativas como trabajo cotidiano, observando tanto situaciones donde se realizan, en palabras de los TraSa "tareas de más", es decir, por fuera de lo reglamentado por el trabajo, y que en tanto, no son reconocidas por las autoridades. Un caso de dicha situación se da cuando el trabajador no se toma el descanso que corresponde por norma/reglamento sino cuando se puede de acuerdo las circunstancias. Además, la distancia entre el trabajo prescripto y el cotidiano se observó en momentos donde los TraSa hacen "tareas de menos". Por ejemplo, diferentes experiencias hicieron referencia a la imposibilidad de llevar a cabo un procedimiento enmarcado y avalado dentro de una política o programa sobre la forma que debería tener la atención a las mujeres embarazadas (contar con acompañamiento y privacidad). Entre los motivos señalados por los TraSa, se encontraron que 
Moglia B. Procesos de atención y cuidado desde la perspectiva de los trabajadores: una metaetnografía en hospitales de Latinoamérica. [Tesis de maestría]. Maestría en Epidemiología, Gestión y Políticas de Salud. Universidad Nacional de Lanús. 2020.

las limitaciones de infraestructura de las instituciones constituían un obstáculo para llevar a cabo lo estipulado, dando lugar a una atención atada a los escenarios de trabajo.

De esta forma, y a partir de dichos espacios, se configuran los sentidos y los significados que los TraSa tienen sobre su trabajo cotidiano en los hospitales. Estos se encuentran ligados a modos de trabajo que sienten bajo presión, donde el tiempo es un recurso escaso y el "deber ser" pasa a ser un "hago lo que puedo con lo que tengo", donde el conflicto emerge entre los TraSa y entre éstos y los usuarios y donde las respuestas son limitadas. Los TraSa remiten a los escenarios de trabajo como obstáculos de lo que podría ser una mejor atención y cuidado. En este sentido, refieren que trabajar "solos, al límite" significa escenarios de trabajo donde no se sienten reconocidos o legitimados por parte de la institución, donde genera rispideces entre compañeros llevando incluso a procesos de atención y cuidado desarticulados entre los profesionales. Destacamos el caso de Colombia, donde los TraSa perciben a los escenarios de trabajo, vinculados a la inestabilidad laboral, como "violentos". Por otro lado, para algunos TraSa el trabajo en el hospital también supone el acceso a ciertos bienes materiales y "calidad de vida", o mejor, estándar de vida que no podrían alcanzar con otro trabajo. Se observa que el malestar co-existe con la gratificación al "sentirse útil", por "ayudar a otros", viendo como un logro haber llegado a ese espacio.

Estas dos miradas que los TraSa tienen sobre su trabajo pueden ser entendidas en el sentido en que Crojethovic (2010) describe las dinámicas organizacionales en hospitales públicos. Esta autora ha asociado al ambiente de incertidumbre y desprotección laboral con "condiciones de precariedad", las cuales impactan en las formas de trabajo de los TraSa y, por lo tanto, en el servicio de atención y cuidado. La autora explica que dichas condiciones de precariedad ha llevado a que los sujetos moldeen las normativas institucionales por fuera de su marco, dando lugar a lo que denominó "iniciativas no regladas", las cuales funcionan como un elemento organizador de los hospitales (Crojethovic, 2010). Y que, a su vez, produce un círculo vicioso donde los TraSa hacen lo posible para que el hospital funcione sin colapsar, pero al mismo tiempo reproducen y sostienen las situaciones de precariedad que hacíamos referencia más arriba en el texto. Esto se pudo observar en los acuerdos implícitos que se dan en el hospital para organizar los horarios de descanso, por ejemplo, los cuales se deben negociar entre los TraSa para que puedan llevarse a cabo, entre otras cosas.

Desde la micropolítica de la organización, Franco y Merhy (2009, 2016) explican que dicha dinámica organizacional en hospitales implica que, al interior de las organizaciones de salud, operan diferentes planos que emergen sobre la estructura dada, constituida y 
Moglia B. Procesos de atención y cuidado desde la perspectiva de los trabajadores: una metaetnografía en hospitales de Latinoamérica. [Tesis de maestría]. Maestría en Epidemiología, Gestión y Políticas de Salud. Universidad Nacional de Lanús. 2020.

preexistente, los cuales hacen posible el funcionamiento de las instituciones. En esos planos aparece lo implícito, lo no estructurado, es decir, aquellas normas, iniciativas y acciones que emergen de lo prescriptivo y lo formal debido a su falta o ausencia. Esto permite, según los autores, encuentros entre actores/sujetos que habilitan relaciones de diferentes intensidades para la producción de salud y, en este sentido, posibilita la acción de los TraSa (Franco \& Merhy, 2009). Estas acciones no son actos congelados en el espacio-tiempo del hospital sino que se los entiende como un proceso dinámico, que se modifica y está atravesado por tantos intereses como actividades en torno a los procesos de atención y cuidado. Por eso, Franco y Merhy (2009) recomiendan el análisis de los sujetos y sus acciones cotidianas para comprender como se produce la atención y el cuidado y, a su vez, resaltan que por medio del trabajo van produciendo el mundo en el que se insertan y así mismos en procesos de subjetivación (Franco \& Methy, 2009).

Estas cuestiones nos conducen a plantear que los procesos de atención y cuidado deben ser pensados en la complejidad del escenario de trabajo en que ocurren, teniendo en cuenta tanto que los hospitales no se organizan, solamente, por normas y leyes que rigen desde el plano formal sino, por el contrario, los TraSa se corren de estas últimas y ahí es donde aparecen sus acciones bajo determinados intereses (Franco \& Methy, 2009). Como así también, se van construyendo, en simultáneo, sentidos y significados en torno a dichas acciones que van orientando los procesos de atención y cuidado. Esta complejidad no responde a escenarios de trabajo caóticos, como algo externo a los sujetos, como algo que la institución impone, sino que manifiestan como códigos socialmente establecidos, no organizados, compartidos y corporizados en la práctica cotidiana dentro del hospital. Esto podría ser tratado como las culturas hospitalarias que terminan orientando los procesos de atención y cuidado, y, al mismo tiempo construyendo y expresando subjetividades (Ortner, 2005). Como desarrollamos en el Marco Conceptual de Referencia, es en el espacio del hospital, siendo un multiespacio (atención a la salud-enfermedad, formación médica y trabajo) donde se configuran subjetividades que aluden tanto al "... conjunto de modos de percepción, afecto, pensamiento, deseo, temor, etc., que animan a los sujetos actuantes" (Ortner, 2005, p. 25) y que se vinculan “... a las formaciones culturales y sociales que modelan, organizan y generan determinadas "estructuras de sentimiento" (Ortner, 2005, p. 25). De esta forma, la subjetividad de los TraSa se construye en torno a dos planos: uno individual, que refiere a un sujeto cognoscente, que reflexiona sobre sí mismo y sus deseos y, otro colectivo, como parte de un conjunto de actores socialmente interrelacionados, que es el plano cultural (Ortner, 
Moglia B. Procesos de atención y cuidado desde la perspectiva de los trabajadores: una metaetnografía en hospitales de Latinoamérica. [Tesis de maestría]. Maestría en Epidemiología, Gestión y Políticas de Salud. Universidad Nacional de Lanús. 2020.

2005). En síntesis, el análisis sobre los escenarios de trabajo nos permitió comprender de qué forma operan los procesos de trabajo de los TraSa en el hospital, modelando subjetividades compartidas y modos de ser y actuar en la institución.

\section{2. 2. Entre "ruidos", "acciones medicamentosas" y "diálogos"}

Este apartado está orientado a interpretar las diferentes prácticas de atención y cuidado (descritas en la síntesis comparativa) para comprender como se configuran en el hospital desde las perspectivas de los TraSa.

En manera general, evidenciamos que la mayoría de los procesos de atención y cuidado se dan en términos prescriptivos, mecanizados y técnicos, donde el/la usuario/a se convierte en paciente de la institución. Crivos (1988) refiere a dicho fenómeno como "inversión de la relación de servicio", donde el hospital pasa de estar al servicio del enfermo a tratarlo como un paciente que se encuentra al servicio del hospital. Este proceso guarda relación con el modelo de intervención médica propuesto por Friedson (1978) en su análisis sobre la profesión médica, el cual plantea que el sector médico entiende el problema del usuario como técnico y por lo tanto, puede ser superado a través de acciones/intervenciones físicas o bioquímicas, suponiendo que puede ser curado. En este sentido, el paciente debe colocarse pasivamente en manos de los TraSa. Este proceso se identificó en aquellas prácticas donde predominan las decisiones del sector médico, como "diagnosticar" y "tratar", en donde se deja de lado no solo al usuario, sino también a los profesionales no-médicos. Según nuestros hallazgos, los psicólogos, psicólogas, trabajadores y trabajadoras sociales señalaron que no tienen un rol decisor en los procesos de atención y cuidado y que no son vistos como parte integral del equipo (Brage \& Vindrola-Padros, 2017), siendo consultados cuando hay circunstancias "difíciles". Es decir, en caso de problemas no abordables ni problematizados desde el paradigma biomédico, como situaciones de violencia o problemas en la adherencia al tratamiento. De esta forma, se observó que las formas de organización de los procesos de atención y cuidado responden a la división del trabajo (Friedson, 1978), donde se diferencian aquellas prácticas realizadas, principalmente, por el sector de enfermería en donde se desempeñan como "intermediario" entre los usuarios y los médicos, de las prácticas exclusivamente asociadas con el sector médico del hospital, tales como diagnosticar y diseño del tratamiento. En este sentido, Friedson (1978) refiere que la medicina ha impuesto un orden en torno a las otras profesiones que la rodean, y actúan bajo petición de los médicos, siendo subordinadas. Teniendo en cuenta los resultados y, a pesar de que ha habido cambios, 
Moglia B. Procesos de atención y cuidado desde la perspectiva de los trabajadores: una metaetnografía en hospitales de Latinoamérica. [Tesis de maestría]. Maestría en Epidemiología, Gestión y Políticas de Salud. Universidad Nacional de Lanús. 2020.

en los hospitales la decisión que más pesa es la que el sector médico establezca. Por eso, cuando describimos en qué consiste hospitalizar a una persona hay que pensar que, a pesar de determinadas autonomías en el ejercicio de la práctica de enfermería o de otras profesiones, las decisiones en torno a la hospitalización son definidas por el médico o la médica. Esto se puede observar también en las prácticas vinculadas al diagnóstico de la enfermedad y tratamiento, ya que termina siendo el sector médico el que termina dominando. Cabe destacar que, a pesar de predominar esta división del trabajo, se encontró cierta superposición de roles médicos. Tal como se observa en los momentos de promoción de salud, donde el sector de enfermería realiza dicha práctica a través de una comunicación prescriptiva sin considerar las circunstancias de los pacientes.

Ahora bien, también se han identificado prácticas que se enmarcan en lo que Friedson (1978) llama modelo de interacción terapéutica, donde el sector médico está a cargo del caso sin tener el monopolio de conocimientos referentes al tratamiento y que deben actuar como parte de un equipo, incluido el paciente. Este modelo lo asociamos con algunas experiencias, desarrolladas en Brasil, en torno a la conformación de equipos multidisciplinarios como forma alternativa de entender y organizar los procesos de atención y cuidado. Para ello nos basamos en lo recuperado del corpus, en particular a través de la categoría de análisis "redes". Esta noción es relevante porque muestra la construcción de un sentido de pertenencia, donde los actores, idealmente, rompen con el corporativismo y orientan sus relaciones sociales en el hospital de manera de garantizar, en mayor medida, hacia prácticas humanizadas de atención. De esta forma, se destacan las prácticas de atención y cuidado vinculadas a lo relacional, como la escucha, el diálogo y el acompañamiento, que asociamos a lo que Kleinman y van der Geest (2009) denominan como "actos éticos clínicos". Estos se evidenciaron principalmente en profesionales no médicos, es decir, enfermeros/as y trabajadores/as sociales, donde se pudo observar que muestran acciones de aproximación o acercamiento hacia los pacientes (Araújo et al., 2018). De esta forma, señalamos que el sector de enfermería reconoce dentro de sus prácticas el escuchar, compartir y expresar ciertas emociones por parte del usuario, lo cual significa que su trabajo no está restringido, solamente, a los procedimientos. En este sentido, establecen "diálogos" con los usuarios, siendo parte importante de su trabajo y de los procesos de atención y cuidado. Al respecto, identificamos la conformación de redes de producción de actos de salud en el hospital, las cuales implicaron el reconocimiento de rivalidades o corporativismos generados a través de las profesiones, su superación a través de discusiones orientadas a un acuerdo y la re-significación en las 
Moglia B. Procesos de atención y cuidado desde la perspectiva de los trabajadores: una metaetnografía en hospitales de Latinoamérica. [Tesis de maestría]. Maestría en Epidemiología, Gestión y Políticas de Salud. Universidad Nacional de Lanús. 2020.

relaciones entre los TraSa y, también, entre éstos y usuarios/as. A partir del corpus se destacan los servicios paliativos y crónicos por ser espacios donde se pudieron dar este modo de producción de salud. En estos ámbitos están implicados procesos de atención y cuidado donde se convive con la enfermedad/padecimiento de los/as usuarios/as, motivando otros abordajes posibles. Los TraSa buscan aliviar el dolor, sabiendo que no existe la posibilidad de cura del/la usuario/a a través del control de síntomas pero sobre todo dando valor a las necesidades de alivio ante malestares psicológicos y espirituales (Cardoso et al. 2013a). Pero para poder dar cuenta de ese tipo de malestar requieren, no solo, sensibilidad y capacitación, sino también, el reconocimiento y valorización en el contexto del hospital (Cardoso et al. 2013a). En aquellos servicios donde la atención está dirigida a usuarios/as con enfermedades crónicas o no curables, la conformación de equipos es el resultado de la puesta en juego, principalmente, de las llamadas "tecnologías leves" por Merhy (2002, 2016), orientándose hacia un sentido social del acto en salud en términos de construcción de acogimientos, vínculos y responsabilidades (Merhy, 2016) y permitiendo la flexibilización de la normatividad morfo funcional (Ayres, 2004). Tal como se evidenciaron en las narrativas de los TraSa, las tecnologías blandas proponen un enfoque alternativo y ético que implica un cambio sobre las formas de asistir y cuidar al otro.

Desde el enfoque de la ética del cuidado, Tronto (1993) explica que el cuidado implica la aceptación de una "carga" por parte de los sujetos involucrados, que a su vez, ponen en juego responsabilidades, compromisos, intereses y acciones. En sintonía, Kleinman y van der Geest (2009) plantean:

\begin{abstract}
El cuidado tiene que ver con el reconocimiento, la preocupación, la afirmación, la asistencia, la responsabilidad, la solidaridad y todos los actos emocionales y prácticos que permitan la vida (...), y cuando todo lo que hay que hacer es estar presente con el enfermo, compartiendo su sufrimiento simple y generalmente en silencio simplemente allí. El cuidado es una experiencia interpersonal; es preocupación y compasión, y, en un sentido más amplio, amor ${ }^{50}$ (Klenman \& van der Geest, 2009, p. 161)
\end{abstract}

Como desarrollamos en el Marco Conceptual de Referencia, dichos autores desarrollan el concepto de cuidado a partir de dos componentes: el emocional y el técnico/práctico, siendo este último el que tiende a dominar en el "cuidado médico" ya que,

\footnotetext{
50 Traducción libre de la autora: Caregiving is about acknowledgment, concern, affirmation, assistance, responsibility, solidarity, and all the emotional and practical acts that enable life (...) and when all there is to do is to be present with the sufferer, sharing his/her suffering by simply and usually silently just being there. Caregiving is an interpersonal experience; it is concern and compassion, and, in a larger sense, love (Klenman \& van der Geest, 2009, p. 161).
} 
Moglia B. Procesos de atención y cuidado desde la perspectiva de los trabajadores: una metaetnografía en hospitales de Latinoamérica. [Tesis de maestría]. Maestría en Epidemiología, Gestión y Políticas de Salud. Universidad Nacional de Lanús. 2020.

para el sector médico, lo significativo gira en torno a la determinación de un diagnostico y tratamiento de la enfermedad, dejando de lado la experiencia del usuario.

Sin embargo, nuestros resultados muestran que, en el hospital, se dan tramas de prácticas de atención y cuidado hegemónicas, ancladas en la racionalidad biomédica y con un sentido de cuidado más bien técnico/práctico y, alternativas, las cuales se orientan a una atención "integral" de los usuarios. Esto coincide con la investigación llevada a cabo por Comelles (2000) en un hospital de quemados, donde explica como en dicho espacio se da una convivencia de prácticas hegemónicas y alternativas. Estas últimas, en mayor medida, se vinculan con la red social del usuario y los saberes populares que ponen en cuestión aquellas situaciones de incertidumbre que la biomedicina no llega a cubrir y terminan impregnándose en las relaciones con los TraSa. De esta forma, el autor sostiene que ambas prácticas forman parte de la lógica institucional y de la cultura del hospital. En este sentido, las redes, que implican un acercamiento a otra forma de atención y cuidado, configuran prácticas alternativas orientadas a una vuelta al arte de cuidar (Kleinman \& van der Geest, 2009).

Nos preguntamos si las redes en los hospitales son resultado de una auto-reflexión crítica de las prácticas clínicas por parte de los TraSa, lo que implicaría no solo poner el experiencias médicas centradas en procedimientos entre signos de interrogación, sino también una forma de resistencia a todas aquellas prácticas que consideren moralmente inadecuadas (Kleinman \& van der Geest, 2009). Si este fuera el caso, estas redes nos permiten pensar que, los procesos de atención y cuidado, además de ser analizados desde una dimensión centrada en las prácticas, podemos considerar una dimensión centrada en las representaciones que tienen los TraSa sobre esas prácticas y, que las orienta. Nos estamos refiriendo a una dimensión ética/moral, siendo lo ético aquello que, como TraSa de un hospital "debe hacer", lo cual se encuentra estipulado y escrito y, lo moral, vinculado a lo que cada TraSa considera que "debe hacer" en relación a su experiencia personal, y a sus propios valores. En este sentido, se introduce otra dimensión para pensar los procesos de atención y cuidado, centrada en las representaciones de los TraSa que van a orientar el desarrollo o no de ciertas prácticas.

Teniendo en cuenta tanto la dimensión de las prácticas como aquella que refiere a las representaciones, las experiencias de los TraSa se comprenden a partir de procesos de diferenciación y marcación de un nosotros con respecto a otros, lo cual se vincula, tal como planteamos en la hipótesis, con la posición social que ocupa cada sujeto, su capital simbólico y material, así como sus intereses. En este sentido, sostenemos que se van construyendo identidades profesionales de cada TraSa, considerándolas como un punto de sutura entre dos 
Moglia B. Procesos de atención y cuidado desde la perspectiva de los trabajadores: una metaetnografía en hospitales de Latinoamérica. [Tesis de maestría]. Maestría en Epidemiología, Gestión y Políticas de Salud. Universidad Nacional de Lanús. 2020.

procesos: el de sujeción, el cual refiere a los discursos y las prácticas que constituyen las posiciones sociales de sujeto y el de subjetivación, es decir, los procesos de producción de subjetividades que llevan aceptar, modificar o rechazar dichos posicionamientos (Hall, 2003). De esta forma, se establecen distintas relaciones entre los TraSa, y de ellos con los/as usuarios/as, y es a través de ese juego entre formas específicas de poder que emergen. Por eso el autor sostiene que las identidades son "más un producto de la marcación de la diferencia y la exclusión que signo de una unidad idéntica y naturalmente constituida (...)” (p. 18).

Asimismo coincidimos con la investigación que realiza Cascón-Pereira (2013) sobre las construcción de identidades de médicos-gestores en dos hospitales de Cataluña donde concluye que las identidades profesionales no son estáticas sino emergentes y discontinuas, donde su construcción tiene que ver con el significado que los TraSa le atribuyen a determinado rol, siendo esos roles los que conducen a ciertas actitudes. En este sentido, la autora busca romper con la construcción de estereotipos proponiendo que se pone en juego un proceso mucho más complejo vinculado con los sentidos que los sujetos le otorgan a determinado rol dentro del hospital. Entonces, los modos de atención y cuidado van a configurarse en torno a identidades construidas a través de relaciones que diferencian y también, por medio de sentidos atribuidos al rol que asume cada TraSa.

A partir de este análisis de las prácticas de atención y cuidado observamos cómo se configuran los enfrentamientos, alianzas o negociaciones, dando a entender que la producción de salud no se trata sólo del cumplimiento de normas, procedimientos y estándares, sino que implican procesos relacionales con los/as usuarios/as y con sus compañeros/as, así como también representaciones en torno a lo que se "debe hacer". En este sentido, podemos pensar al hospital como un espacio de cura, formación médica y también de cuidado, entre ruidos, acciones medicamentosas y diálogos, que van a dar lugar a diversos procesos de atención y cuidado.

\section{2. 3. La biomedicina no alcanza.}

Siguiendo con el análisis, esta tercer línea argumental se vincula con la racionalidad biomédica (Camargo, 2005) que se da en los hospitales, y donde se identifica cierta incomodidad en relación a dicho saber ante nuevos problemas o viejos problemas que empiezan a visibilizarse. Lo que nosotros llamamos incomodidad puede ser pensado también, como lo que Bonet (1999) denominó "tensión estructurante de la práctica biomédica" para referirse a la relación que se da entre el saber biomédico/dimensión científica-racional y el 
Moglia B. Procesos de atención y cuidado desde la perspectiva de los trabajadores: una metaetnografía en hospitales de Latinoamérica. [Tesis de maestría]. Maestría en Epidemiología, Gestión y Políticas de Salud. Universidad Nacional de Lanús. 2020.

sentir/dimensión humano-pasional, es decir, "entre las exigencias del modelo biomédico con su énfasis en el saber y en las prácticas guiadas por algoritmos y protocolos por un lado y la experiencia individual, la dimensión de lo vivido, del sentir por el otro...." (p.133).

Considerando la biomedicina como racionalidad dominante en los hospitales, nos interesa distinguir aquellos procesos de conformación subjetiva, los cuales involucran factores socioculturales que orientan los modos de pensar, sentir y actuar y, además, tienen que ver con la apropiación y reflexión de dichos modos en relación a las particularidades contextuales de cada sujeto (Farreta, 2017). De esta forma, Ortner (2006) señala que existen contracorrientes subjetivas que coexisten con las formaciones culturales hegemónicas, las cuales constituyen los fundamentos para la crítica y el cuestionamiento del mundo. En este sentido, los TraSa pueden encarnar plenamente la cultura dominante, lo cual se observa en la atención que se da en los hospitales, pero también refiere que puede no darse así (Ortner, 2006). La autora explicita que esto último no implica que los sujetos queden "fuera de la cultura", ya que esto no es posible, sino que implica pensar en términos de “... una conciencia plenamente cultural..." (p. 148), multidimensional y reflexiva. En este sentido, incorporamos el concepto de la medicina como forma simbólica (Good, 2003), es decir, “....como un medio de experiencia, un modo de compromiso con el mundo. En un medio dialógico, de confrontación, de interpretación, de conflicto y, a veces, de transformación" (p. 166). De esta forma, entendemos que los TraSa experimentan distintas incomodidades a partir del saber biomédico, que actúan como limitantes en la atención de determinados problemas y que implican cuestionamiento y críticas a dicha visión del mundo. A continuación retomamos los aspectos recuperados del corpus sobre la racionalidad biomédica que intervienen en los procesos de atención y cuidado con el propósito de visibilizar que, según los TraSa, la biomedicina no alcanza.

Como ya explicamos, los procesos de atención en los hospitales se asocian con (1) el biologicismo como principal referente teórico-práctico; (2) la visión mecánica del/la usuario/a sin subjetividad, sin intenciones y sin deseos y (3) las acciones médicas respaldadas por una única "verdad". Estos aspectos son semejantes con las descripciones realizadas en la investigación de García, Recoder y Margulies (2017) sobre la atención en un centro obstétrico, donde observan que el ingreso al "mundo medico-institucional" implica la adopción de términos técnicos y la pérdida de privacidad del cuerpo para entregarse a las intervenciones medicas, instaurando un nuevo orden de verdad. En nuestros hallazgos, este 
Moglia B. Procesos de atención y cuidado desde la perspectiva de los trabajadores: una metaetnografía en hospitales de Latinoamérica. [Tesis de maestría]. Maestría en Epidemiología, Gestión y Políticas de Salud. Universidad Nacional de Lanús. 2020.

nuevo orden lleva a legitimar determinados accionares de acuerdo a la posición jerárquica ${ }^{51}$ que ocupen, provocando conflictos entre profesionales médicos y no médicos, principalmente con aquellos que no son reconocidos como parte del equipo, como los trabajadores sociales o psicólogos. Asimismo, García, Recoder y Margulies (2017), recuperando la investigación de Comelles (2000), hacen hincapié, en cómo el proceso de institucionalización biomédica implica la negación de la presencia social y cultural del paciente. Esta negación fue descripta por las autoras en torno a la limitación de las informaciones y las restricciones espaciales generadas en la atención, construyendo relaciones que habilitan una serie de conflictos que no se resuelven y que, según Comelles (2000), se explican a raíz de la dificultad de aceptar la presencia social y cultural del otro, siendo esto un componente habitual en la cotidianeidad del servicio. Asimismo, García, Recoder y Margulies (2017) señalan la presencia de estereotipos en la caracterización y valorización sobre los pacientes, vinculados a una supuesta ignorancia, incompetencia y peligrosidad, que servirían para potenciar las distancias con los TraSa.

Nos parece que esta forma de vincularse entre los TraSa y los usuarios guarda relación con las representaciones generadas en la mayoría de los TraSa acerca del paciente, esto es como carentes de habilidades de comprensión y, en alguno casos, bajo la etiqueta de "no colaborativo" al no cumplir con las indicaciones de la autoridad medica (Aguiar, d'Oliveira, \& Schraiber, 2013). Además, como adelantamos previamente, se observa la dominancia de prácticas prescriptivas, donde el paciente requiere autorización del profesional para llevar a cabo el cuidado en contexto de hospitalización, lo que evidencia al hospital como el espacio donde el saber biomédico busca regular y disciplinar a los usuarios, convirtiéndolos en pacientes. Estas características coinciden con aquellas señaladas por Menéndez al describir el modelo medico hegemónico (MMH) tales como el carácter biologicista, la relación asimétrica y subordinada entre médico-paciente, la exclusión del saber del paciente, la profesionalización formalizada y la identificación ideológica con la racionalidad científica (Menéndez, 1978, 1983, 1990).

No obstante, Menéndez (1998, 2015), además de pensar a la biomedicina como modelo, la describió y analizó como una forma de atención y un saber cambiante y modificable. La biomedicina, como todo sistema médico, forma parte de un sistema sociocultural y, como tal, configura prácticas tales como hospitalizar, diagnosticar y tratar, así

\footnotetext{
${ }^{51}$ Esto se vincula con lo señalado en el apartado 6.2.2. sobre la propuesta explicativa de Friedson (1979) en torno a la división del trabajo.
} 
Moglia B. Procesos de atención y cuidado desde la perspectiva de los trabajadores: una metaetnografía en hospitales de Latinoamérica. [Tesis de maestría]. Maestría en Epidemiología, Gestión y Políticas de Salud. Universidad Nacional de Lanús. 2020.

como representaciones en torno a la salud, la enfermedad, la atención y el cuidado. La biomedicina se expresa de manera diferente y cambiante a lo largo del tiempo, no es homogénea ni inmutable, lo cual lleva a generar avances vinculados a la eficacia medica pero también se debe pensar en limitaciones. Estas son reconocidas por algunos de los TraSa, a pesar de la dominancia de la biomedicina en los espacios del hospital, en torno, principalmente, a las dificultades para explicar y de abordar ciertos padecimientos.

Con respecto a estas ideas y en relación al corpus, encontramos que dichos TraSa tienen la necesidad de formación en determinados problemas sociales que se observan de forma recurrente en los servicios de atención, reclamando el apoyo de las autoridades correspondientes, que por medio de sus cargos jerárquicos darían legitimidad a las intervenciones que los TraSa buscan llevar a cabo. Los TraSa identificaron como problemas de difícil abordaje desde el paradigma biomédico a la violencia de género o la violencia física hacia ancianos (Acosta et al., 2018; Lima et al., 2010), destacando que, a pesar de los años de formación no han aprendido la forma de proceder ante estos (Acosta et al., 2018). Además, tampoco hay protocolos clínicos específicos para atender dichas problemáticas ni una estructura física adecuada para su atención en los hospitales, obstaculizando aun más otro tipo de abordaje por fuera de la biomedicina. Estas exigencias son las mismas que relata Valderrama (2013) en su investigación etnográfica sobre la conformación de servicios paliativos tomando a los profesionales de medicina y enfermería como punto de partida para reflexionar en torno a la práctica asistencial. Dichos actores consideran que esta última se había vuelto poco operativa para una demanda cuya curación, en muchos casos, no era posible y requerían de una transformación en la forma de atender, donde la atención debería estar centrada en la persona enferma y su familia (Valderrama, 2013). En este sentido, entendemos que los procesos de atención y cuidado se dan de manera dinámica en los hospitales, donde la racionalidad biomédica no alcanza y los TraSa entran en conflicto.

Para entender la dinámica en que se encuentran los TraSa se retoma el concepto de drama social de Turner (1974), quién sostiene que es a partir de las situaciones de conflicto entre grupos de personas o sujetos, que comparten valores e intereses comunes, donde irrumpe una tensión, generándose el "drama". Turner (1974) detalla que surge a partir de la oposición de intereses y actitudes, constituyéndose, en algunos casos, lo que llamó la forma procesual del drama. Asimismo, resulta interesante el concepto ya que nos permite mostrar aquellos aspectos sociales y relacionales que suelen ser invisibilizados cotidianamente. En este sentido, situamos a la racionalidad biomédica como central en la construcción de la 
Moglia B. Procesos de atención y cuidado desde la perspectiva de los trabajadores: una metaetnografía en hospitales de Latinoamérica. [Tesis de maestría]. Maestría en Epidemiología, Gestión y Políticas de Salud. Universidad Nacional de Lanús. 2020.

estructura de los servicios de salud, la que ordena y organiza, en gran parte, el funcionamiento del hospital. La racionalidad biomédica termina constituyendo ese marco normativo donde la acción queda subordinada. Turner (1974) plantea cuatro fases constituyentes: la primera refiere a la brecha generada a nivel de las relaciones sociales cuando se rompe alguna de las normas que las regulan. El autor habla de una burla como símbolo de disidencia, donde el sujeto actúa, consciente o inconscientemente, como representante de otras partes y, por lo tanto, no se ve como un actor solitario. El segundo momento es la crisis, el cual tiene que ver con la expansión de la brecha en las interacciones sociales y, es seguida, por una fase de acción reparadora para evitar que se siga expandiendo. Estos son los mecanismos de acción y reparación llevados a cabo por sujetos que representan la estructura del sistema social alterado, ponen en evidencia la acción simbólica para reparar el drama social, ya sea volviendo al orden anterior o encontrando un equilibrio entre los grupos que se oponen (Turner, 1974). La última fase es la reintegración del grupo social o su división irreparable de dicho conjunto.

En este sentido, pensamos las incomodidades que experimentan algunos TraSa de los hospitales como tensión y conflicto a la estructura que ha ido construyendo la racionalidad biomédica debido a que identificamos momentos en que las acciones guiadas por dicho enfoque no alcanzan para lograr que el usuario mejore recupere su bienestar. Aparece la brecha en las relaciones sociales, que termina configurando una crisis dada por la confrontación a una racionalidad con normas que parecen ser obsoletas. Ahora bien, ante esta alteración social se dan mecanismos de acción y reparación, tales como las represalias generadas por otros TraSa que encarnan y representan a la estructura. Estos pueden funcionar, llevando a la reintegración de esos sujetos al grupo social o, provocar una división en este último, lo cual se refleja en nueva normas sociales, tales como las que se proponen desde la ética del cuidado.

Por último, es importante destacar que estas incomodidades ponen en discusión una estructura de normas vinculadas a determinados símbolos que a su vez incitan a la acción social, ya sea en términos de reproducción de un orden social a través de forma rituales que serian interesantes indagar ya que "inducen a desear lo que se debe hacer" (Traducción de Turner, 1974, p. 67) o en términos de ruptura de ese conjunto de símbolos que implican cambios en las relaciones sociales y en los sistemas morales que guían las prácticas medicas. 
Moglia B. Procesos de atención y cuidado desde la perspectiva de los trabajadores: una metaetnografía en hospitales de Latinoamérica. [Tesis de maestría]. Maestría en Epidemiología, Gestión y Políticas de Salud. Universidad Nacional de Lanús. 2020.

\section{2. 4. De estar "satisfecho" a estar "frustrado" y sentirse "discriminado"}

En este último apartado colocamos el foco en las emociones, que se mostraron tanto en algunas narrativas en torno a la satisfacción generada por el trabajo y el "sentirse útil" así como en situaciones de insatisfacción, sufrimiento, discriminación y dolor, siendo estas últimas las más frecuentes. Habiendo definido las emociones como aquellas expresiones de lo sentido con respecto a determinada situación, construidas social y culturalmente aunque que se expresan a nivel individual, en primer lugar, presentamos las prácticas y discursos a las que se asocian; en segundo lugar, identificamos quién las expresa y hacia quien se dirige y, por último, describimos los modos de relacionamiento específicos que generan (Spivak \& L'hoste, 2019). Este análisis permite observar cómo las emociones, al colocar en escena el contexto de la interacción social, pueden ser vistas como una vía de acceso al malestar/bienestar en el trabajo y a la salud de los TraSa. Detenemos la mirada en aquellas situaciones de malestar, donde aparece la insatisfacción, el sufrimiento, el dolor y la discriminación en el hospital ya que permiten describir aspectos que problematizan los procesos de trabajo en el hospital y, además, refieren a la mayoría de las expresiones.

Entonces, en primer lugar, aparecen prácticas y discursos vinculados a la desvalorización por parte de los médicos/as, principalmente, hacia otros TraSa, reconociendo la racionalidad biomédica como estructural y central para la organización de los servicios y otras racionalidades que son referidas como "secundarias" para la atención y cuidado. En ese sentido, distinguimos el uso de represalias discursivas vinculadas con el acercamiento hacia otras alternativas de atención y cuidado por fuera del modelo biomédico, el cual se produce ante la recurrencia de problemas de difícil abordaje que requiere la complementación con otras disciplinas no médicas. Esto lleva a formas de relacionarse basadas, según los TraSa en la discriminación entre los profesionales médicos y los profesionales no-médicos; entre los que pertenecen a la planta estable del hospital y los que no; entre mujeres y varones (LunaGarcía et al., 2015), que termina configurando un "clima de hostilidad" en la cotidianeidad del servicio. De esta forma, identificamos que la angustia, la frustración y la impotencia describen las emociones en torno a las relaciones entre los TraSa, principalmente entre aquellos que representan y defienden prácticas de atención diferentes o alternativas a los modelos dominantes de atención biomédica.

Otras situaciones donde se pudo evidenciar malestares son aquellas que emergen de las relaciones entre los TraSa y los/as usuarios/as. Éstas se dieron, en su mayoría, en términos de distanciamiento y se visualizó que, ante circunstancias de sufrimiento de un/a usuario/a, los 
Moglia B. Procesos de atención y cuidado desde la perspectiva de los trabajadores: una metaetnografía en hospitales de Latinoamérica. [Tesis de maestría]. Maestría en Epidemiología, Gestión y Políticas de Salud. Universidad Nacional de Lanús. 2020.

TraSa se enfocaban en llevar a cabo sus prácticas de diagnosticar, tratar, hospitalizar y comunicar (dependiendo de los casos) sin implicar a la persona atendida. Esto se da en términos de una "callosidad profesional" o "armadura", que se constituye como armazón para hacerle frente y lograr la pretendida objetividad que la ciencia médica demanda, confiriendo un sentido de utilidad a ese TraSa. Esto coincide en la investigación de García, Recoder y Margulies (2017) cuando utilizan el concepto de "indiferencia afectiva" para describir al servicio de obstetricia como un espacio cerrado y protegido para los profesionales, de modo de no involucrarse con la emocionalidad y sentimientos de los acompañantes de las usuarias. Asimismo dichas relaciones sociales aparecen, en el corpus, asociadas ciertas "conductas necesarias del trabajo", avaladas por la autoridad médica. Algunas de estas son percibidas e identificadas por los TraSa, tal como las amenazas o elevar la voz, nombradas como violencias; mientras otras son banalizadas restándole importancia, indicando que no son intencionadas (Aguiar et al., 2013).

Por último, señalamos a los escenarios de trabajo vinculados a las condiciones inadecuadas en que tiene lugar, principalmente a los recursos materiales y que lleva a los TraSa a expresar miedos y ansiedades ante accidentes físicos. En el mismo sentido, dichos sujetos expresan la impotencia y molestia asociadas a no poder dar la respuesta que desean, debido a las limitaciones de recursos o equipos materiales. En cuanto a estas situaciones, las expresiones son dirigidas como reclamos a la autoridad o al equipo de gestión y describe relaciones conflictivas donde los TraSa no se sienten reconocidos.

Ahora bien, estas situaciones que involucran la angustia, la frustración, la impotencia, la discriminación, el distanciamiento, los miedos, entre otras, ponen en evidencia que los modos de trabajar y de intervenir en los procesos de atención y cuidado están ligados a una dimensión emocional que los TraSa expresan en torno a las singularidades de las circunstancias. Asimismo, a partir de las emociones se puede observar cómo afecta la salud los TraSa, desde su perspectiva.

Entonces, los procesos de atención y de cuidado que llevan a cabo los TraSa, implican la puesta en juego de una dimensión emocional que entendemos como significativa debido al tipo de trabajo que se realiza, el lidiar con enfermedades, padecimientos y sufrimientos del otro tiene un efecto. Este puede ser contenido a través de distintas estrategias pero también puede no ser manejado y, de esta manera afectar la salud de los TraSa. Por ejemplo, no es lo mismo que la atención se dé en un escenario de trabajo donde se cuente con recursos materiales adecuados y con un equipo de trabajo abierto al diálogo, que en otro donde dichas 
Moglia B. Procesos de atención y cuidado desde la perspectiva de los trabajadores: una metaetnografía en hospitales de Latinoamérica. [Tesis de maestría]. Maestría en Epidemiología, Gestión y Políticas de Salud. Universidad Nacional de Lanús. 2020.

condiciones no se dan o en un escenario donde no haya recursos materiales suficientes pero si un equipo especifico que contenga a los TraSa o estrategias de trabajo propias de un servicio que permitan dar lugar a discutir dichos obstáculos. Claramente estamos frente a una gran diversidad de escenarios que hay que estar atentos, así como también en las relaciones entre TraSa y éstos con los/as usuarios/as para indagar en los procesos de salud-enfermedad de los TraSa. Por eso consideramos los abordajes socio/etno-epidemiológicos (Almeida-Filho, 1992, 2000; Menéndez, 2008) ya que, no solo hacen hincapié en factores aparentes, tales como recursos materiales, elementos de seguridad o conocimiento de los TraSa sino también en aspectos vinculados a sentidos y significados acerca del trabajo y la dimensión emocional puede ser una vía de acceso a eso.

\section{3. A modo de cierre}

Este último apartado está orientado a recapitular las interpretaciones realizadas sobre las experiencias de los TraSa con respecto a los procesos de atención y cuidado en los hospitales. De esta forma se elaboró el siguiente esquema (Figura 3): 
Moglia B. Procesos de atención y cuidado desde la perspectiva de los trabajadores: una meta-etnografía en hospitales de Latinoamérica. [Tesis de maestría]. Maestría en Epidemiología, Gestión y Políticas de Salud. Universidad Nacional de Lanús. 2020.

Figura 3. Esquema de síntesis

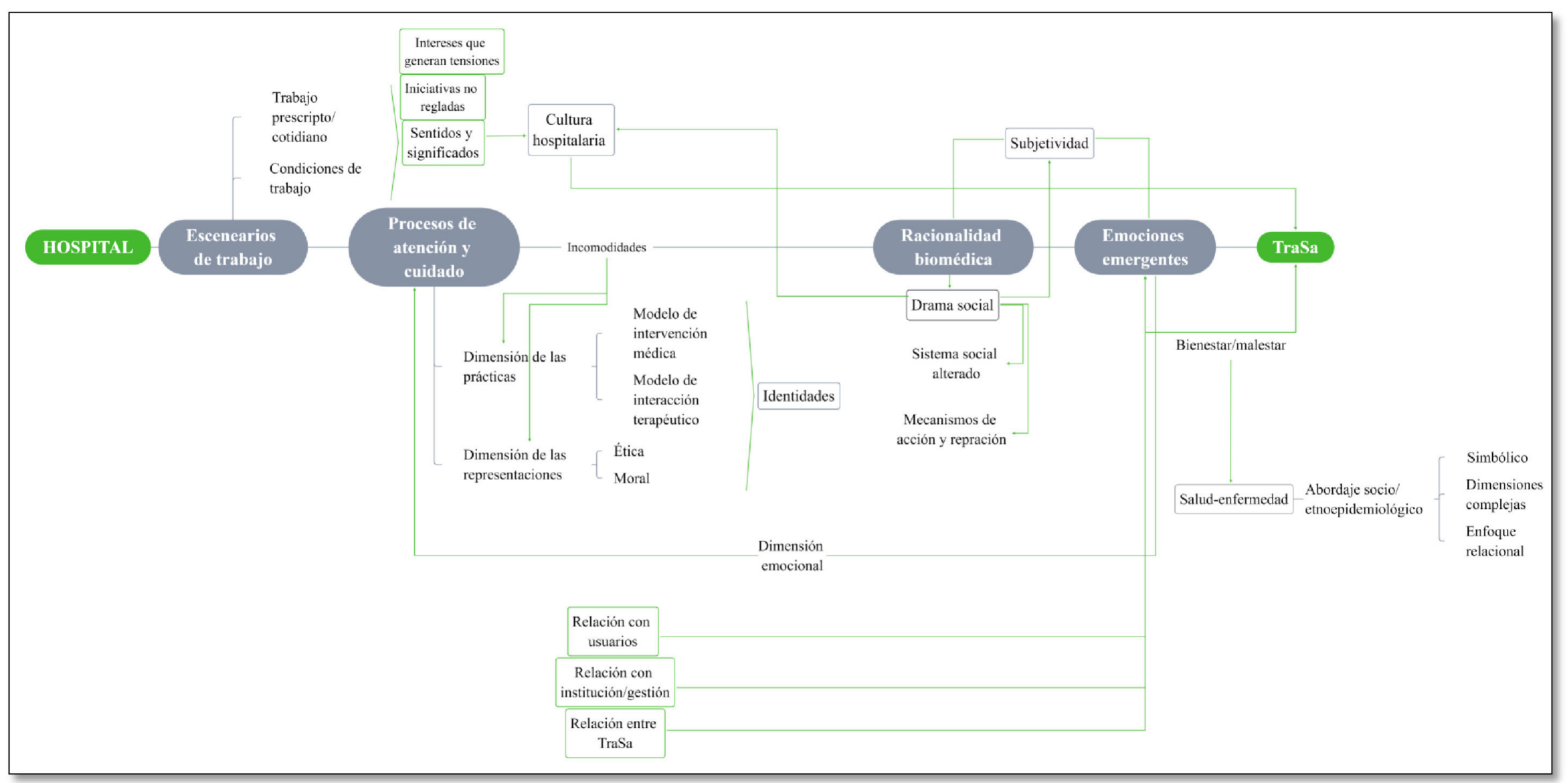

Fuente: elaboración propia a través del programa Xmind (Versión de prueba) 
Moglia B. Procesos de atención y cuidado desde la perspectiva de los trabajadores: una metaetnografía en hospitales de Latinoamérica. [Tesis de maestría]. Maestría en Epidemiología, Gestión y Políticas de Salud. Universidad Nacional de Lanús. 2020.

Para leer el esquema anterior se debe partir del espacio Hospital y de los actores, TraSa. Estos dos delimitan una serie de procesos que vamos a desarrollar de manera sintética en este cierre, y también, pueden ser vistos como representantes de dos niveles de analisis. El institucional del hospital, como el nivel macro-contextual y el singular de los TraSa, como el nivel micro-subjetivo, ambos en articulación e interacción, lo cual se observa en los procesos que interpretamos a partir de las cuatro grandes categorías de analisis delimitadas.

Si comenzamos el análisis desde el espacio más singular, el de las emociones, observamos que si bien fueron diversas, la mayoría refirieron a situaciones de malestar las cuales, conducen a la reflexión sobre la salud-enfermedad de los TraSa, dejando abierta la posibilidad de una mirada etno o socio-epidemiológica para su abordaje. Esto implica una evaluación que vaya mas allá de normas de seguridad o encuestas en las que se basan la mayoría de estos estudios, para abordar lo simbólico y aspectos que tienen que ver con formas de vincularse con un otro (ya sea otro TraSa o usuario/a). Tales relaciones, además, forman parte de los procesos de atencion y cuidado -al mismo tiempo que los modelan- delimitando una dimensión emocional que invita a pensar en aquellas estrategias de trabajo vinculadas con lidiar con el sufrimiento y la enfermedad.

Otra dimensión identificada para pensar los procesos de atención y cuidado fue, por un lado, la de las prácticas desarrolladas por los TraSa que agrupamos en los modelos propuesto por Freidson (1978), vinculadas a la intervención médica y al modelo de interacción terapéutica. Por otro lado, observamos una dimensión de las representaciones, la cual tiene que ver con lo que los TraSa consideran que deben hacer, desde la ética, generalmente ligada a un sentido ideal de la atención y cuidado y la moral, vinculada la experiencicas personal de cada TraSa y sus propios valores. Estas dimensiones separadas para el análisis deben ser reunidas para comprender la dinámica hospitalaria. Resulta interesante abordarlas desde el concepto de identidades porque pueden ser adscriptas a determinadas formas de ser-hacer cotidianamente en la institución del hospital, sin perder la diversidad que las caracteriza.

En este sentido, los procesos de atención y cuidado varían permanentemente, lo cual implica necesariamente conflictos, disputas e incomodidades. En este caso, hicimos referencia a las limitaciones de la biomedicina que fueron señaladas por los TraSa y que interpretamos en términos de drama social (Turner, 1974). Estas transformaciones del sistema social del hospital implican la puesta en marcha de mencanismos de acción y reparación por parte de actores que encarnan la racionalidad biomedica. En algunos casos, esto funciona, y en otros, puede provocar fracturas abriendo espacio a otras racionalidades, que incorporan al usuario 
Moglia B. Procesos de atención y cuidado desde la perspectiva de los trabajadores: una metaetnografía en hospitales de Latinoamérica. [Tesis de maestría]. Maestría en Epidemiología, Gestión y Políticas de Salud. Universidad Nacional de Lanús. 2020.

dentro de la atención y el cuidado, a las emociones y a otros enfoques de trabajo. Estos cambios atraviesan a los sujetos y a su relacion con el hospital, modificando subjetividades.

Ahora bien, las subjetividades se configuran en articulación con una cultura hospitalaria, que llevan a diferentes TraSa, a compartir algo común, por participar de la misma institución, haber compartido trayectorias históricas e institucionales, participar del mismo momento socio-histórico, entre otros aspectos. Este conjunto de sentidos y significados compartidos en torno a los escenarios de trabajo, organizan la atención y el cuidado, asi como también lo hacen las tensiones generadas a partir de intereses contrapuestos y las iniciativas no regladas producto de la distancia entre el trabajo prescipto y el trabajo cotidiano. Particularme, los procesos de atencion y cuidado terminan siendo configurados a partir de la distancia entre lo que deben hacer (ética), lo que desean hacer (moral) y lo que pueden hacer los TraSa, siendo dicho espacio donde se puede ver la creatividad y agencia de los TraSa (Sy et al., 2020). Todo esto da lugar a escenarios de trabajo que se superponen con una estructura formal y normada, configurando un espacio de formación médica, de atención de enfermedades y de cuidado.

De esta manera, dicho esquema sintetiza una serie de características y procesos comunes al corpus con respecto a la atención y el cuidado y llevados a cabo en los hospitales de América Latina. Tomando como referencia dichos aspectos hemos construido un modelo de atención en hospitales, basado en las experiencias de los TraSa, que como tal, varía de acuerdo a los contextos locales en los cuales se planteen. Si bien, articula con el MMH propuesto por Menéndez $(1978 ; 1983 ; 1990)$, constituye un modelo situado en Latinoamérica que, intenta dar cuenta de la lógica de atención en las instituciones hospitalarias. Cabe destacar, que tal como lo señaló Menéndez (2020) un modelo es un instrumento metodológico que permite construir abstracciones de un alto nivel, las cuales deben ser desarrolladas en articulación con contextos socio-históricos específicos para lograr su entendimiento procesual.

En este modelo, que llamaremos Médico Hospitalar, se caracteriza por:

a) la presencia de normas de trabajo explícitas, generalmente provenientes del plano formal a partir de la relación del TraSa con la institución del hospital e implícitas vinculadas a arreglos, consensos y disputas entre los TraSa, las cuales organizan la atención;

b) condiciones de trabajo que se caracterizan por una deficiente infraestructura, escasez de insumos y de profesionales y formas de contratación flexibles; 
Moglia B. Procesos de atención y cuidado desde la perspectiva de los trabajadores: una metaetnografía en hospitales de Latinoamérica. [Tesis de maestría]. Maestría en Epidemiología, Gestión y Políticas de Salud. Universidad Nacional de Lanús. 2020.

c) una dinámica de trabajo continuo donde siempre hay tareas pendientes, que varían de acuerdo con el rol que asume cada TraSa;

d) el desarrollo de prácticas de atención y cuidado heterogéneas, donde se encuentran aquellas específicas de cada profesión y otras prácticas articuladas entre las profesiones;

e) el desarrollo de procesos reflexivos que cuestionan la lógica y práctica médica hegemónica

f) la presencia de una ética del cuidado que permea el trabajo cotidiano;

g) la inclusión en el proceso de atención y cuidado de la posible "convivencia" con la enfermedad-padecimiento, no solo una orientación a la cura;

h) un poder mayor de decisión que recae sobre el sector biomédico, en relación a otras profesiones;

i) emociones que emergen como constitutivas de los procesos de atención y cuidado; al tiempo que se desarrollan mecanismos de distanciamiento respecto del involucramiento emocional, buscando racionalizar y objetivar el proceso de atención;

j) la configuración de identidades profesionales vinculadas a las relaciones de diferenciación entre TraSa y a los sentidos que se le dan a determinado rol.

Estas características, que hacen al modelo de atención en hospitales, resultan interesantes para indagar en aquellas dimensiones que atraviesan los procesos de atención y cuidado desde la perspectiva de los TraSa, teniendo en cuenta que sus expresiones van a variar de acuerdo a los contextos particulares. En este sentido, se estructuran, por un lado, aquellos aspectos asociados al proceso de trabajo, en términos generales, en el hospital (a-c). Estas tres primeras características tienen relación con la organización del trabajo y las rutinas de atención, donde se pudo identifiar aquellos sentidos y significados que se apartan del orden impuesto desde la estructura dada, verticial y normativa de los hospitales, dando lugar a un cojunto de escenarios de trabajo diversos. En estos escenarios es donde tienen lugar la producción, reproducción y los cambios en las culturas hospitalarias y de las subjetividades de los TraSa.

Por otro lado, se sistematizan las particularidades de los procesos de atención y cuidado (d-j), las cuales muestran la trama compleja de las relaciones entre TraSa. Estas permiten profundizar en las prácticas hegemónicas y alternativas de atención y los procesos simbólicos, identitarios, emocionales y reflexivos que interpelan a los sujetos y de este modo, a los propios procesos de atención y cuidado. 
Moglia B. Procesos de atención y cuidado desde la perspectiva de los trabajadores: una metaetnografía en hospitales de Latinoamérica. [Tesis de maestría]. Maestría en Epidemiología, Gestión y Políticas de Salud. Universidad Nacional de Lanús. 2020.

\section{REFLEXIONES FINALES}

La propuesta meta-etnográfica que hemos desarrollado, en sus dos momentos de síntesis (comparativa e interpretativa) permitió describir y analizar las experiencias de los TraSa respecto a los procesos de atención y cuidado en hospitales de Latinoamérica.

A partir de la síntesis comparativa identificamos categorías que utilizan los propios TraSa y otras que provienen de los análisis desarrollados por diversos investigadores, que nos permitieron recuperar distintas dimensiones comunes o convergentes para comprender los procesos de atención y cuidado en los hospitales. De esta forma, indagamos en los sentidos y significados que le atribuyen a los escenarios de trabajo, así como también describimos las prácticas desarrolladas en dichos contextos, los saberes y racionalidades puestos en juego, los vínculos construidos y las emociones emergentes.

En el segundo momento de síntesis interpretativa, articulamos distintos conceptos teóricos, algunos ya presentados en nuestro Marco Conceptual de Referencia y otros que fueron incorporados en esa instancia, para dar lugar a una nueva interpretación en torno al problema de investigación. De esta forma, elaboramos cuatro argumentos: el primero vinculado a explicar la relación de los TraSa con el hospital, cómo se conforma, culturalmente, su subjetividad a partir de sentidos y significados expresados que se interrelacionan y configuran una cultura hospitalaria particular. En otras palabras, se ve el hospital como un espacio donde se dan procesos simbólicos inmersos en el flujo social que pueden encauzar en muchas direcciones. El segundo argumento expusimos cómo los TraSa llevan a cabo no solo prácticas técnicas sino también relacionales para atender y cuidar. Lo que observamos fue la dinámica que adquieren en la práctica médica y como pueden configurarse identidades médicas particulares. El tercer argumento plantea las limitaciones de la racionalidad biomédica y el proceso de ruptura que se da en algunos TraSa al reflexionar sobre su práctica y, por último, explicamos la relevancia de la dimensión emocional para pensar el proceso de atención y cuidado y también, para abordar las distintas afecciones que el trabajo en salud puede ocasionar en los TraSa, permitiendo introducir aspectos subjetivos y simbólicos.

Dichas líneas argumentales nos llevan a respaldar la hipótesis planteada al inicio de la tesis, en la cual se afirmó que los procesos de atención y cuidado de la salud en el ámbito del hospital, involucran no solo un saber técnico especializado, sino también una red de relaciones establecidas en el ámbito institucional, que van a delimitar y modelizar los vínculos y las características que adquiera la atención. Además, se señaló y explicó la importancia de 
Moglia B. Procesos de atención y cuidado desde la perspectiva de los trabajadores: una metaetnografía en hospitales de Latinoamérica. [Tesis de maestría]. Maestría en Epidemiología, Gestión y Políticas de Salud. Universidad Nacional de Lanús. 2020.

incluir los intereses, asociados a la posición social del TraSa, para pensar la organización que adquiere la atención.

Continuando con lo establecido en la hipótesis, se puede ver que los procesos de atención y cuidado superan la racionalidad biomédica, y ponen en juego, en simultáneo, normas institucionales y subjetividades en el espacio de trabajo. Particularmente, dimos cuenta de las limitaciones de la biomedicina y de la necesidad, por parte de los TraSa, de pensar otras racionalidades o epistemologías que estén atentas a las demandas de salud hoy en el contexto del hospital. En este sentido, aquellos TraSa formados por fuera de la ciencia biomédica (psicología, trabajo social), en su mayoría, fueron introduciendo otros conceptos, otras formas de atender, otras miradas acerca de la salud-enfermedad-atención que pusieron en disputa la racionalidad biomédica. No en términos de negación de los aportes de esta última, sino que se fueron centrando en la discusión y ampliación de sus prácticas y representaciones en torno a los procesos de atención y cuidado. Esto puso en evidencia las múltiples racionalidades que se desenvuelven en el trabajo en los hospitales no solo de los TraSa sino también de los usuarios. Asimismo, resulta interesante destacar que estas racionalidades pueden ser recuperadas partir de aquellos TraSa que se ven incomodados por problemas que caen afuera de las soluciones planteadas por la racionalidad biomédica y, por eso, ponen en marcha nuevas estrategias de atención, considerando otras voces, tanto de profesionales como de usuarios.

Ahora bien, la racionalidad biomédica u otras tienen visibilidad en las investigaciones, no tanto las emociones que los TraSa expresan. Las emociones constituyeron una dimensión emergente del corpus que nos permitió pensar por qué dicho aspecto del proceso de atención y cuidado, que desde nuestro punto de vista debería ser relevante considerando que los hospitales son espacios de padecimientos, sufrimientos, muertes, curas y salvaciones, no resultaba de interés en los autores y aparecía de forma secundaria. Una explicación puede estar relacionada con la visión que se tiene del hospital, esto es como un espacio donde se busca explicaciones racionales y objetivas desde la ciencia médica, donde se va gestionando una supuesta separación con lo emocional, ya que dicha dimensión no estaría legitimada en los discursos y prácticas biomédicas. Sin embargo, las emociones emergen a través de los TraSa, y considerarlas mostró su relevancia para profundizar en los procesos de saludenfermedad que atraviesan los TraSa en el servicio. Asimismo, podemos intuir que esta visión del hospital y la invisiblización de la dimensión emocional se vinculan a lógicas patriarcales dominantes en las sociedades latinoamericanas. Entendemos que existen estereotipos que se 
Moglia B. Procesos de atención y cuidado desde la perspectiva de los trabajadores: una metaetnografía en hospitales de Latinoamérica. [Tesis de maestría]. Maestría en Epidemiología, Gestión y Políticas de Salud. Universidad Nacional de Lanús. 2020.

han configurado en los géneros y, en simultáneo, ha llevado a la naturalización de ciertas características, por ejemplo aquellas que atribuyen a las mujeres como sujetos débiles, emocionales y sensibles, en contraposición con la fortaleza, racionalidad y objetividad científica. Sería interesante y necesario indagar sobre este punto con una mayor rigurosidad ya que, a pesar de que existe un proceso fuerte de feminización del conjunto de TraSa (PNUD, 2018) en salud, se sigue reproduciendo lógicas de atención y cuidado ancladas en el patriarcado. De esta manera, señalamos que, al momento de pensar en procesos de atención y cuidado, se pone en juego racionalidades que parecen dominar las emociones, de forma que estas últimas quedan por fuera del proceso, como si no fueran parte del trabajo médico. Sin embargo, observamos que las emociones atraviesan y constituyen parte del hospital, y los TraSa no pueden prescindir de éstas porque forman parte de su construcción subjetiva como TraSa en hospitales, y más allá de éstos. En este sentido, sostenemos que racionalidad y emoción son características estructurales de los procesos de atención y que, de esa manera, se comprende las particularidades y características de los procesos de atención. Como se desarrolló al inicio de la tesis, nos alejamos de aquellas visiones que plantean a los hospitales como clones idénticos y, en cambio, tal como proponen van der Geest y Flinker (2004), sostenemos que se configuran una variedad de culturas hospitalarias, las cuales reflejan y refuerzan los procesos sociales y culturales dominantes de una sociedad dada.

Finalmente, tal como se planteó en la parte final de la hipótesis, se hallaron, a pesar de la diversidad de procesos que han atravesado las políticas sanitarias de cada país latinoamericano, ciertas características comunes o convergentes en los procesos de atención y cuidado llevados a cabo en los hospitales. Lo que nos condujo a la construcción de un Modelo Médico Hospitalar que comprende dichos aspectos.

Para terminar, consideramos que la presente tesis debe ser entendida como un primer acercamiento a nuestro problema de investigación: las experiencias de los TraSa con respecto a los procesos de atención y cuidado en hospitales, pero también constituye un punto de partida a partir de una serie de interrogantes que fueron emergiendo a lo largo del proceso de escritura. El corpus no permitió una aproximación a ciertos actores que son parte del colectivo de TraSa en los hospitales, tales como el sector de camilleros, administración o maestranza. Al respecto surge la pregunta si dichos TraSa responden o no a las representaciones sociales que los/as investigadores/as se hacen sobre quienes trabajan en un hospital. Tal vez no se abordaron porque son sectores invisibilizados, que si bien consideramos que ocupan lugares claves en los procesos de trabajo, no se terminan de asociar con la categoría de TraSa. 
Moglia B. Procesos de atención y cuidado desde la perspectiva de los trabajadores: una metaetnografía en hospitales de Latinoamérica. [Tesis de maestría]. Maestría en Epidemiología, Gestión y Políticas de Salud. Universidad Nacional de Lanús. 2020.

Asimismo, me pregunto sobre las organizaciones de representación gremial, que tampoco aparecen como actores significativos en el hospital, pensando en los escenarios de trabajo. Otra ausencia vinculada al corpus refiere a los países representados en este último. Llamamos la atención porque determinados países y, también, determinados sectores no son abordados desde las investigaciones cualitativas. Creemos que, más allá del recorte establecido, existen otros factores que intervienen tales como la actitud defensiva por parte de médicos u otras autoridades que no permiten ese tipo de trabajo, el cual suele ser visto como una especie de evaluación de servicio o del sector.

Por otro lado, seria de interés indagar y profundizar sobre esas experiencias que se dan en determinados servicios que permiten una atención humanizada, para recuperar, además, la perspectiva de los usuarios/as y, quizás, pensando en una extensión a otros servicios.

Otras preguntas que emergen remiten al contexto mundial de pandemia y la relevancia que adquiere ser TraSa en los sistemas públicos de atención. En este sentido, entendemos que esta irrupción en su cotidianeidad puede ser indagada en términos de "drama social" ya que llevó a modificar, desordenar y provocar tensiones y conflictos en los modos de atender y cuidar. En este sentido, nos preguntamos, ¿cómo afectó a los TraSa? ¿En qué sentidos los afecta? ¿Qué aspectos sobre dichos modos se pusieron en disputa en los hospitales? ¿Qué incomodidades y emociones emergieron? ¿Cómo se describren dichas emergencias al incluir una perspectiva de género? Estos son algunos de los interrogantes que situamos hoy, en nuestra región, y que consideramos interesantes indagar y comparar teniendo como punto de partida esta tesis. 


\section{REFERENCIAS BIBLIOGRÁFICAS}

Abu-Lughod L, Lutz C. (1990). Language and the Politics of Emotion. Cambridge: University Press.

Acosta DF, Gomes VLO, Oliveira DC, Marques SC, Fonseca AD. (2018). Representações sociais de enfermeiras acerca da violência doméstica contra a mulher: Estudo com abordagem estrutural. Revista Gaúcha de Enfermagem, 39(0). https://doi.org/10.1590/19831447.2018.61308

Aguiar JM, d'Oliveira AFPL, Schraiber LB. (2013). Violência institucional, autoridade médica e poder nas maternidades sob a ótica dos profissionais de saúde. Cadernos de Saúde Pública, 29(11), 2287-2296. https://doi.org/10.1590/0102-311x00074912

Almeida Filho N. (1992). Por una etnoepidemiología. Esbozo de un nuevo paradigma epidemiológico. Cuadernos Médico Sociales, 61:43-47.

Almeida-Filho N. (2000). La ciencia tímida. Ensayos de deconstrucción de la Epidemiología. Buenos Aires: Lugar Editorial.

Álvarez Pedrosian E. (2009). Los estrategas del Maciel. Etnografía de un hospital público. Montevideo: Comisión Sectorial de Investigación Científica de la Universidad de la República.

Andersen HM. (2004). "Villagers": Differential treatment in a Ghanaian hospital. Social Science \& Medicine. 59: 2003-2012.

Araújo BBM, Pacheco STA, Rodrigues BMRD, Silva LF, Rodrigues BRD, Arantes PCC. (2018). Prática social da enfermagem na promoção do cuidado materno ao prematuro na unidade neonatal. Texto \& Contexto - Enfermagem, 27(4), e2770017. https://doi.org/10.1590/0104-07072018002770017

Aredes JDS, Firmo JOA, Giacomin KC. (2018). A morte que salva vidas: complexidades do cuidado médico ao paciente com suspeita de morte encefálica. Cadernos de Saúde Pública. 34.

Aredes JS, Giacomin KC and Firmo JOA, (2018b). O médico diante da morte no pronto socorro. Revista de Saúde Pública. 52: 42-42.

Aredes JS, Giacomin KC, Firmo JOA. (2018a). A práxis médica no pronto atendimento diante do paciente com sequelas crônicas: culpa, temor e compaixão. Trabalho, Educação e Saúde. 16(3): 1177-1199.

Aredes JS, Firmo JOA, Giacomin KC. (2018). A morte que salva vidas: Complexidades do cuidado médico ao paciente com suspeita de morte encefálica. Cadernos de Saúde Pública, 34(11). https://doi.org/10.1590/0102-311x00061718

Arenas-Monreal L, Hernández-Tezoquipa I, Valdez-Santiago R, Bonilla-Fernández P. (2004). Las instituciones de salud y el autocuidado de los médicos. Salud Pública de México, 46(4), 326-332. https://doi.org/10.1590/S0036-36342004000400007

Auyero J. (2013). Pacientes del Estado. Buenos Aires: Eudeba.

Ayres JRCM. (2018). El cuidado. Los modos de ser (del) humano y las prácticas de salud. En: Paiva V, Ayres JRCM, Capriati A, Amuchástegui A, Pecheny M. (Ed.). Prevención, 
Moglia B. Procesos de atención y cuidado desde la perspectiva de los trabajadores: una metaetnografía en hospitales de Latinoamérica. [Tesis de maestría]. Maestría en Epidemiología, Gestión y Políticas de Salud. Universidad Nacional de Lanús. 2020.

promoción y cuidado: enfoques de vulnerabilidad y derechos humanos. Temperley: TesseoPress. p. 111-140.

Azevedo CS, Sá MC, Cunha M, Matta GC, Miranda L, Grabois V. (2017). Racionalização e Construção de Sentido na Gestão do Cuidado: Uma experiência de mudança em um hospital do SUS. Ciência \& Saúde Coletiva, 22(6), 1991-2002. https://doi.org/10.1590/141381232017226.13312016

Baasch D, Laner AS. (2011). Os significados do trabalho em unidades de terapia intensiva de dois hospitais brasileiros. Ciência \& Saúde Coletiva, 16(suppl 1), 1097-1105. https://doi.org/10.1590/S1413-81232011000700041

Baggio MA, Erdmann AL. (2016). The occurrence of the care «of us» in the movements and fluctuations of the interactive processes in the hospital environment. Texto \& Contexto Enfermagem, 25(1). https://doi.org/10.1590/0104-070720160000160014

Ballesteros MS, Freidin B, Wilner A. (2017). Esperar para ser atendido. En: Pecheny M, Palumbo M, compiladores. Esperar y hacer esperar: Escenas y experiencias en salud, dinero y amor. Buenos Aires: Teseo. p. 63-99.

Barber N. (2015). Experiencias de enfermedad y procesos de constitución de subjetividades [tesis de doctorado]. Buenos Aires: Universidad de Buenos Aires.

Bolaños Florido LP. (2016). El estudio socio-histórico de las emociones y los sentimientos en las Ciencias Sociales del siglo XX. Revista de Estudios Sociales, (55), 178-191.

Bonet O. (1999). Saber e Sentir. Uma etnografia da aprendizagem da biomedicina. Physis Revista de Saúde Coletiva. 9: 123-150.

Bonet O. (2004). Saber e sentir: uma etnografia da aprendizagem da biomedicina. Rio de Janeiro: Editora Fiocruz.

Bourdin GL. (2016). Antropología de las emociones: conceptos y tendencias. Cuicuilco, 23(67), 55-74.

Brage E, Vindrola-Padros C. (2017). An ethnographic exploration of the delivery of psychosocial care to children with cancer in Argentina. European Journal of Oncology Nursing, 29, 91-97. https://doi.org/10.1016/j.ejon.2017.05.002

Braz C. (2017). Transmasculinidades, salud y espera Antropología del tiempo y el acceso a la salud para hombres trans en Brasil. En: Pecheny M, Palumbo M, compiladores. Esperar y hacer esperar: Escenas y experiencias en salud, dinero y amor. Buenos Aires: Teseo. p. 147165.

Busanello J, Kerber NPC, Lunardi Filho WD, Lunardi VL, Mendoza-Sassi RA, Azambuja EP. (2011). Parto humanizado de adolescentes: concepção dos trabalhadores da saúde. 6.

Camargo Jr KRD. (2005). A biomedicina. Physis: Revista de Saúde Coletiva. 15: 177-201.

Campos GWS. (2006). Gestión en salud. Buenos Aires: Lugar Editorial.

Campos GWS. (2009). Método paideia: análisis y co-gestión de colectivos. Buenos Aires: Lugar Editorial.

Canclini NG. (2004). Diferentes, desiguales y desconectados: mapas de la interculturalidad. Barcelona: Gedisa. 
Moglia B. Procesos de atención y cuidado desde la perspectiva de los trabajadores: una metaetnografía en hospitales de Latinoamérica. [Tesis de maestría]. Maestría en Epidemiología, Gestión y Políticas de Salud. Universidad Nacional de Lanús. 2020.

Carapinheiro G. (1993). Saberes e poderes no hospital: uma sociologia dos serviços hospitalares. Porto: Afrontamento.

Cardoso GB, Silva ALAD. (2010). O processo de trabalho na enfermagem: articulação das tecnologias do cuidado. Rev. enferm. UERJ, 451-455.

Cardoso DH, Muniz RM, Schwartz, Arrieira ICO. (2013a). Cuidados paliativos na assistência hospitalar: A vivência de uma equipe multiprofissional. Texto \& Contexto - Enfermagem, 22(4), 1134-1141. https://doi.org/10.1590/S0104-07072013000400032

Cardoso DH, Viegas ADC, Muniz RM, Schwartz E, Thofehrn MB. (2013b). Care delivery in the terminality: Difficulties of a multidisciplinary team in hospital care. Avances en enfermería, 31(2).

Cascón-Pereira R. (2013). ¿Doctores o gestores? La identidad profesional dual del mando intermedio en dos hospitales catalanes. En: Romaní O, editor. Etnografía, técnicas cualitativas e investigación en salud: un debate abierto. Terragona: Publicacions URV. p. 239-262.

Castilla MV. (2016). Tuberculosis, sufrimiento y vida cotidiana en barrios marginales y vulnerables del Área Metropolitana de Buenos Aires. Trabajo y sociedad: Indagaciones sobre el empleo, la cultura y las prácticas políticas en sociedades segmentadas. (26): 101-116.

Caudill W. (1958). El hospital psiquiátrico como comunidad terapéutica. Buenos Aires: Escuela.

Cerrutti M. (2007). Problemas de salud, utilización de servicios y conductas preventivas de los migrantes limítrofes en la Argentina. En: Jelin E, directora. Salud y Migración Regional. Ciudadanía, Discriminación y Comunicación Intercultural. Buenos Aires: IDES. p. 15-33.

Collin KM, Valleala UM, Herranen S, Paloniemi S. (2012). Ways of interprofessional collaboration and learning in emergency work. Studies in Continuing Education. 34 (3): 281300 .

Comelles JM. (2000). Tecnología, cultura y sociabilidad. Los límites culturales del hospital contemporáneo. En: Perdiguero E, Comelles J, editores. Medicina y cultura. Estudios entre la Medicina y la Antropología. Barcelona: Edicions Bellaterra. p. 305-353.

Cortés B. (1997). Experiencia de enfermedad y narración: el malentendido de la cura. Nueva Antropología. XVI (53).

Coser RL. (1962). Life in the ward. East Lansing: Michigan State University Press.

Costa MA, Abrahão AL. (2018). O processo de trabalho no arquivo médico: Novas perspectivas na produção do ato de cuidar em saúde. Ciência \& Saúde Coletiva, 23(4), 12111219. https://doi.org/10.1590/1413-81232018234.06292016

Crivos M. (1988). Estudio antropológico de una sala de hospital. Medicina y Sociedad. Revista sobre Organización y Financiación de la Salud. 11.

Crojethovic M. (2010). El efecto de la informalidad en la dinámica organizacional. El análisis de los hospitales públicos de la Provincia de Buenos Aires. VI Jornadas de Sociología de la UNLP; 9-10 dic. Universidad Nacional de La Plata. Facultad de Humanidades y Ciencias de la Educación. La Plata, Argentina 
Moglia B. Procesos de atención y cuidado desde la perspectiva de los trabajadores: una metaetnografía en hospitales de Latinoamérica. [Tesis de maestría]. Maestría en Epidemiología, Gestión y Políticas de Salud. Universidad Nacional de Lanús. 2020.

Damín N. (2014). El Estado, la espera y la dominación política en los sectores populares: entrevista al sociólogo Javier Auyero. Salud Colectiva. 10 (3): 407-415.

Del Mónaco R. (2015). Migraña y (des) encuentros: encierros y relaciones vinculares a partir de dolores de cabeza crónicos. Cuadernos de Antropología Social. (41): 109-127.

do Amaral RA, Moraes CW, Ostermann GT. (2013). Cuidando do cuidador: Grupo de funcionários no Hospital Geral. Rev. SBPH, 13(2), 270-285.

dos Santos TD, de Oliveira Aquino AC, de Pinho Chibante CL, do Espírito Santo FH. (2013). The nursing team and the family member accompanying adult patients in the hospital context. An exploratory study. Inv Educ Enferm, 31(2).

Epele M. (2007). La lógica de la sospecha: Sobre criminalización del uso de drogas, complots y barreras de acceso al sistema de salud. Cuadernos de Antropología Social. (25): 151-168.

Epele M. (2011). Emergencies and rescues: The logics of vulnerability and care among drug users in Buenos Aires, Argentina. Addiction Research \& Theory. 19(2): 161-169.

Epele M. (2017). Sobre las posiciones etnográficas en la antropología de la salud en el sur de las Américas. Salud Colectiva. 13 (3): 359-373.

Farji Neer A, Mertehikian Y, Cunial S, Kolkowskial E. (2017) Procesos y experiencias en torno a los tratamientos de reproducción médicamente asistida. En: Pecheny M, Palumbo M, compiladores. Esperar y hacer esperar: Escenas y experiencias en salud, dinero y amor. Buenos Aires: Teseo. p. 99-125.

Feltrin RB, Velho L. (2016). Representações do corpo feminino na menopausa: estudo etnográfico em um hospital-escola brasileiro. Sexualidad, Salud y Sociedad, Revista Latinoamericana. 22: 148-174.

Fernandes AT, Nery AA, Filho SAM. (2018). Feelings experienced by health workers in occurrence of accidents with biological material. 12.

Fernández Vázquez SS, Szwarc L. (2017). Esperando un aborto exitoso. Tensiones en la espera por abortar con pastillas en el Área Metropolitana de Buenos Aires. En: Pecheny M, Palumbo M, compiladores. Esperar y hacer esperar: Escenas y experiencias en salud, dinero y amor. Buenos Aires: Teseo. p. 39-63.

Ferrer M. (2015). La Maquila de Médicos: Una etnografía en la guardia del Hospital Nacional de Clínicas. Universidad Nacional de Córdoba, Facultad de Filosofía y Humanidades, Departamento de Antropología, Córdoba.

Ferrero L. (2003). Tiempo y ritual en la organización del cuidado médico. Cuadernos de Antropología Social. 18: 165-183.

Ferreira, J. (2011). A Consulta Médica como Drama Social-um olhar etnográfico. Cad. Saúde Coletiva, 19.

Fisher B, Tronto J. (1990). Toward a Femminist Teory of Care. E. Abel, M. Nelson, Circles of Care. Work and Identity in Women's Lives, State University of New York, Albany.

Formozo GA, Oliveira DC. (2010). Representações sociais do cuidado prestado aos pacientes soropositivos ao HIV. Revista Brasileira de Enfermagem, 63(2), 230-237. https://doi.org/10.1590/S0034-71672010000200010 
Moglia B. Procesos de atención y cuidado desde la perspectiva de los trabajadores: una metaetnografía en hospitales de Latinoamérica. [Tesis de maestría]. Maestría en Epidemiología, Gestión y Políticas de Salud. Universidad Nacional de Lanús. 2020.

Foster GM, Anderson BG. (1978). Medical anthropology. New York: John Wiley \& Sons.

Foucault M. (1975). The birth of the clinic: An archaeology of medical perception. Trans. A.M. Sheridan-Smith. New York: Vintage Press.

Foucault M. (1990). La vida de los hombres infames. Ensayos sobre desviación y dominación. Madrid: La Piqueta.

Franco TB, Merhy EE. (2009) Mapas analíticos: una mirada sobre la organización y sus procesos de trabajo. Salud Colectiva. 5(2):181-194

Franco TB, Merhy EE. (2011). El reconocimiento de la producción subjetiva del cuidado. Salud Colectiva. 7(1): 9-20.

Franco TB, Merhy EE. (2016). Trabajo, producción del cuidado y subjetividad en salud. Ciudad Autónoma de Buenos Aires, Argentina: Lugar Editorial.

Franco TB. (2016). Las redes en la micropolítica del proceso de trabajo en salud. En: T. B. Franco \& E. E. Merhy. (Ed.), Trabajo, producción del cuidado y subjetividad en salud (pp. 197-209). Ciudad Autónoma de Buenos Aires, Argentina: Lugar Editorial.

Freidson E. (1970). Professional dominance: The social structure of medical care. New York: Atherton Press.

Freidson, E. (1978). La profesión médica. Península.

García G. (2013). Rutinas médicas y estandarización: reflexiones etnográficas sobre la institucionalización de la prevención de la transmisión madre-hijo del VIH en un centro obstétrico del sur de la ciudad de Buenos Aires. Cuadernos de Antropología Social. 37: p. 85108.

García Martínez SJ. (2016). Guardias y salud: una relación a contramano. Estudio sobre empleo, trabajo y salud en trabajadores de los hospitales públicos del Gran Buenos Aires. Argentina, 2010-2012. [Tesis de maestría]. Lanús: Universidad Nacional de Lanús.

García MG, Recoder ML, Margulies S. (2017). Espacio, tiempo y poder en la atención hospitalaria de la salud y la enfermedad: Aportes de una etnografía de un centro obstétrico. Salud Colectiva. 13(3):391-409.

Geertz C. (1973). La interpretación de las culturas, España: Gedisa

Gibson D. (2004). The gaps in the gaze in South African hospitals. Social Science \& Medicine. 59 (10): 2013-2024.

Goffman E. (1961). Asylums. Harmondsworth: Penguin.

Goldberg A, Silveira C. (2013). Desigualdad social, condiciones de acceso a la salud pública y procesos de atención en inmigrantes bolivianos de Buenos Aires y São Paulo: una indagación comparativa. Saúde e Sociedade. 22 (2): 283-297.

Goldberg A. (2013). Tuberculosis en inmigrantes bolivianos del Área Metropolitana de Buenos Aires: narrativas y procesos asistenciales. En: Martínez Hernáez Á, Masana Bofarull L, Digiacomo SM, editores. Evidencias y narrativas en la atención sanitaria una perspectiva antropológica. Tarragona/Porto Alegre: Publicacions URV y Associação Brasileira da Rede Unida. p. 113-137. 
Moglia B. Procesos de atención y cuidado desde la perspectiva de los trabajadores: una metaetnografía en hospitales de Latinoamérica. [Tesis de maestría]. Maestría en Epidemiología, Gestión y Políticas de Salud. Universidad Nacional de Lanús. 2020.

Good B. (1994). Medicine, rationality, and experience: an anthropological perspective, The Lewis Henry Morgan lectures. Cambridge: Cambridge University Press.

Grimson A, Semán P. (2005). Presentación: La cuestión cultura. Etnografías contemporáneas, 1(April), 11-22.

Hall S. (2003). Introducción: ¿quién necesita identidad? Cuestiones de identidad cultural, 1339.

Henckes N, Nurok M. (2015). 'The first pulse you take is your own'-but don't forget your colleagues'. Emotion teamwork in pre-hospital emergency medical services. Sociology of health \& illness. 37(7): 1023-1038.

Henderson S, Stacey CL, Dohan D. (2008). Social stigma and the dilemmas of providing care to substance users in a safety-net emergency department. Journal of Health Care for the Poor and Underserved. 19(4): 1336-1349.

Herrero BT, Brigidi S, Hurtado I. (2014). Antropologias en bata blanc: praxis y problemas del trabajo etnográfico en hospitales. En: Romaní O, editor. Etnografía, metodologías cualitativas e investigación en salud: un debate abierto. Tarragona: Publicacions UVR. p . 191-213.

Hilligoss B. (2014). Selling patients and other metaphors: A discourse analysis of the interpretive frames that shape emergency department admission handoffs. Social Science \& Medicine. 102: 119-128.

Iedema R, Ball C, Daly B, Young J, Green T, Middleton P M, Comerford D. (2012). Design and trial of a new ambulance-to-emergency department handover protocol:"IMISTAMBO'. BMJ Quality \& Safety. 21(8): 627-633.

Iedema R, Merrick E. (2016). Analysing teamwork in health care: What matters when clinicians negotiate the continuity of clinical tasks and care responsibilities? Communication \& medicine. 13(1): 85-97.

Inhorn MC. (2004). Privacy, privatization, and the politics of patronage: ethnographic challenges to penetrating the secret world of Middle Eastern, hospital-based in vitro fertilization. Social Science \& Medicine. 59(10): 2095-2108.

Jelin E. (2007). Salud y migración regional. Ciudadanía, discriminación y comunicación intercultural. Buenos Aires: IDES.

Kelley ML, Parke B, Jokinen N, Stones M, Renaud D. (2011). Senior-friendly emergency department care: an environmental assessment. Journal of Health Services Research \& Policy. 16(1): 6-12.

Kleinman A. (2013). From illness as culture to caregiving as moral experience. New England Journal of Medicine.

Kleinman A, van der Geest S. (2009). 'Care'in health care. Remaking the moral world of medicine. Medische Antropologie, 21(1), 159.

Klossoswski DG, Godói VC, Xavier CR, Fujinaga CI. (2016). Assistência integral ao recémnascido prematuro: Implicações das práticas e da política pública. Revista CEFAC, 18(1), 137-150. https://doi.org/10.1590/1982-021620161814515 
Moglia B. Procesos de atención y cuidado desde la perspectiva de los trabajadores: una metaetnografía en hospitales de Latinoamérica. [Tesis de maestría]. Maestría en Epidemiología, Gestión y Políticas de Salud. Universidad Nacional de Lanús. 2020.

Lima MAG, Trad LAB. (2011). «Circuloterapia»: Uma metáfora para o enfrentamento da dor crônica em duas clínicas de dor. Physis: Revista de Saúde Coletiva, 21(1), 217-236. https://doi.org/10.1590/S0103-73312011000100013

Lima MLC, Souza ER, Lima MLLT, Barreira AK, Bezerra ED, Acioli RML. (2010). Assistência à saúde dos idosos vítimas de acidentes e violência: Uma análise da rede de serviços SUS no Recife (PE, Brasil). Ciência \& Saúde Coletiva, 15(6), 2677-2686. https://doi.org/10.1590/S1413-81232010000600006

Littike D, Sodré F. (2015). A arte do improviso: O processo de trabalho dos gestores de um Hospital Universitário Federal. Ciência \& Saúde Coletiva, 20(10), 3051-3062. https://doi.org/10.1590/1413-812320152010.00042015

Lopes DFM, Silva A, Garanhani ML, Merighi MAB. (2007). Ser trabalhador de enfermagem da Unidade de Centro de Material: Uma abordagem fenomenológica. Revista da Escola de Enfermagem da USP, 41(4), 675-682. https://doi.org/10.1590/S0080-62342007000400019

Luna-García JE, Urrego Mendoza Z, Gutiérrez Robayo M, Martínez Durán A. (2015). Violencia en el trabajo en el sector público de la salud: una visión desde las personas trabajadoras. bogotá, colombia 2011 - 2012. Revista de la Facultad de Medicina, 63(3), 407417. https://doi.org/10.15446/revfacmed.v63n3.51027

Luz KR, Vargas MAO, Barlem ELD, Schmitt PH, Ramos FRS, Meirelles BHS. (2016). Estratégias de enfrentamento por enfermeiros da oncologia na alta complexidade. Revista Brasileira de Enfermagem, 69(1), 67-71. https://doi.org/10.1590/0034-7167.2016690109i

Margulies S, Barber N, Recoder ML. (2006). VIH-SIDA y "adherencia" al tratamiento enfoques y perspectivas. Antípoda. Revista de antropología y arqueología. (3): 281-300.

Margulies S. (2010). Etiología y riesgo en la construcción clínica de la enfermedad VIH-sida: Ensayo de antropología de la medicina. Intersecciones en Antropología. 11(1): 215-225.

Martinovich V. (2019). Análisis documental: síntesis de aspectos metodológicos para maestría y doctorado. Lanús: Universidad Nacional de Lanús.

Mauss M. (1979). A expressão obrigatória dos sentimentos. In: Cardoso de Oliveira R. Mauss. São Paulo: Ática, p. 325-335.

Menéndez EL. (1978). El modelo médico y la salud de los trabajadores. En: Basaglia F. y otros, editores. La salud de los trabajadores. Aportes para una política de la salud. México. Nueva Imagen. p. 11-53.

Menéndez EL. (1983). Hacia una práctica médica alternativa. Hegemonía y autoatención en salud. México: Cuaderno $\mathrm{N}^{\circ} 86$ de la Casa Chata.

Menéndez EL. (1990). Antropología médica. Orientaciones, desigualdades y transacciones, México: Ediciones de la Casa Chata.

Menéndez EL. (1994). Le enfermedad y la curación ¿Qué es medicina tradicional? Alteridades. 4(7): 71-83.

Menéndez EL. (2002). La parte negada de la cultura. Relativismo, diferencias y racismo. Barcelona: Ediciones Bellaterra. 
Moglia B. Procesos de atención y cuidado desde la perspectiva de los trabajadores: una metaetnografía en hospitales de Latinoamérica. [Tesis de maestría]. Maestría en Epidemiología, Gestión y Políticas de Salud. Universidad Nacional de Lanús. 2020.

Menéndez EL. (2003) Modelos de atención de los padecimientos: de exclusiones teóricas y articulaciones prácticas. Ciencia \& Saúde Coletiva. 8(1): 185-207.

Menéndez EL. (2015). Las enfermedades ¿ son solo padecimientos?: biomedicina, formas de atención" paralelas" y proyectos de poder. Salud Colectiva. 11(3): 301-330.

Menéndez EL. Epidemiología sociocultural: propuestas y posibilidades. Región y sociedad. 2008; 20(SPE2): 5-50.

Merhy EE. (2006). Salud: cartografía del trabajo vivo. Buenos Aires: Lugar Editorial.

Merhy EE. (2016). El cuidado es un acontecimiento y no un acto. En Franco TB, Merhy EE, editores. Trabajo, producción del cuidado y subjetividad en salud. Ciudad Autónoma de Buenos Aires, Argentina: Lugar Editorial. p. 151-160.

Michalewicz A, Pierri C, Ardila-Gómez S. (2014). Del proceso de salud/enfermedad/atención al proceso salud/enfermedad/cuidado: elementos para su conceptualización. Anuario de investigaciones, 21, 217-224.

Mol A. (2008). The logic of Care. Health and problem of patient choice. London: Routledge.

Molina-Marín G, Oquendo-Lozano T, Arango-Castrillón A, Flórez-García MV. (2013). Características dos serviços pediátricos que atendem crianças com pneumonia adquirida na comunidade, Medellín (Colômbia), 2012. 16.

Morales Castellón Y. (2016). Trabajar en el hospital público: salud, trabajo y empleo en profesionales de la salud del conurbano bonaerense. 2010-2012. [Tesis de Maestría]. Lanús: Universidad Nacional de Lanús.

Muñoz Martínez R. (2013). Un antropólogo en la consulta hospitalaria. En: Romaní O, editor. Etnografía, metodologías cualitativas e investigación en salud: un debate abierto. Tarragona: Publicacions URV. p. 213-239

Murphy E, Dingwall R. (2007). Informed consent, anticipatory regulation and ethnographic practice. Social Science \& Medicine. 65(11): 2223-2234.

Nava Diosdado R, Flores Cisneros C, Méndez Jiménez J, Serrano Zamago A, de HoyosBermea A, Ricco-Monge S. (2011). Valores en Medicina: etnografía de sus representaciones en un hospital de cardiología en México. Cuicuilco. 52: 115-132.

Negrín G. (2016). Proceso de trabajo en salud. La problemática del pluriempleo en trabajadores/as de la salud en hospitales públicos de Gran Buenos aires. Argentina, 20102012. [Tesis de Maestría]. Lanús: Universidad Nacional de Lanús.

Noblit GW, Hare RD. (1988) Meta-Ethnography: Synthesizing Qualitative studies. Newbury Park: Sage Publications.

Nugus P. (2019). Re-structuring the negotiated order of the hospital. Sociology of health \& illness. 41(2): 378-394.

Oliveira MJ. (2014). Uma etnografia sobre o atendimento psicoterapêutico a transexuais. Revista Estudos Feministas. 22(3): 839-862.

Ortega J, Tiseyra MV, Morcillo S, Gálvez M. (2017). Otros cuerpos, otros tiempos Experiencias de espera de personas trans en el sistema público de salud. En: Pecheny M, 
Moglia B. Procesos de atención y cuidado desde la perspectiva de los trabajadores: una metaetnografía en hospitales de Latinoamérica. [Tesis de maestría]. Maestría en Epidemiología, Gestión y Políticas de Salud. Universidad Nacional de Lanús. 2020.

Palumbo M, compiladores. Esperar y hacer esperar: Escenas y experiencias en salud, dinero y amor. Buenos Aires: Teseo. p. 125-147.

Ortner S. (2005). Geertz, subjetividad y conciencia posmoderna. Etnografías contemporáneas. 1(1): 25-54.

Pagnamento LV. (1993). Cómo los médicos aprenden a ser médicos: la residencia en clínica médica del Hospital San Martín de La Plata. [Tesis de licenciatura]. Buenos Aires: Universidad de Buenos Aires.

Palmer SP. (2014). Nurse retention and satisfaction in Ecuador: Implications for nursing administration. Journal of Nursing Management, 22(1), 89-96. https://doi.org/10.1111/jonm.12043

Pan R, Silva MTR, Fidelis TLN, Vilela LS, Silveira-Monteiro CA, Nascimento LC. (2018). Conhecimento de profissionais de saúde acerca do atendimento inicial intra-hospitalar ao paciente vítima de queimaduras. Revista Gaúcha de Enfermagem, 39(0). https://doi.org/10.1590/1983-1447.2018.2017-0279

Parsons K, Gaudine A, Swab M. (2018). Older nurses' experiences of providing direct care in hospital nursing units: a qualitative systematic review. JBI database of systematic reviews and implementation reports. 16(3): 669-700.

Parsons T. (1951). The social system. Glencoe: Free Press.

Pecheny M, Palumbo M. (2017) Esperar y hacer esperar: Escenas y experiencias en salud, dinero y amor. Buenos Aires: Teseo.

Pereyra H. (2017). Trayectorias en busca de una córnea Reificación en la espera por un trasplante de tejido. En: Pecheny M, Palumbo M, compiladores. Esperar y hacer esperar: Escenas y experiencias en salud, dinero y amor. Buenos Aires: Teseo. p. 165-185.

Person J, Spiva L, Hart P. (2013). The culture of an emergency department: an ethnographic study. International Emergency Nursing. 21(4): 222-227.

Programa de las Naciones Unidas para el Desarrollo. (2018). Aportes para el desarrollo humano en Argentina 2018: Género. En: El Sector Salud: Feminización y Brechas Laborales. Buenos Aires: PNUD.

Rocha APF, Souza KR, Teixeira LR. (2015). A saúde e o trabalho de médicos de UTI neonatal: Um estudo em hospital público no Rio de Janeiro. Physis: Revista de Saúde Coletiva, 25(3), 843-862. https://doi.org/10.1590/S0103-73312015000300009

Rosado IVM, Russo GHA, Maia EMC. (2015). Produzir saúde suscita adoecimento? As contradições do trabalho em hospitais públicos de urgência e emergência. Ciência \& Saúde Coletiva, 20(10), 3021-3032. https://doi.org/10.1590/1413-812320152010.13202014

Rostagnol S, Viera M. (2006). Derechos sexuales y reproductivos: condiciones habilitantes y sujetos morales en los servicios de salud. Estudio en el Centro Hospitalario Pereira Rossell, Uruguay. En: Checa S, compiladora. Realidades y coyunturas del aborto, entre el derecho y la necesidad. Buenos Aires: Paidós. p. 1-21.

Ruiz Coronel A. (2004) Etnografía de urgencia: el hospital de Xoco. Boletín Oficial del Instituto Nacional de Antropología e Historia. Espacios de la Ciudad de México. 75-76: 109215. 
Moglia B. Procesos de atención y cuidado desde la perspectiva de los trabajadores: una metaetnografía en hospitales de Latinoamérica. [Tesis de maestría]. Maestría en Epidemiología, Gestión y Políticas de Salud. Universidad Nacional de Lanús. 2020.

Silbergleit C. (2009). Produciendo saberes hegemónicos: el caso de la residencia médica en un hospital universitario. [Tesis de licenciatura]. Buenos Aires: Universidad de Buenos Aires.

Silva LM, Santos MA. (2006). Construindo pontes: relato de experiência de uma equipe multidisciplinar em transtornos alimentares. medicina (Ribeirao Preto. Online), 39(3), 415. https://doi.org/10.11606/issn.2176-7262.v39i3p415-424

Silva RC, Soares MC, Jardim VMR, Kerber NPC, Meincke SMK. (2013). O discurso e a prática do parto humanizado de adolescentes. Texto \& Contexto - Enfermagem, 22(3), 629636. https://doi.org/10.1590/S0104-07072013000300008

Silva RC, Soares MC, Muniz RM, Andrade FP, Torres AAP, Gomes V. (2011). La concepción de los profesionales de salud sobre el parto humanizado en la adolescencia. Enfermería Global, 10(24), 0-0. https://doi.org/10.4321/S1695-61412011000400025

Sirimarco M, Spivak L'Hoste A. (2019). Antropología y emoción: reflexiones sobre campos empíricos, perspectivas de análisis y obstáculos epistemológicos. Horizontes Antropológicos, 25(54), 299-322.

Soto Roy Á. (2015). Escenarios del trabajo, una aproximación a la heterogeneidad del trabajo contemporáneo en Latinoamérica. Revista de Estudios Sociales, (51), 198-212.

Souza Minayo MC. (2013). La artesanía de la investigación cualitativa. Lugar Editorial.

Souza GA, Giacomin K, Aredes JS, Firmo JOA. (2018). Comunicação da morte: Modos de pensar e agir de médicos em um hospital de emergência. Physis: Revista de Saúde Coletiva, 28(3), e280324. https://doi.org/10.1590/s0103-73312018280324

Spinelli H, Trotta A, Guevel C, Santoro A, García S, Negrin G, Morales Y. (2013). Los trabajadores de la salud. Trabajo, empleo, organización y vida institucional en hospitales públicos del aglomerado Gran Buenos Aires, Argentina 2010-2012. Buenos Aires: OPS/OMS.

Spinelli H. (2010). Las dimensiones del campo de la salud en Argentina. Salud Colectiva. 6(3): 275-293.

Strauss A, Corbin J. (2002). Bases de la investigación cualitativa. Técnicas y procedimientos para desarrollar la teoría fundamentada. Antioquia: Editorial de la Universidad de Antioquia.

Sutton LH, García RF, Hernández RA, Roche OFR. (2013). Expectativas y experiencias de los usuarios del Sistema de Salud en México: Un estudio de satisfacción con la atención médica. México DF: Universidad Nacional Autónoma de México.

Sy A. (2013). La observación participante como técnica privilegiada en el acceso a la ritualización de prácticas en torno a la salud: A propósito de la propuesta del frente de artistas del Borda. Papeles de Trabajo No 26.

Sy A, Moglia B, Aragunde GE, Derossi PD. (2020). La urgencia bajo la lupa: una revisión de la producción científica sobre servicios de emergencia en hospitales desde la etnografía (en prensa).

Tanassi LM. (2004). Compliance as strategy: the importance of personalised relations in obstetric practice. Social Science \& Medicine. 59(10): 2053-2069. 
Moglia B. Procesos de atención y cuidado desde la perspectiva de los trabajadores: una metaetnografía en hospitales de Latinoamérica. [Tesis de maestría]. Maestría en Epidemiología, Gestión y Políticas de Salud. Universidad Nacional de Lanús. 2020.

Taylor SJ, Bogdan R. (1994). Introducción a los métodos cualitativos de investigación. La búsqueda de significados. Barcelona: Paidós.

Testa M. (1997). Análisis de Instituciones Hipercomplejas. En: Merhy E, Onocko R, organizadores. Praxis en Salud: un Desafío para lo Público. Buenos Aires: Lugar Editorial. p. 11-70.

Tosal Herrero B, Brigidi S, Hurtado I. (2013). Antropólogas en bata blanca: praxis y problemas del trabajo etnográfico en hospitales. En: Romaní O., editor. Etnografía, metodologías cualitativas e investigación en salud: un debate abierto. Tarragona: URV. p.191213.

Tronto J. (1993). Moral Boundaries. A political argument for an ethic of care. New York: Routledge.

Turner V. (1974). Social Dramas and Ritual Metaphors. En: Dramas, Fields and Metaphors: Symbolic Action in Human Society. London: Cornell University Press.

Valderrama MJ. (2013). La escucha del sufrimiento en la relación clínica. En: MartínezHernáez A, Masana L, DiGiacomo SM, editores. Evidencias y narrativas en la atención sanitaria Una perspectiva antropológica. Tarragona / Porto Alegre (Rio Grande do Sul-Brasil): Publicacions URV / Associação Brasileira da Rede Unida. p. 265-282.

van Amstel H, van der Geest S. (2004). Doctors and retribution: the hospitalisation of compensation claims in the Highlands of Papua New Guinea. Social Science \& Medicine. 59(10): 2087-2094.

van der Geest S, Finkler K. (2004). Hospital ethnography: introduction. Social Science \& Medicine. 59(10): 1995-2001.

Vermeulen E. (2004). Dealing with doubt: making decisions in a neonatal ward in The Netherlands. Social Science \& Medicine. 59(10): 2071-2085.

Webster F, Rice K, Dainty KN, Zwarenstein M, Durant S, Kuper A. (2015). Failure to cope: the hidden curriculum of emergency department wait times and the implications for clinical training. Academic Medicine. 90(1): 56-62.

Wind G. (2008). Negotiated interactive observation: Doing fieldwork in hospital settings. Anthropology and Medicine. 15(2): 79-89.

Zaman S. (2004). Poverty and violence, frustration and inventiveness: hospital ward life in Bangladesh. Social Science \& Medicine. 59(10): 2025-2036. 


\section{APÉNDICES}

Apéndice A - Cuadro 1. Listado de artículos que conforman el corpus documental ............102 
Moglia B. Procesos de atención y cuidado desde la perspectiva de los trabajadores: una meta-etnografía en hospitales de Latinoamérica. [Tesis de maestría]. Maestría en Epidemiología, Gestión y Políticas de Salud. Universidad Nacional de Lanús. 2020.

\section{Apéndice A - Cuadro 1. Listado de artículos que conforman el corpus documental.}

\begin{tabular}{|c|c|c|c|c|c|}
\hline $\mathbf{N}^{\circ}$ & Autoría & Título del artículo & Revista & $\begin{array}{l}\text { Año de } \\
\text { publicación }\end{array}$ & Enlace \\
\hline 1 & Littike D, Sodré F. & $\begin{array}{l}\text { A arte do improviso: o processo } \\
\text { de trabalho dos gestores de um } \\
\text { Hospital Universitário Federal. }\end{array}$ & $\begin{array}{l}\text { Ciência \&amp; Saúde } \\
\text { Coletiva }\end{array}$ & 2015 & $\begin{array}{l}\text { http://www.scielo.br/scielo.php?script=sci } \\
\underline{\text { arttext\&pid=S1413- }} \\
\underline{81232015001003051 \& l a n g=p t}\end{array}$ \\
\hline 2 & $\begin{array}{l}\text { Brage E, Vindrola- } \\
\text { Padros C. }\end{array}$ & $\begin{array}{l}\text { An ethnographic exploration of } \\
\text { the delivery of psychosocial care } \\
\text { to children with cancer in } \\
\text { Argentina. }\end{array}$ & Eur J Oncol Nurs & 2017 & $\begin{array}{l}\text { https://discovery.ucl.ac.uk/id/eprint/155893 } \\
\underline{\text { 3/1/Full\%20manuscript\%20for\%20RPS.pdf }}\end{array}$ \\
\hline 3 & $\begin{array}{l}\text { Formozo GA., Oliveira } \\
\text { DC. }\end{array}$ & $\begin{array}{l}\text { Nursing staff's social } \\
\text { representations about nursing } \\
\text { care for people living with } \\
\text { HIV/AIDS. }\end{array}$ & $\begin{array}{l}\text { Rio de Janeiro; s.n; } \\
\text { 2007. } 211 \text { p. ilus, tab. }\end{array}$ & 2007 & $\begin{array}{l}\text { http://www.bdtd.uerj.br/tde busca/termo.ph } \\
\text { p?codArquivo }=750\end{array}$ \\
\hline 4 & $\begin{array}{l}\text { Lima MLC, Souza ER, } \\
\text { Lima MLLT, Barreira } \\
\text { AK, Bezerra ED, Acioli } \\
\text { RML. }\end{array}$ & $\begin{array}{l}\text { Assistência à saúde dos idosos } \\
\text { vítimas de acidentes e violência: } \\
\text { uma análise da rede de serviços } \\
\text { SUS no Recife (PE, Brasil). }\end{array}$ & $\begin{array}{l}\text { Ciência \&amp; Saúde } \\
\text { Coletiva; 15(6); 2677- } \\
2686\end{array}$ & 2010 & $\begin{array}{l}\text { http://www.scielosp.org/scielo.php?script=s } \\
\text { ci_arttext\&pid=S1413- } \\
\underline{81232010000600006 \& \text { lang }=p t}\end{array}$ \\
\hline 5 & $\begin{array}{l}\text { Klossoswski DG, Godói } \\
\text { VC, Xavier CR, } \\
\text { Fujinaga CI. }\end{array}$ & $\begin{array}{l}\text { Assistência integral ao recém- } \\
\text { nascido prematuro: implicações } \\
\text { das práticas e da política pública. }\end{array}$ & $\begin{array}{l}\text { Revista CEFAC; } 18(1) \\
137-150\end{array}$ & 2016 & $\begin{array}{l}\text { http://www.scielo.br/scielo.php?script=sci } \\
\underline{\text { arttext\&pid=S1516- }} \\
\underline{18462016000100137 \& \text { lang=pt }}\end{array}$ \\
\hline
\end{tabular}


Moglia B. Procesos de atención y cuidado desde la perspectiva de los trabajadores: una meta-etnografía en hospitales de Latinoamérica. [Tesis de maestría]. Maestría en Epidemiología, Gestión y Políticas de Salud. Universidad Nacional de Lanús. 2020.

Continuación. Apéndice A - Cuadro 1. Listado de artículos que conforman el corpus documental.

\begin{tabular}{|c|c|c|c|c|c|}
\hline $\mathbf{N}^{\circ}$ & Autoría & Título del artículo & Revista & $\begin{array}{l}\text { Año de } \\
\text { publicación }\end{array}$ & Enlace \\
\hline 6 & $\begin{array}{l}\text { Molina-Marín G, } \\
\text { Oquendo-Lozano T, } \\
\text { Arango-Castrillón A, } \\
\text { Flórez-García MV. }\end{array}$ & $\begin{array}{l}\text { Características de servicios de } \\
\text { pediatría que atienden niños(as) } \\
\text { con neumonía adquirida en la } \\
\text { comunidad, Medellín } \\
\text { (Colombia), 2012. }\end{array}$ & $\begin{array}{l}\text { Revista Gerencia y } \\
\text { Políticas de Salud; } \\
\text { 12(25); 133-148 }\end{array}$ & 2013 & $\begin{array}{l}\text { http://www.scielo.org.co/scielo.php?script= } \\
\text { sci_arttext\&pid=S1657- } \\
\text { 70272013000200010\&lang=pt }\end{array}$ \\
\hline 7 & Lima MAG, Trad LAB. & $\begin{array}{l}\text { Circle therapy: a metaphor for } \\
\text { coping with chronic pains in two } \\
\text { pain clinics. }\end{array}$ & Physis (Rio J.) & 2011 & $\begin{array}{l}\text { http://www.scielo.br/pdf/physis/v21n1/v21n } \\
\underline{\text { 1a12.pdf }}\end{array}$ \\
\hline 8 & $\begin{array}{l}\text { Souza GA, Giacomin K, } \\
\text { Aredes JS, Firmo JOA. }\end{array}$ & $\begin{array}{l}\text { Comunicação da morte: modos } \\
\text { de pensar e agir de médicos em } \\
\text { um hospital de emergencia. }\end{array}$ & $\begin{array}{l}\text { Physis: Revista de } \\
\text { Saúde Coletiva }\end{array}$ & 2019 & $\begin{array}{l}\text { http://www.scielo.br/scielo.php?script=sci } \\
\text { arttext\&pid=S0103- } \\
\underline{73312018000300619 \& \text { lang=es }}\end{array}$ \\
\hline 9 & $\begin{array}{l}\text { Pan R, Silva MTR, } \\
\text { Fidelis TLN, Vilela LS, } \\
\text { Silveira-Monteiro CA, } \\
\text { Nascimento LC. }\end{array}$ & $\begin{array}{l}\text { Conhecimento de profissionais } \\
\text { de saúde acerca do atendimento } \\
\text { inicial intra-hospitalar ao } \\
\text { paciente vítima de queimaduras. }\end{array}$ & $\begin{array}{l}\text { Revista Gaúcha de } \\
\text { Enfermagem; 39(); - }\end{array}$ & 2018 & $\begin{array}{l}\text { http://www.scielo.br/scielo.php?script=sci } \\
\text { arttext\&pid=S1983- } \\
\underline{14472018000100446 \& \text { lang=pt }}\end{array}$ \\
\hline 10 & Silva LM, Santos MA. & $\begin{array}{l}\text { Building bridges: a } \\
\text { multidisciplinary team } \\
\text { experience report on eating } \\
\text { disorders. }\end{array}$ & $\begin{array}{l}\text { Medicina (Ribeiräo } \\
\text { Preto) }\end{array}$ & 2006 & $\begin{array}{l}\text { http://www.revistas.usp.br/rmrp/article/view } \\
\text { 1398/399 }\end{array}$ \\
\hline 11 & $\begin{array}{l}\text { Cardoso DH, Muniz } \\
\text { RM, Schwartz E, } \\
\text { Arrieira, ICO. }\end{array}$ & $\begin{array}{l}\text { Cuidados paliativos na } \\
\text { assistência hospitalar: a vivência } \\
\text { de uma equipe multiprofissional. }\end{array}$ & $\begin{array}{l}\text { Texto \& Contexto - } \\
\text { Enfermagem; 22(4); } \\
1134-1141\end{array}$ & 2013 & $\begin{array}{l}\text { http://www.scielo.br/scielo.php?script=sci } \\
\text { arttext\&pid=S0104- } \\
\underline{07072013000400032 \& \text { lang=pt }}\end{array}$ \\
\hline
\end{tabular}


Moglia B. Procesos de atención y cuidado desde la perspectiva de los trabajadores: una meta-etnografía en hospitales de Latinoamérica. [Tesis de maestría]. Maestría en Epidemiología, Gestión y Políticas de Salud. Universidad Nacional de Lanús. 2020.

Continuación. Apéndice A - Cuadro 1. Listado de artículos que conforman el corpus documental.

\begin{tabular}{|c|c|c|c|c|c|}
\hline $\mathbf{N}^{\circ}$ & Autoría & Título del artículo & Revista & $\begin{array}{l}\text { Año de } \\
\text { publicación }\end{array}$ & Enlace \\
\hline 12 & $\begin{array}{l}\text { Amaral RA, Moraes } \\
\text { CW, Ostermann GT. }\end{array}$ & $\begin{array}{l}\text { Taking care of who takes care: } \\
\text { employees of a General } \\
\text { Hospital. }\end{array}$ & Rev. SBPH & 2010 & $\begin{array}{l}\text { http://pepsic.bvsalud.org/pdf/rsbph/v13n2/v } \\
\text { 13n2a09.pdf }\end{array}$ \\
\hline 13 & $\begin{array}{l}\text { Aredes JS, Firmo JOA, } \\
\text { Giacomin KC. }\end{array}$ & $\begin{array}{l}\text { Deaths that save lives: The } \\
\text { complexities of medical care for } \\
\text { patients with suspected brain } \\
\text { death. }\end{array}$ & $\begin{array}{l}\text { Cadernos de Saude } \\
\text { Publica }\end{array}$ & 2018 & $\underline{\text { http://www.scielo.br/pdf/csp/v34n11/1678- }}$ \\
\hline 14 & $\begin{array}{l}\text { Luz KR, Vargas MAO, } \\
\text { Barlem ELD, Schmitt } \\
\text { PH, Ramos FRS, } \\
\text { Meirelles BHS. }\end{array}$ & $\begin{array}{l}\text { Estratégias de enfrentamento por } \\
\text { enfermeiros da oncologia na alta } \\
\text { complexidade. }\end{array}$ & $\begin{array}{l}\text { Revista Brasileira de } \\
\text { Enfermagem; 69(1); 67- } \\
71\end{array}$ & 2016 & $\begin{array}{l}\text { http://www.scielo.br/scielo.php?script=sci } \\
\text { arttext\&pid=S0034- } \\
\underline{71672016000100067 \& \text { lang=pt }}\end{array}$ \\
\hline 15 & $\begin{array}{l}\text { Oliveira VJ, Penna } \\
\text { CMM. }\end{array}$ & $\begin{array}{l}\text { Ethos and pathos in the delivery } \\
\text { room. }\end{array}$ & $\begin{array}{l}\text { Revista gaucha de } \\
\text { enfermagem }\end{array}$ & 2017 & $\begin{array}{l}\text { http://www.scielo.br/pdf/rgenf/v38n2/en_01 } \\
\underline{\text { 02-6933-rgenf-1983-144720170267761.pdf }}\end{array}$ \\
\hline 16 & $\begin{array}{l}\text { Rosado IVM, Russo } \\
\text { GHA, Maia EMC. }\end{array}$ & $\begin{array}{l}\text { Generating health elicits illness? } \\
\text { The contradictions of work } \\
\text { performed in emergency care } \\
\text { units of public hospitals. }\end{array}$ & $\begin{array}{l}\text { Ciencia e Saude } \\
\text { Coletiva }\end{array}$ & 2015 & $\begin{array}{l}\text { http://www.scielo.br/pdf/csc/v20n10/1413- } \\
\text { 8123-csc-20-10-3021.pdf }\end{array}$ \\
\hline
\end{tabular}


Moglia B. Procesos de atención y cuidado desde la perspectiva de los trabajadores: una meta-etnografía en hospitales de Latinoamérica. [Tesis de maestría]. Maestría en Epidemiología, Gestión y Políticas de Salud. Universidad Nacional de Lanús. 2020.

\section{Continuación. Apéndice A - Cuadro 1. Listado de artículos que conforman el corpus documental.}

\begin{tabular}{|c|c|c|c|c|c|}
\hline $\mathbf{N}^{\circ}$ & Autoría & Título del artículo & Revista & $\begin{array}{l}\text { Año de } \\
\text { publicación }\end{array}$ & Enlace \\
\hline 17 & $\begin{array}{l}\text { Rocha APF, de Souza } \\
\text { KR, Teixeira LR. }\end{array}$ & $\begin{array}{l}\text { Health and medical work of } \\
\text { neonatal ICU physicians: A } \\
\text { study in a public hospital in Rio } \\
\text { de Janeiro. }\end{array}$ & Physis & 2015 & $\begin{array}{l}\text { http://www.scielo.br/pdf/physis/v25n3/0103 } \\
\text {-7331-physis-25-03-00843.pdf }\end{array}$ \\
\hline 18 & $\begin{array}{l}\text { Busanello J, da Costa } \\
\text { Kerber NP, Filho WDL, } \\
\text { Lunardi VL, Mendoza- } \\
\text { Sassi RA, de Azambuja } \\
\text { EP. }\end{array}$ & $\begin{array}{l}\text { Humanized parturition of } \\
\text { adolescents: View of health } \\
\text { workers. }\end{array}$ & Revista Enfermagem & 2011 & $\begin{array}{l}\text { http://www.facenf.uerj.br/v19n2/v19n2a08. } \\
\text { pdf }\end{array}$ \\
\hline 19 & $\begin{array}{l}\text { Silva RC, Soares MC, } \\
\text { Muniz RM, Andrade FP, } \\
\text { Torres AAP, Gomes V. }\end{array}$ & $\begin{array}{l}\text { La concepción de los } \\
\text { profesionales de salud sobre el } \\
\text { parto humanizado en la } \\
\text { adolescencia. }\end{array}$ & $\begin{array}{l}\text { Enfermería Global; } \\
\text { 10(24); - }\end{array}$ & 2011 & $\begin{array}{l}\text { http://scielo.isciii.es/scielo.php?script=sci_a } \\
\underline{\text { tttext\&pid=S1695- }} \\
\underline{61412011000400025 \& \text { lang }=p t}\end{array}$ \\
\hline 20 & $\begin{array}{l}\text { Arenas-Monreal L, } \\
\text { Hernández-Tezoquipa I, } \\
\text { Valdez-SantiagoR, } \\
\text { Bonilla-Fernández P. }\end{array}$ & $\begin{array}{l}\text { Las instituciones de salud y el } \\
\text { autocuidado de los médicos. }\end{array}$ & $\begin{array}{l}\text { Salud Pública de } \\
\text { México; 46(4); 326-332 }\end{array}$ & 2004 & $\begin{array}{l}\text { http://www.scielo.org.mx/scielo.php?script= } \\
\text { sci_arttext\&pid=S0036- } \\
\underline{36342004000400007 \& \text { lang=pt }}\end{array}$ \\
\hline 21 & Palmer, SP. & $\begin{array}{l}\text { Nurse retention and satisfaction } \\
\text { in Ecuador: Implications for } \\
\text { nursing administration. }\end{array}$ & $\begin{array}{l}\text { Journal of Nursing } \\
\text { Management }\end{array}$ & 2014 & $\begin{array}{l}\underline{\mathrm{https}: / / \text { onlinelibrary.wiley.com/doi/epdf/10. }} \\
\underline{1111 / \text { jonm.12043 }}\end{array}$ \\
\hline 22 & Costa MA, Abrahão AL. & $\begin{array}{l}\text { O processo de trabalho no } \\
\text { arquivo médico: novas } \\
\text { perspectivas na produção do ato }\end{array}$ & $\begin{array}{l}\text { Ciência \&amp; Saúde } \\
\text { Coletiva; 23(4); 1211- } \\
1219\end{array}$ & 2018 & $\begin{array}{l}\text { http://www.scielosp.org/scielo.php?script=s } \\
\underline{\text { ci_arttext\&pid=S1413- }} \\
\underline{81232018000401211 \& \text { lang }=p t}\end{array}$ \\
\hline
\end{tabular}


Moglia B. Procesos de atención y cuidado desde la perspectiva de los trabajadores: una meta-etnografía en hospitales de Latinoamérica. [Tesis de maestría]. Maestría en Epidemiología, Gestión y Políticas de Salud. Universidad Nacional de Lanús. 2020.

\section{Continuación. Apéndice A - Cuadro 1. Listado de artículos que conforman el corpus documental.}

\begin{tabular}{|c|c|c|c|c|c|}
\hline $\mathbf{N}^{\circ}$ & Autoría & Título del artículo & Revista & $\begin{array}{l}\text { Año de } \\
\text { publicación }\end{array}$ & Enlace \\
\hline 23 & $\begin{array}{l}\text { Araújo BBM, Pacheco } \\
\text { STA, Rodrigues, } \\
\text { BMRD, Silva LF, } \\
\text { Rodrigues BRD, Arantes } \\
\text { PCC }\end{array}$ & $\begin{array}{l}\text { Prática social da enfermagem na } \\
\text { promoção do cuidado materno } \\
\text { ao prematuro na unidade } \\
\text { neonatal. }\end{array}$ & $\begin{array}{l}\text { Texto \&amp; Contexto } \\
\text { - Enfermagem; 27(4) }\end{array}$ & 2018 & $\begin{array}{l}\text { http://www.scielo.br/scielo.php?script=sci } \\
\underline{\text { arttext\&pid=S0104- }} \\
\underline{07072018000400306 \& \text { lang=pt }}\end{array}$ \\
\hline 24 & $\begin{array}{l}\text { Azevedo CS, Sá MC, } \\
\text { Cunha M, Matta GC, } \\
\text { Miranda L, Grabois V. }\end{array}$ & $\begin{array}{l}\text { Racionalização e Construção de } \\
\text { Sentido na Gestão do Cuidado: } \\
\text { uma experiência de mudança em } \\
\text { um hospital do SUS. }\end{array}$ & $\begin{array}{l}\text { Ciência \&amp; Saúde } \\
\text { Coletiva; 22(6); 1991- } \\
2002\end{array}$ & 2017 & $\begin{array}{l}\text { http://www.scielo.br/scielo.php?script=sci } \\
\underline{\text { arttext\&pid=S1413- }} \\
\underline{81232017002601991 \& \text { lang }=p t}\end{array}$ \\
\hline 25 & $\begin{array}{l}\text { Fernandes AT, Nery AL, } \\
\text { Filho SAM, Morais } \\
\text { RLGL, Oliveira JS, } \\
\text { Oliveira YNS. }\end{array}$ & $\begin{array}{l}\text { Feelings experienced by health } \\
\text { workers in occurrence of } \\
\text { accidents with biological } \\
\text { material. }\end{array}$ & Rev. Paul. Enferm. & 2018 & $\begin{array}{l}\text { http://repen.com.br/revista/wp- } \\
\text { content/uploads/2018/11/Sentimentos- } \\
\text { vivenciados-por-trabalhadores-de- } \\
\text { sa\%C3\%BAde-na-ocorr\%C3\%AAncia-de- } \\
\begin{array}{l}\text { acidentes-com-material- } \\
\text { biol\%C3\%B3gico.pdf }\end{array}\end{array}$ \\
\hline 26 & $\begin{array}{l}\text { Medeiros JV, Jorge } \\
\text { MSB. }\end{array}$ & $\begin{array}{l}\text { Situação de um serviço de saúde } \\
\text { pública de Fortaleza: realidade } \\
\text { vivenciada pelo enfermeiro. }\end{array}$ & $\begin{array}{l}\text { Revista Brasileira de } \\
\text { Enfermagem; 53(4); } \\
555-563\end{array}$ & 2000 & $\begin{array}{l}\text { http://www.scielo.br/scielo.php?script=sci } \\
\text { arttext\&pid=S0034- } \\
\underline{71672000000400010 \& l a n g=p t}\end{array}$ \\
\hline 27 & $\begin{array}{l}\text { Acosta DF, Gomes } \\
\text { VLO, Oliveira DC, }\end{array}$ & $\begin{array}{l}\text { Social representations of nurses } \\
\text { concerning domestic violence }\end{array}$ & $\begin{array}{l}\text { Revista gaucha de } \\
\text { enfermagem }\end{array}$ & 2018 & $\underline{\text { http://www.scielo.br/pdf/rgenf/v39/1983- }}$ \\
\hline
\end{tabular}


Moglia B. Procesos de atención y cuidado desde la perspectiva de los trabajadores: una meta-etnografía en hospitales de Latinoamérica. [Tesis de maestría]. Maestría en Epidemiología, Gestión y Políticas de Salud. Universidad Nacional de Lanús. 2020.

Continuación. Apéndice A - Cuadro 1. Listado de artículos que conforman el corpus documental.

\begin{tabular}{|c|c|c|c|c|c|}
\hline $\mathbf{N}^{\circ}$ & Autoría & Título del artículo & Revista & $\begin{array}{l}\text { Año de } \\
\text { publicación }\end{array}$ & Enlace \\
\hline 28 & $\begin{array}{l}\text { Baasch D, Laner Ados } \\
\text { S. }\end{array}$ & $\begin{array}{l}\text { The meanings of working in } \\
\text { intensive care units of two } \\
\text { Brazilian hospitals. }\end{array}$ & Cien Saude Colet. & 2011 & $\begin{array}{l}\text { http://www.scielo.br/scielo.php?script=sci } \\
\text { arttext\&pid=S1413- } \\
\underline{81232011000700041 \& \operatorname{lng}=\text { en\&nrm=iso\&tl }} \\
\underline{\text { ng=en }}\end{array}$ \\
\hline 29 & $\begin{array}{l}\text { dos Santos TD, de } \\
\text { Oliveira Aquino AC, de } \\
\text { Pinho Chibante CL, do } \\
\text { Espírito Santo FH. }\end{array}$ & $\begin{array}{l}\text { The nursing team and the family } \\
\text { member accompanying adult } \\
\text { patients in the hospital context. } \\
\text { An exploratory study. }\end{array}$ & $\begin{array}{l}\text { Investigación y } \\
\text { Educación en } \\
\text { Enfermería; 31(2); 218- } \\
225\end{array}$ & 2013 & $\begin{array}{l}\text { http://www.scielo.org.co/scielo.php?script }= \\
\underline{\text { sci_arttext\&pid=S0120- }} \\
\text { 53072013000200007\&lang=pt }\end{array}$ \\
\hline 30 & $\begin{array}{l}\text { Baggio MA, Erdmann } \\
\text { AL. }\end{array}$ & $\begin{array}{l}\text { The occurrence of the care 'of us' } \\
\text { in the movements and } \\
\text { fluctuations of the interactive } \\
\text { processes in the hospital } \\
\text { environment. }\end{array}$ & $\begin{array}{l}\text { Texto \&amp; contexto } \\
\text { enferm }\end{array}$ & 2016 & $\begin{array}{l}\text { http://www.scielo.br/scielo.php?script=sci } \\
\text { arttext\&pid=S0104- } \\
\underline{07072016000100325 \& \text { lang }=p t}\end{array}$ \\
\hline 31 & $\begin{array}{l}\text { da Silva RC, Soares } \\
\text { MC, Jardim VMR, } \\
\text { Kerber NPC, Meincke } \\
\text { SMK. }\end{array}$ & $\begin{array}{l}\text { The speech and practice of } \\
\text { humanizing childbirth in } \\
\text { adolescents. }\end{array}$ & $\begin{array}{l}\text { Texto e Contexto } \\
\text { Enfermagem }\end{array}$ & 2013 & $\begin{array}{l}\text { http://www.scielo.br/pdf/tce/v22n3/v22n3a0 } \\
\text { 8.pdf }\end{array}$ \\
\hline 32 & $\begin{array}{l}\text { Cardoso GB, Da Silva } \\
\text { ALA. }\end{array}$ & $\begin{array}{l}\text { The work process in nursing: } \\
\text { Interrelating care technologies. }\end{array}$ & Revista Enfermagem & 2010 & $\underline{\text { http://www.facenf.uerj.br/v18n3/v18n3a20. }}$ \\
\hline
\end{tabular}


Moglia B. Procesos de atención y cuidado desde la perspectiva de los trabajadores: una meta-etnografía en hospitales de Latinoamérica. [Tesis de maestría]. Maestría en Epidemiología, Gestión y Políticas de Salud. Universidad Nacional de Lanús. 2020.

Continuación. Apéndice A - Cuadro 1. Listado de artículos que conforman el corpus documental.

\begin{tabular}{|c|c|c|c|c|c|}
\hline $\mathbf{N}^{\circ}$ & Autoría & Título del artículo & Revista & $\begin{array}{l}\text { Año de } \\
\text { publicación }\end{array}$ & Enlace \\
\hline 33 & $\begin{array}{l}\text { Luna-García JE, Urrego- } \\
\text { Mendoza Z, Gutiérrez- } \\
\text { Robayo M, Martínez- } \\
\text { Durán A. }\end{array}$ & $\begin{array}{l}\text { Violence at work in the public } \\
\text { health sector: A view from the } \\
\text { working people. Bogotá, } \\
\text { Colombia. 2011-2012. }\end{array}$ & $\begin{array}{l}\text { Revista Facultad de } \\
\text { Medicina }\end{array}$ & 2015 & $\begin{array}{l}\text { http://www.scielo.org.co/pdf/rfmun/v63n3/v } \\
\text { 63n3a08.pdf }\end{array}$ \\
\hline 34 & $\begin{array}{l}\text { Aguiar JM, d'Oliveira } \\
\text { AFPL,Schraiber LB. }\end{array}$ & $\begin{array}{l}\text { Violência institucional, } \\
\text { autoridade médica e poder nas } \\
\text { maternidades sob a ótica dos } \\
\text { profissionais de saúde. }\end{array}$ & Cad. saúde pública & 2013 & $\begin{array}{l}\text { http://www.scielo.br/scielo.php?script=sci } \\
\underline{\text { arttext\&pid=S0102-311X2013001100015 }}\end{array}$ \\
\hline 35 & $\begin{array}{l}\text { Lopes DFM, Silva A, } \\
\text { Garanhani MLM, } \\
\text { Miriam AB. }\end{array}$ & $\begin{array}{l}\text { Ser trabalhador de enfermagem } \\
\text { da Unidade de Centro de } \\
\text { Material: uma abordagem } \\
\text { fenomenológica }\end{array}$ & $\begin{array}{l}\text { Revista da Escola de } \\
\text { Enfermagem da USP; } \\
41(4) ; 675-682\end{array}$ & 2007 & $\begin{array}{l}\text { http://www.scielo.br/scielo.php?script=sci } \\
\text { arttext\&pid=S0080- } \\
\underline{62342007000400019 \& \text { lang=pt }}\end{array}$ \\
\hline 36 & $\begin{array}{l}\text { Habekost Cardoso D, da } \\
\text { Costa Viegas A, Pozza } \\
\text { dos Santos B, Manfrin }\end{array}$ & $\begin{array}{l}\text { Care delivery in the terminality: } \\
\text { difficulties of a multidisciplinary } \\
\text { team in hospital care }\end{array}$ & Av. enferm & 2013 & $\begin{array}{l}\text { http://www.scielo.br/scielo.php?pid=S0104- } \\
\underline{07072013000400032 \& \text { script=sci arttext\&tlng }}= \\
\underline{\text { en }}\end{array}$ \\
\hline
\end{tabular}

Muniz R, Schwartz E,

Buss Thofehrn M. 